NUREG/CR-5963

PNL-8844

\title{
Continuous AE Crack Monitoring of A Dissimilar Metal Weldment at Limerick Unit 1
}

Prepared by

P. H. Hutton, M. A. Friesel, J. F. Dawson

Pacific Northwest Laboratory

Prepared for

U.S. Nuclear Regulatory Commission 


\section{AVAILABILITY NOTICE}

Avallability of Reterence Materials Cited in NRC Publications

Most documents cited in NRC publications will be available from one of the following sources:

1. The NRC Public Document Room, 2120 L Street, NW.. Lower Level, Washington, DC 20555-0001

2. The Supprintendent of Documents, U.S. Government Printing Office, Mall Stop SSOP, Washington, DC $20402-9328$

3. The National Technical Information Service, Springfield, VA 22161

Although the listing that follows represents the majority of documents cited in NRC publications, it is not intended to be exhaustive.

Referenced documents avallable for inspection and copying for a fee trom the NRC Public Document Roorn include NRC correspondence and internal NRC memoranda: NRC bulletins, circulars, information notices, inspection and investigation notices; licensee event reports; vendor reports and correspondence; Commission papers: and applicant and licensee documents and correspondence.

The following documents in the NUREG series are avallable for purchase from the GPO Sales Program: formal NRC staff and contractor reports. NRC-sponsored conference proceedings, international agreement reports. grant publications, and NAC booklets and brochures. Also avallable are regulatory guides. NRC regulations in the Code of Federal Regulations, and Nucleal Regulatory Commission issuances.

Documents available from the National Technical Information Service Include NUREG-serles reports and technical reports prepared by other Federal agencies and reports prepared by the Atomic Energy Commission. forerunner agency to the Nuclear Regulatory Commission.

Documents available from public and special technical libraries include all open literature items. such as books. journal articies, and transactions. Federal Register notices. Foderal and State legislation, and congressional reports can ustially be obtained from these libraries.

Documents such as theses, dissertations, for eign reports and translations, and non-NRC conterence proceedings are available for purchase from the organization sponsoring the publication cited.

Single copies of NRC draft reports are avaliable tree, to the extent of supply. upon written request to the Office of Administration. Distribution and Mail Services Section. U.S. Nuclear Regulatory Commission. Washington. DC: $20555-0001$

Copies of industry codes and standards used in a substantive manner in the NRC regulatory process are maintained at the NRC Library, 7920 Norfolk Avenue. Bethesda. Maryland. for use by the public. Codes and standards are usually copyrighted and may be purchased from the originating organization or, If they are American National Standards, from the American National Standards Institute, 1430 Broadway. New York. NY 10018

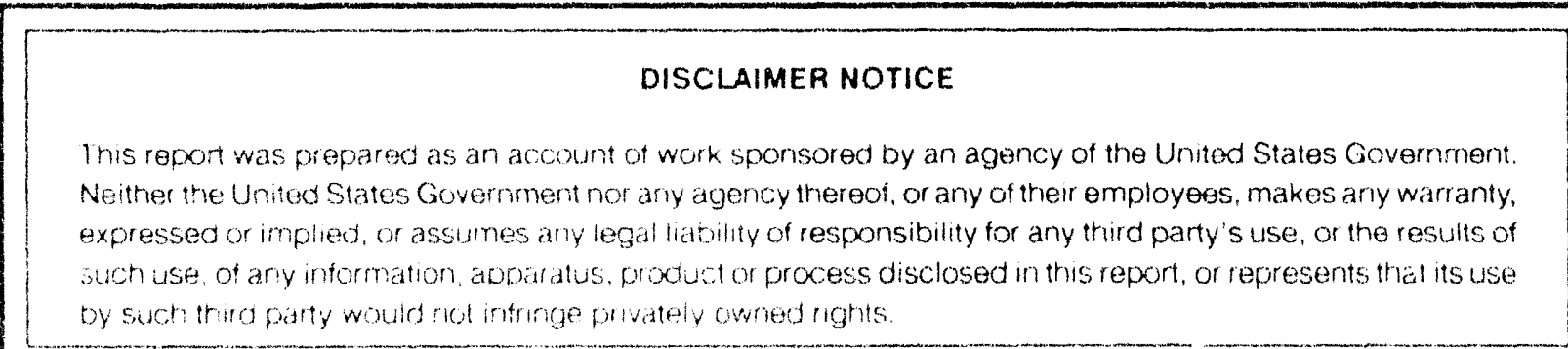


NUREG/CR-5963

PNL-8844

R5, GS

\section{Continuous AE Crack Monitoring of A Dissimilar Metal Weldment at Limerick Unit 1}

Manuscript Completed: October 1993

Date Published: December 1993

Prepared by

P. H. Hutton, M. A. Friesel, J. F. Dawson

Pacific Northwest Laboratory

Richland, WA 99352

\section{Prepared for}

Division of Engineering

Office of Nuclear Regulatory Research U.S. Nuclear Regulatory Commission Washington, DC 20555-0001 NRC FINs B2913 and L1100

\section{DISCLAIMER}

This report was prepared as an account of work sponsored by an agency of the United States Government. Neither the United States Government nor any agency thereof, nor any of their employees, makes any warranty, express or implied, or assumes any legal liability or responsibility for the accuracy, completeness, or usefulness of any information, apparatus, product, or process disclosed, or represents that its use would not infringe privately owned rights. Reference herein to any specific commercial product, process, or service by trade name, trademark, manufacturer, or otherwise does not necessarily constitute or imply its endorsement, recommendation, or favoring by the United States Government or any agency thereof. The views and opinions of authors expressed herein do not necessarily state or reflect those of the United States Government or any agency thereof. 


\begin{abstract}
Acoustic emission (AE) technology for continuous surveillance of a reactor component(s) to detect crack initiation and/or crack growth has been developed at Pacific Northwest Laboratory (PNL), operated by Battelle Memorial Institute, under support from the U. S. Nuclear Regulatory Commission, Office of Nuclear Regulatory Research (U. S. NRC-RES). The technology was validated off-reactor in several major tests, but it had not been validated by monitoring crack growth on an operating reactor system. A flaw indication was identified during normal inservice inspection of piping at Philadelphia Electric Company (PECO) Limerick Unit 1 reactor during the 1989 refueling outage.
\end{abstract}

Abstract

Evaluation of the flaw indication showed that it could remain in place during the subsequent fuel cycle without compromising safety. The existence of this flaw indication offered a long sought opportunity to validate AE surveillance to detect and evaluate crack growth during reactor operation. Through the cooperation and support of PECO and the U. S. NRC-RES, AE instrumentation was installed by PNL and PECO under PECO Mod. No. 043-002 to monitor the flaw indication during two complete fuel cycles. This report discusses the results obtained from the AE monitoring over the period May 1989 to March 1992 (two fuel cycles). 


\section{Contents}

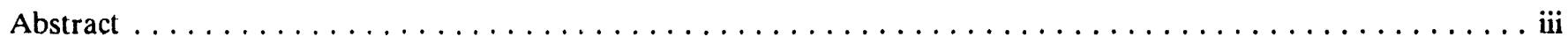

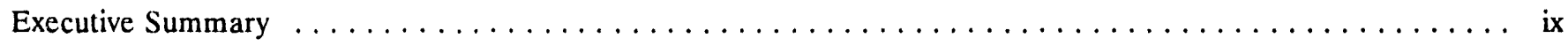

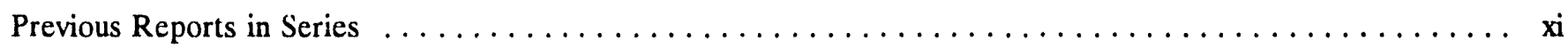

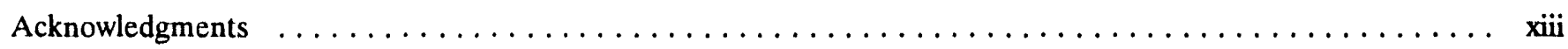

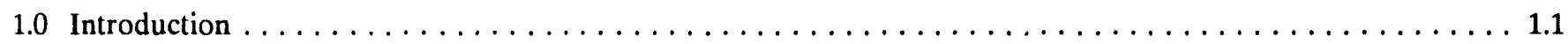

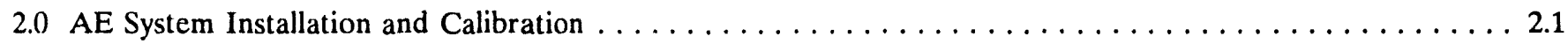

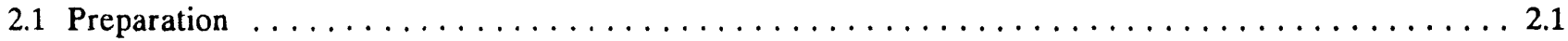

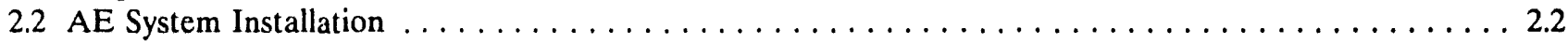

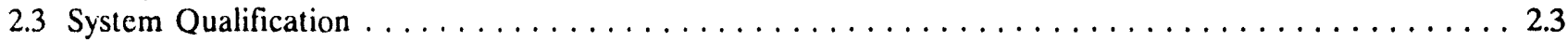

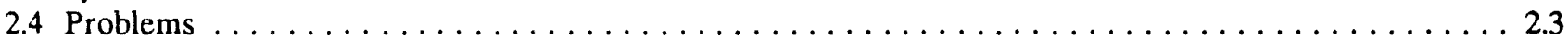

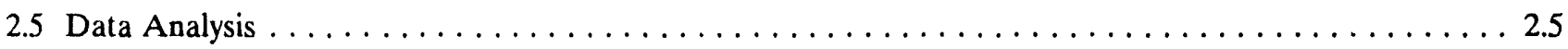

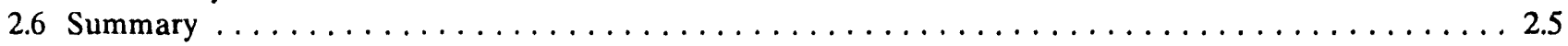

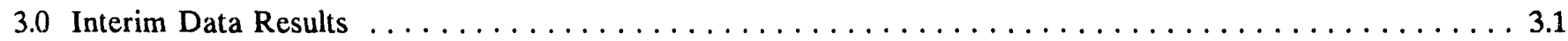

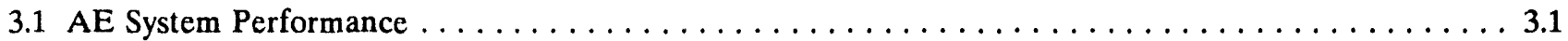

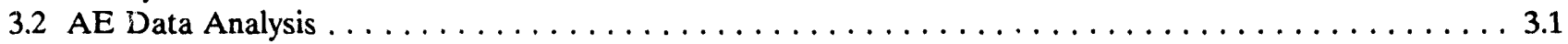

3.3 Flaw Indication from ISI Results and Crack-Arrest-Verification-Specimen Indications $\ldots \ldots \ldots . . \ldots 3.2$

3.4 Correlation between AE, CAVS, and UT Results $\ldots \ldots \ldots \ldots \ldots$

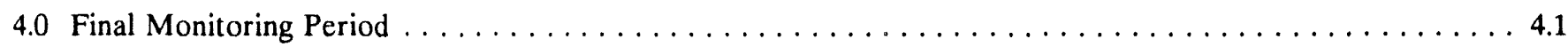

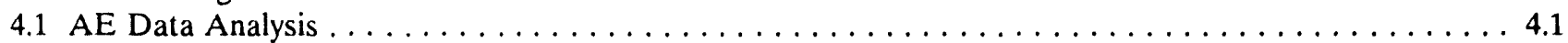

4.2 ISI and Crack-Arrest-Verification-Specimen Results $\ldots \ldots \ldots \ldots \ldots \ldots$

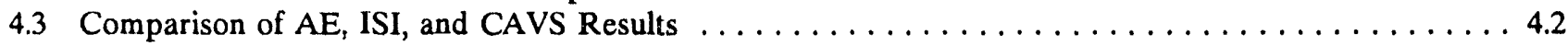

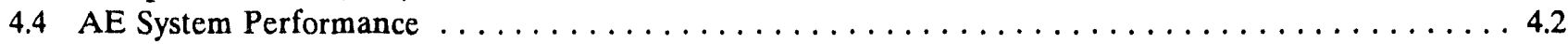

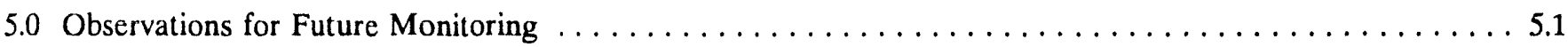

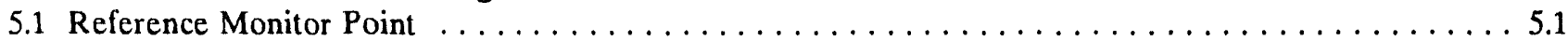

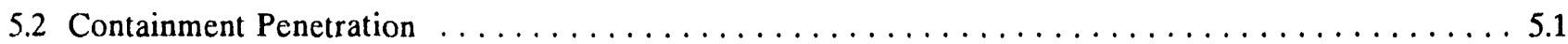

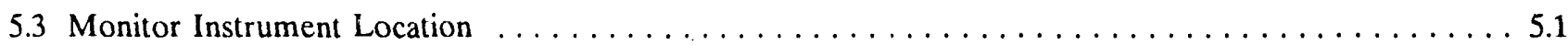

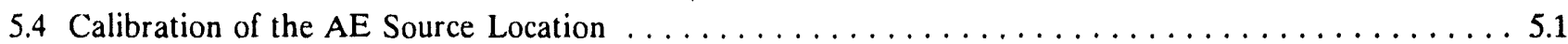

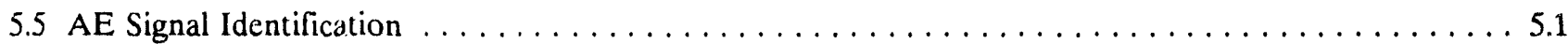

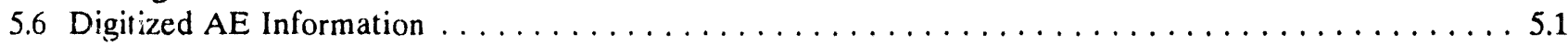

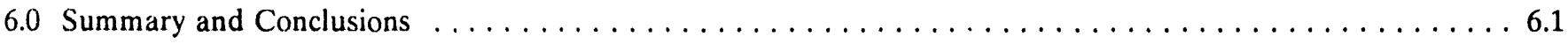

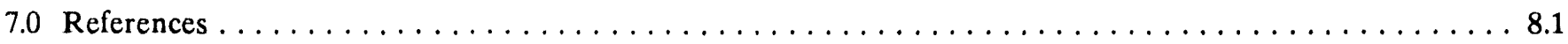




\section{Figures}

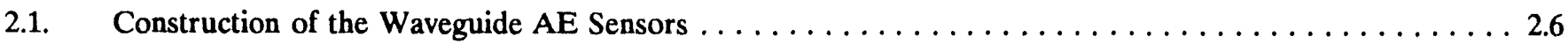

2.2. Sensitivity Test of Waveguide AE Sensors on Calibration Block $\ldots \ldots \ldots \ldots \ldots \ldots \ldots \ldots \ldots \ldots .7$

2.3. Location of AE Sensors on Pipe Weld NRR-1RD-1A N2H - Limerick Unit $1 \ldots \ldots \ldots \ldots \ldots \ldots$

2.4. Waveguide AE Sensors Mounted Near Weld VRR-1RD-1A N2H - Limerick Unit $1 \ldots \ldots \ldots \ldots$

2.5. Waveguide AE Sensor Being Pressure Coupled to the Pipe Surface - Limerick Unit $1 \ldots \ldots \ldots$

2.6. Electronic Pulser Mounted Near AE Sensor No. 3 - Limerick Unit $1 \ldots \ldots \ldots \ldots \ldots \ldots \ldots \ldots$

2.7. Waveguide AE Sensors Emerging from Weld Region - Limerick Unit $1 \ldots \ldots \ldots \ldots \ldots \ldots \ldots .12$

2.8. Waveguide AE Sensor Head $\ldots \ldots \ldots \ldots \ldots \ldots \ldots \ldots \ldots \ldots \ldots \ldots \ldots \ldots \ldots \ldots \ldots \ldots \ldots$

2.9. AE System Preamplifiers Mounted in Junction Box in Reactor Enclosure, Elevation 283' - Limerick

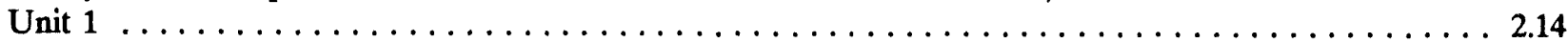

2.10. AE Monitor Instrument Mounted in a Cabinet in Reactor Enclosure, Elevation 283' - Limerick Unit

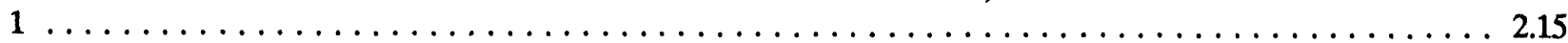

2.11. Test of Signal Source Location by AE System Using Signal Input from 0.5-mm Pencil Lead Breaks -

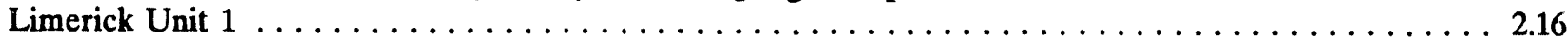

2.12. Sensitivity Test of Waveguide AE Sensors Installed on Reactor Pipe - Limerick Unit $1 \ldots \ldots \ldots \ldots$

2.13. Response of AE Sensors to Pulser Signal on $6 / 9 / 89 \ldots \ldots \ldots \ldots \ldots \ldots \ldots \ldots \ldots \ldots \ldots \ldots \ldots$

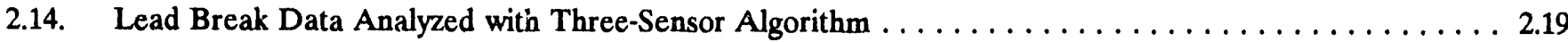

3.1. AE Source Location Elements Superimposed on Pipe Cross Section with Flaw Profile - N2H Weld at

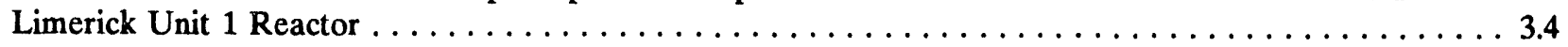

3.2. AE Rate - Crack Growth Rate Relationship for Cyclic Fatigue Crack Growth (Hutton 1985) . . . . . 3.5

3.3. Crack Growth Over the Period $5 / 89$ to $9 / 90$ as Indicated by AE - N2H Weld at Limerick Unit 1

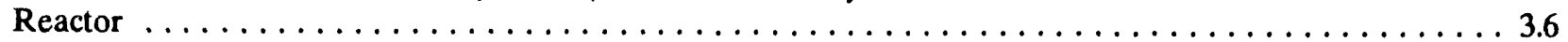

3.4. Crack Growth Values Derived from AE Data over the Period 8/89 to 9/90 - Shown on Pipe Crack Section $-\mathbf{N} 2 \mathrm{H}$ Weld at Limerick Unit 1 Reactor $\ldots \ldots \ldots \ldots \ldots \ldots \ldots \ldots \ldots \ldots \ldots \ldots \ldots$

3.5. UT Detection Threshold (20\% of Wall) Superimposed on Crack Growth Prediction from AE Data -

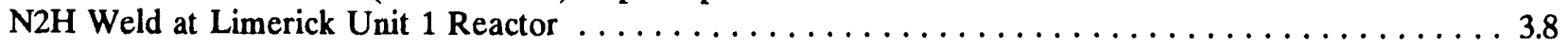

4.1. Crack Growth Values $\geq 0.1^{\prime \prime}$ Estimated from AE Data over the Period 5/89 to $9 / 90-$ N2H Weld at

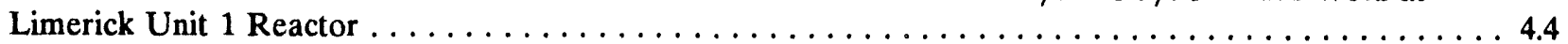

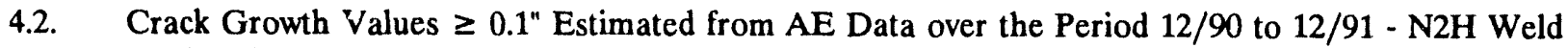

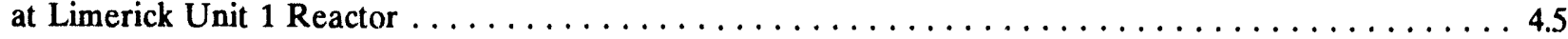




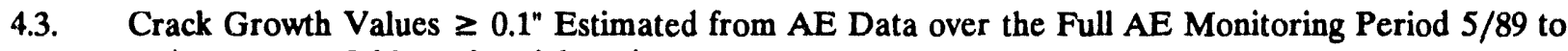
12/91 - N2H Weld at Limerick Unit 1 Reactor

4.4. AE Source Location Elements Superimposed on Pipe Cross Section with Flaw Profile - N2H Weld at

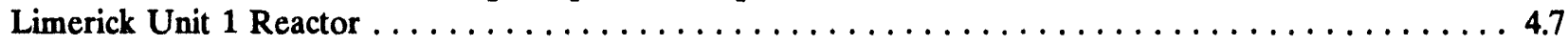

4.5. Flaw Indication Plot $-\mathrm{N} 2 \mathrm{H}$ Weld at Limerick Unit 1 Reactor $\ldots \ldots \ldots \ldots \ldots \ldots \ldots \ldots \ldots \ldots$

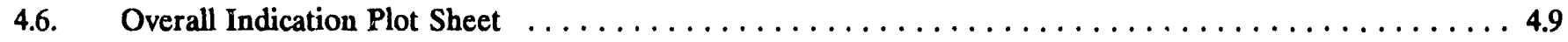

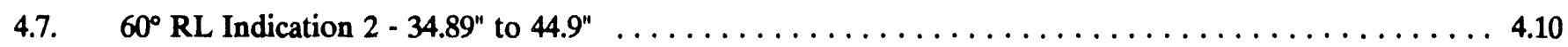

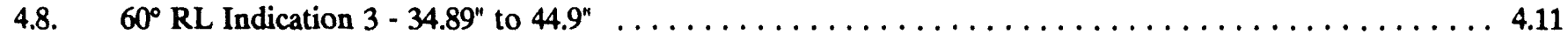

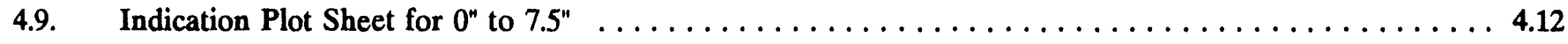

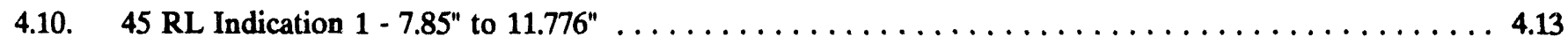

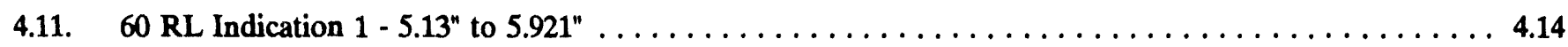




\section{Tables}

2.1. Comparison of Watts Bar and Limerick $\mathrm{AE}$ Installations $\ldots \ldots \ldots \ldots \ldots \ldots \ldots \ldots \ldots \ldots \ldots \ldots \ldots$

3.1. AE Event Count by Source Location Element - 5/12/89 - 10/6/89 - N2H Weld at Limerick Unit 1

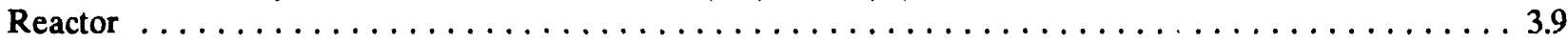

3.2. AE Event Count by Source Location Element - 10/6/89 - 6/4/90 - N2H Weld at Limerick Unit 1

Reactor ........................................ 3.11

3.3. AE Event Count by Source Location Element - 6/4/90 - 9/11/90 - N2H Weld at Limerick Unit 1

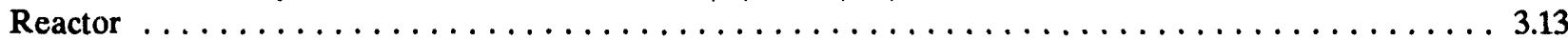

3.4. Filtered AE Event Count by Source Location Element - 5/12/89 - 10/6/89 - N2H Weld at Limerick

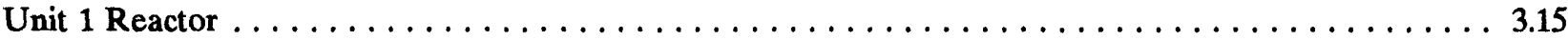

3.5. Filtered AE Event Count by Source Location Element - 10/6/89 - 6/4/90 N2H - Weld at Limerick

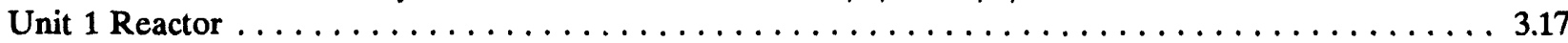

3.6. Filtered AE Event Count by Source Location Element - 6/4/90 - 9/11/90 - N2H Weld at Limerick

Unit 1 Reactor . . . . . . . . . . . . . . . . . . . . . . . . . . . . . . . . . . 3.19

3.7. Crack Growth Predicted from AE Data - 5/12/89 to 10/6/89 - N2H Weld at Limerick Unit 1

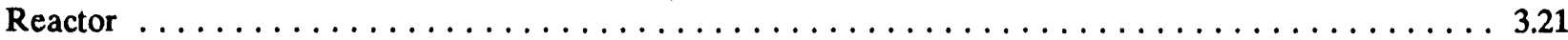

3.8. Crack Growth Predicted from AE Data - 10/6/89 to 6/4/90 - N2H Weld at Limerick Unit 1 Reactor . 3.23

3.9. Crack Growth Predicted from AE Data - 6/4/90 to 9/11/90 - N2H Weld at Limerick Unit 1 Reactor .. 3.25

3.10. Indicated Crack Growth Rate at the N2H Weld Over Period $5 / 89$ to $9 / 90 \ldots \ldots \ldots \ldots \ldots \ldots .26$

4.1. Filtered AE Event Count by Source Location Element - 12/13/90 to 4/27/91 - N2H Weld at

Limerick Unit 1 Reactor . . . . . . . . . . . . . . . . . . . . . . . . . . . . . . . . . . . . . 4.15

4.2. Filtered AE Event Count by Source Location Element - 4/28/91 to 8/9/91 - N2H Weld at Limerick

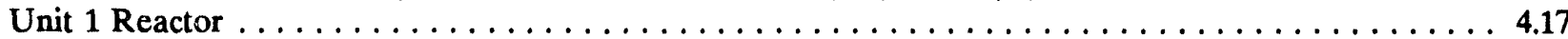

4.3. Filtered AE Event Count by Source Location Element - 8/9/91 to 12/18/91 - N2H Weld at Limerick

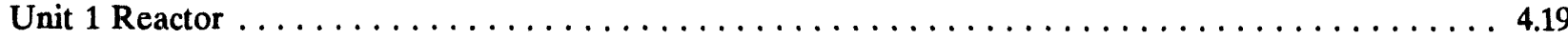

4.4. Crack Growth Predicted from AE Data - 12/13/90 to 4/27/91 - N2H Weld at Limerick Unit 1

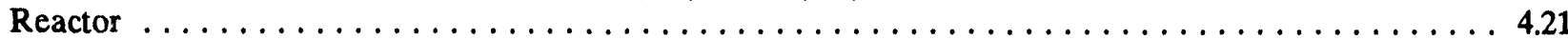

4.5. Crack Growth Predicted from AE Data - 4/28/91 to 8/8/91 - N2H Weld at Limerick Unit 1 Reactor .. 4.23

4.6. Crack Growth Predicted from AE Data - 8/9/91 to 12/18/91 Plus Totals for 5/12/89 to 12/18/91 -

$\mathrm{N} 2 \mathrm{H}$ Weld at Limerick Unit 1 Reactor $\ldots \ldots \ldots \ldots \ldots \ldots \ldots \ldots \ldots \ldots \ldots \ldots \ldots \ldots \ldots \ldots$ 


\section{Executive Summary ${ }^{1}$}

This program, with the objective of validating the application of acoustic emission (AE) monitoring to reactor components to detect crack initiation and growth during reactor operation, was started in March 1989 at Philadelphia Electric Co. (PECO) Limerick Unit 1 Generating Station in Pennsylvania. At that time, PECO made the decision to apply AE technology developed by $\mathrm{Pa}-$ cific Northwest Laboratory (PNL), operated by Battelle Memorial Institute, to monitor a flaw indication detected in a recirculation nozzle-to-safe end weld during routine inservice ultrasonic inspection. The technology was developed over several years under a major program supported by the U. S. Nuclear Regulatory Commission, Office of Nuclear Regulatory Research

(NRC-RES). The first monitoring period (fuel cycle) at Limerick was supported by funding from PECO with instrumentation supplied by NRC-RES from the PNL research program. The second monitoring period (fuel cycle) was funded jointly by PECO and NRC-RES. Installation and operation of the $\mathrm{AE}$ system has been a joint PECO-PNL effort with PNL performing the data analysis function. The guidelines of American Society of Mechanical Engineers (ASME) Code Case N-471, "Acoustic Emission for Successive Inspections, Section $\mathrm{XI}$, Div. 1" were followed in applying the AE system.

The AE monitoring of the $\mathrm{N} 2 \mathrm{H}$ weld demonstrated that continuous AE monitoring can be effectively applied to an operating reactor plant. The system was installed, calibrated, and maintained without causing any perturbations in the reactor schedule. AE and ultrasonic ISI results generally agreed relative to growth of the flaw indication observed in the $\mathrm{N} 2 \mathrm{H}$ weld. Both showed limited growth during the first monitoring period (fuel cycle) and no growth during the second period (fuel cycle). The relationship identified for relating $\mathrm{AE}$ to crack growth produced rational results which were similar in magnitude to that indicated by the ISI.

AE indicated limited flaw growth in an area adjacent to the ISI flaw indication which was not confirmed by ISI. Inspection using an advanced technique which has greater sensitivity such as Synthetic Aperture Focusing Technique for ultrasonic testing may provide a resolution of the validity of the indication.

Several observations were noted in the course of the effort which will contribute to enhanced effectiveness of future $\mathrm{AE}$ monitoring of reactor components. Future applications of $\mathrm{AE}$ monitoring will also benefit from the transfer of technology to a commercial company(ies) that is proceeding outside this program. It is important for the effective use of the technology that it be available on a commercial basis.

$1_{\text {RES FIN. Budget No. L1100; RES Conted: J. Murara }}$ 


\section{Previous Reports in Series}

By intention, this list does not include routine monthly and quarterly reports.

Hutton, P. H. and E. B. Schwenk, Pacific Northwest Laboratory, "Program to Develop Acoustic EmissionFlaw Relationship for Inservice Monitoring of Nuclear Pressure Vessels, Progress Report No. 1, July 1, 1976February 1, 1977," USNRC Report NUREG-0250-1 (1977).

Hutton, P. H. and E. B. Schwenk, Pacific Northwest Laboratory, "Program to Develop Acoustic EmissionFlaw Relationship for Inservice Monitoring of Nuclear Pressure Vessels, Progress Report No. 1, July 1, 1976February 1, 1977," USNRC Report NUREG-0250-2 (1977).

Hutton, P. H., R. J. Kurtz, E. B. Schwenk, and C. Pavloff, Pacific Northwest Laboratory, "Program to Develop Acoustic Emission-Flaw Relationship for Inservice Monitoring of Nuclear Pressure Vessels, Annual Report, July 1, 1976-October 1, 1977," USNRC Report NUREG/CR-0123 (1978).

Hutton, P. H., R. J. Kurtz, E. B. Schwenk, and C. Pavloff, Pacific Northwest Laboratory, "Program to Develop Acoustic Emission-Flaw Relationship for Inservice Monitoring of Nuclear Pressure Vessels, Progress Report, October 1, 1977-January 1, 1978," USNRC Report NUREG/CR-0124 (1978).

Doctor, P. G., T. P. Harrington, and P. H. Hutton, Pacific Northwest Laboratory, "Pattern Recognition Methods for Acoustic Emission Analysis," USNRC Report NUREG/CR-0910 (1979).

Hutton, P. H., E. B. Schwenk, and R. J. Kurtz, Pacific Northwest Laboratory, "Estimate of Feasibility to Develop Acoustic Emission Flaw Relationships for Inservice Monitoring of Nuclear Pressure Vessels," USNRC Report NUREG/CR-0800 (1979).

Hutton, P. H., T. T. Taylor, J. F. Dawson, R. A. Pappas, and R. J. Kurtz, Pacific Northwest Laboratory, "Acoustic Emission Monitoring of ASME Section III Hydrostatic Test," USNRC Report NUREG/CR-2880 (1982).
Hutton, P. H. and R. J. Kurtz, Pacific Northwest Laboratory, "Acoustic Emission for On-line Monitoring: Results of Intermediate Vessel Test Monitoring and Reactor Hot Functional Testing," Vol. 4, p. 1-19, in Proceedings of the Eleventh Water Reactor Safety Research Information Meeting, USNRC Conference Proceeding NUREG/CP-0048, Vol. 4 (1984).

Hutton, P. H., J. F. Dawson, M. A. Frisel, J. C. Harris, and R. A. Pappas, Pacific Northwest Laboratory, "Acoustic Emission Monitoring of Hot Functional Testing," USNRC Report NUREG/CR-3693 (1984).

Hutton, P. H. and R. J. Kurtz, Pacific Northwest Laboratory, "Acoustic Emission/Flaw Relationship for Inservice Monitoring of Nuclear Pressure Vessels, Quarterly Report, October 1983-March 1984," USNRC Report NUREG/CR-3825, Vols. 1 and 2 (1984).

Hutton, P. H., R. J. Kurtz, M. A. Friesel, R. A. Pappas, J. R. Skorpik, J. F. Dawson, Pacific Northwest Laboratory, "Summary of Detection, Location, and Characterization Capabilities of $\mathrm{AE}$ for Continuous Monitoring of Cracks in Reactors," Vol. 4, p. 362-380 in Proceedings of the Twelfth Water Reactor Safety Research Information Meeting, USiNRC Conference Proceeding NUREG/CP-0058, Vol. 4 (1985).

Hutton, P. H. and R. J. Kurtz, Pacific Northwest Laboratory, "Acoustic Emission/Flaw Relationship for Inservice Monitoring of Nuclear Pressure Vessels, Quarterly Report, April-September 1984," USNRC Report NUREG/CR-3825, Vols. 3 and 4 (1985).

Hutton, P. H., R. J. Kurtz, R. A. Pappas, J. F. Dawson, L. S. Dake, and J. R. Skorpik, Pacific Northwest Laboratory, "Acoustic Emission Results Obtained From Testing the ZB-1 Intermediate Scale Pressure Vessel, USNRC Report NUREG/CR-3915 (1985).

Hutton, P. H. and R. J. Kurtz, Pacific Northwest Laboratory, "Acoustic Emission/Flaw Relationship for Inservice Monitoring of Nuclear Pressure Vessels, Progress Report, October 1984-March 1985, USNRC Report NUREG/CR-4300, Vol. 1 (1985). 
Hutton, P. H., R. J. Kurtz, and M. A. Friesel, Pacific Northwest Laboratory, "Progress for On-Line Acoustic Emission Monitoring of Cracks in Reactor Systems," Vol. 2, p. 553-564 in Proceedings of the Thirteenth Water Reactor Safety Research Information Meeting, USNRC Conference Proceeding NUREG/CP-0072, Vol. 2 (1986).

Hutton, P. H. and R. J. Kurtz, Pacific Northwest Laboratory, "Acoustic Emission/Flaw Relationship for Inservice Monitoring of Nuclear Pressure Vessels, Progress Report, April-September 1985," USNRC Report NUREG/CR-4300, Vol. 2 (1986).

IIutton, P. H. and R. J. Kurtz, Pacific Northwest Laboratory, "Acoustic Emission/Flaw Relationship for Inservice Monitoring of Nuclear Pressure Vessels, Progress Report, October 1985-March 1986, USNRC Report NUREG/CR-4300, Vol. 3, No. 1 (1986).

Hutton, P. H., Pacific Northwest Laboratory, "Acoustic Emission/Flaw Relationship for In-service Monitoring of Nuclear Pressure Vessels, Progress Report, April 1986-September 1986," USNRC Report NUREG/CR4300, Vol. 3, No. 2 (1987).
Hutton, P. H., M. A. Friesel, and R. J. Kurtz, Pacific Northwest Laboratory, "Progress for On-Line Acoustic Emission Monitoring of Cracks in Reactor Systems," Vol. 2, p. 43-56, in Proceedings of the Fourteenth Water Reactor Safety Research Information Meeting, USNRC Conference Proceeding NUREG/CP-0082, Vol. 2 (1987).

Hutton, P. H., M. A. Friesel, J. F. Dawson, and J. C. Harris, Pacific Northwest Laboratory, "Acoustic Emission System Calibration at Watts Bar Unit 1 Nuclear Reactor," USNRC Report NUREG/CR-5144 (1988).

Hutton, P. H., M. A. Friesel, and R. J. Kurtz, Pacific Northwest Laboratory, "On-line Acoustic Emission Monitoring for Crack Growth in LWRs," Vol. 2, p. 333342, in Proceedings of the Fifteenth Water Reactor Safety Research Information Meeting, USNRC Conference Proceeding NUREG/CP-0091, Vol. 2 (1988).

Hutton, P. H., R. J. Kurtz, M. A. Friesel, J. R. Skorpik, and J. F. Dawson, Acoustic Emission/Flaw Relationships for Inservice Monitoring of LWRs, USNRC Report NUREG/CR-5645 (1991). 


\section{Acknowledgements}

The authors wish to recognize the progressive attitude on the part of PECO in permitting the test application of $\mathrm{AE}$ monitoring to a real problem on an operating reactor and the continued outstanding support by the U. S. NRC-RES under the program direction of Dr. J. Muscara in the development and application of continuous AE monitoring. This program benefitted from the outstanding cooperation on the part of PECO staff in the planning and execution of the work. Ron DeGregorio, Ken Collier, John Turner, Jose Vega, Anthony Wesstrom, Laura Carlson, Tony Gryscavage, Jim O'Brien, Jack McElroy, and Mike Lind have been prominent among the many who have been very supportive of the work. 


\subsection{Introduction}

In the course of normal inservice inspection at Limerick Unit 1 reactor during the 1989 refueling outage, it was found that the recirculation nozzle-to-safe end weld VRR-1RD-1A N2H showed a flaw indication. The indication appears to be an intergranular stress corrosion crack (IGSCC) crack 7 inches long with a nominal depth of 0.25 inches and a maximum depth of 0.4 inches. It is located between 31.8 and 38.8 inches $\left(257^{\circ}\right.$ to $\left.314^{\circ}\right)$ circumference measuring clockwise from top-dead-center looking with the flow. The flaw indication was evaluated for continued service of the piping using fracture mechanics methods, and a crackarrest-verification specimen was installed for assurance that the indicated flaw would not grow undetected. In aduition, Philadelphia Electric Company (PECO) made the decision to apply acoustic emission (AE) monitoring on a continuous monitoring basis to validate a more direct method of determining if a flaw indication was growing during reactor operation. The purpose of this effort was to validate technology for continuous $A E$ monitoring of reactor components which had been developed by Pacific Northwest Laboratory (PNL) under the support of the U. S. Nuclear Regulatory Commission (NRC), Office of Research. The dèvelopment program followed a planned sequence of:

- Develop initial AE/flaw relationships by laboratory testing of crack growth specimens.

- Evaluate and refine the technology developed in the laboratory by $A E$ monitoring pipe rupture tests, heavy section steel technology vessel tests, and fatigue testing of a thick wall vessel under simulated reactor conditions.
- Validate continuous AE monitoring on a nuclear power reactor system.

The first two steps had been completed and the weld monitoring at Limerick provided an opportunity to address the third step.

The AE monitoring at Limerick Unit 1 uniquely provided AE data from suspected IGSCC in a reactor component which could be compared to the amount of crack growth measured at the end of the monitoring cycle by ultrasonic methods. There was no previous calibration of $\mathrm{AE}$ data produced by ISGC cracking as it progresses slowly in a reactor component. Previous AE/IGSCC data obtained during technology development activities proved that IGSCC could be detected by $A E$ and gave a general indication of the overall pattern of AE vs. IGSCC (Electric Power Research Institute 1980). This information was derived from accelerated tests (two weeks to a month to grow through the wall of a 4 -in. Schedule 80 pipe). It is impractical in an R\&D program to conduct a test truly simulating reactor conditions where the time for significant IGSCC growth would normally be measured in years.

This report discusses the program results in three parts:

- AE system installation and calibration

- Interim data results

- Final data results and overall summary. 


\subsection{AE System Installation and Calibration}

\subsection{Preparation}

A planning meeting was held at the Limerick Plant on March 4, 1989, at which P. H. Hutton, PNL, reviewed the status of AE technology for continuous monitoring of reactor components to detect crack growth. The decision was made at that meeting to proceed with installation of $\mathrm{AE}$ equipment to monitor the flaw indication in weld VRR-1RD-1A N2H at Limerick Unit 1. This decision was conditional on the basis that all work inside the drywell associated with the installation must be completed by March 24, 1989. This requirement was met; however, further access to the drywell resulting from unforeseeable delay in reactor startup was ultimately utilized for additional system checkout.

By prior agreement from the NRC, Office of Research, Materials Engineering Branch, equipment developed at PNL under the NRC AE research program was utilized in the installation at Limerick. This consisted of waveguide $\mathrm{AE}$ sensors and mounting clamps (4), preamplifiers (4), and an eight-channel AE data acquisi-

tion/recording instrument. All signal cabling was provided and installed by PECO. Preparation and installation of the $\mathrm{AE}$ system at Limerick followed the requirements of the American Society of Mechanical Engineers (ASME) Code Case titled "Acoustic Emission for Successive Inspections, Section XI, Div. 1."

As the first step in preparation, existing three-foot-long waveguide $A E$ sensors were modified to provide ninefoot-long waveguides by welding on additional lengths of 0.125 -in. diameter Type 304 stainless steel wire. Construction of the waveguide $A E$ sensors is shown in Figure 2.1. The AE system was then assembled in the laboratory at PNL, and the sensors were mounted on a 4-in. x 12-in. x 12-in. steel calibration block one at a time to calibrate the sensor response characteristics and sensitivity. The sensors were pressure coupled to the surface of the block in a manner similar to that used to mount them on a reactor. A broad-band acoustic signal was then generated by impinging a helium gas jet from a 30-psi source through a \#18 hypodermic needle onto the surface of the block with the needle held $1 / 8$ inch above the surface of the block and 1-1/2 inches from the sensor waveguide tip. The resulting spectral responses shown in Figure 2.2 are a logarithmic measure. The analyzer reference point is the top of the grid which corresponds to $0 \mathrm{~dB}$ on the logarithmic scale.
Working from the top down, the logarithmic scale is in $\mathrm{dB}$ below reference $(10 \mathrm{~dB} /$ division $)$. The analyzer reference value is 1 milliwatt when a $50 \Omega$ input is used. The corresponding voltage values can be determined by:

$$
V_{\text {peat }}=\frac{0.244}{\left[\log ^{-1}(d B m / 20)\right] \times 0.707}
$$

Thus, on a voltage scale, the reference corresponds to 317 millivolts peak with the analyzer on the $0 \mathrm{~dB}$ scale.

Figure 2.2 shows that the peak response of the sensors occurs at 400 to $425 \mathrm{kHz}$ and that the sensitivity to the helium gas excitation is $0.08,0.18,0.18$, and 0.11 millivolts $_{\text {peak }}$ for sensors $\# 1, \# 2$, \#3, and \#4 respectively at the sensor output taking into account the $40 \mathrm{~dB}$ external gain used to produce the traces. The frequency range of the peak response and the overall response profile are very important to the resistance of the $\mathrm{AE}$ system to interference from noise such as coolant flow noise. Sensors with a response profile similar to those seen in Figure 2.2 have been used successfully in the presence of flow noise on a PWR. The sensor sensitivity was considered acceptable even though the waveguide sensors were 9 feet long.

The performance of the monitor system minus the sensors was checked using an Acoustic Emission Simulator, Model No. AES-1, from Acoustic Emission Associates, Laguna Niguel, California 92677. This is a special-purpose signal generator which facilitates imposing a time delay between similar signals out of two different channels to qualify delta time determination by an $\mathrm{AE}$ monitor instrument. This, in turn, influences the signal source location capability of the instrument. For input delays of 100,150 , and $200 \mu$ seconds, the measurement accuracy was within $4 \%$. For inputs of 25 and $50 \mu \mathrm{sec}$ onds, the measurement accuracy was within $10 \%$. These input time delays represent the range of values expected to be significant in this test. The accuracy with the larger time delays is quite good, but the accuracy with the smaller time delays is marginal because the inherent measurement error is a larger portion of the total time delay.

The signal identification module was evaluated in accordance with the method described in the ASME Code 
Case, "Acoustic Emission for Successive Inspections, Section XI. Div. 1." This calls for installation of a representative waveguide $\mathrm{AE}$ sensor on a calibration block, connecting the sensor to the monitoring system, and exciting the sensor ten times by each of the following three methods:

1. Fracture a $0.3-\mathrm{mm}, 2 \mathrm{H}$ pencil lead against the surface of the block in accordance with ASTM E976.

2. Strike the surface of the block with a 0.25 -in. diameter steel ball dropped from a uniform height.

3. Inject a multi-cycle (five cycles minimum) burst signal into the block with a transducer and a waveform generator.

The requirement in the Code Case is that the signal identification module flag at least 8 out of 10 lead fracture signals as crack growth AE signals and at least 8 out of 10 of the other types of signals as not being crack growth AE signals. The results obtained in this evaluation were:

- Pencil lead break - 10 out of 10 identified as crack growth signals

- Ball drop - 6 out of 10 identified as not being crack growth signals

- Pulser - 10 out of $\mathbf{1 0}$ identified as not being crack growth signals.

\subsection{AE System Installation}

The initial emphasis was focused on installing the $\mathrm{AE}$ sensors on the pipe, installing signal cable from the sensors to a containment penetration where the leads could be connected to leads through the containment wall, and calibration of the installed sensors. All of this work required entry to the drywell. Installation was started March 22, 1989 and proceeded as a joint effort by PECO and PNL personnel. The installed AE system is shown in Figures 2.3 through 2.10.
In Figure 2.3, the specific location of the AE sensors and the flaw indication are shown. Location of the flaw indication is taken from Limerick Unit 1 ISI report \#89-003. Figure 2.4 shows the waveguide sensors mounted on the nozzle and safe-end. A force of at least 30 pounds is applied to the waveguide with the pressure bolt which is threaded into the mounting bracket (Figure 2.5). Since the waveguide is tapered from 0.125 -in. diameter to 0.050 -in. diameter at the tip, the 30 pounds force results in about 15,000 pounds per square inch interface pressure between the waveguide tip and the surface of the pipe. Experimental evaluation of the interface pressure vs. acoustic coupling efficiency in the 300 to $500 \mathrm{kHz}$ frequency range has shown that 15,000 pounds per square inch is effective. Some improvement can be achieved with higher pressure, but it becomes a trade-off between the difficulty of achieving higher interface pressures vs. the limited gain to be obtained. An Inconel spring is included in the line-of-force to help maintain a uniform pressure in the presence of temperature changes. A hightemperature electronic pulser is mounted in the vicinity of the $\mathrm{AE}$ sensors (Figure 2.6) to provide a means of qualitatively testing $\mathrm{AE}$ sensor sensitivity during reactor operation.

As shown in Figure 2.7, after the waveguides exit the opening in the shielding wall, the outer end is supported in a location away from the opening. This removes the critical sensor head (Figure 2.8), which contains the piezoelectric crystal and a $20 \mathrm{~dB}$ gain amplifier, from the area of high temperature and possible neutron beams through the shielding annulus. It is important that the sensor head be maintained at no more than $200^{\circ} \mathrm{F}$ and away from neutron beams.

PECO personnel installed RG58 coaxial cables from the AE sensor heads to a containment boundary penetration where the wires were connected through a Cannon plug to two-wire pairs which were installed in the penetration plug. The RG58 cable picked up again at the outer end of the penetration plug and went to the preamplifiers (Figure 2.9) and to the $\mathrm{AE}$ monitor instrument (Figure 2.10). The AE monitor instrument is installed in the same cabinet with the crack-arrest-verification specimen instrumentation. A set of differential amplifiers has been added between the preamplifiers and the $\mathrm{AE}$ monitor instrument to help overcome a 
noise problem; this is discussed further under Section 2.4, Problems.

\subsection{System Qualification}

After the AE system is installed, there are two qualification steps to be performed. One evaluates the signal detection and source location function of the total system and the other evaluates the response sensitivity of the installed waveguide $\mathrm{AE}$ sensors.

The signal source location results obtained from cracking $0.5-\mathrm{mm}$ pencil leads on the pipe surface to simulate an AE signal are shown in Figure 2.11. This is an accepted method of simulating an AE signal, and it is easily used in a field circumstance. Figure 2.11 is a roll-out of the pipe section and shows the AE sensors (black squares) plus the signal source determination (letters). The axial spacing of the sensors is 3-1/2 inches, and they are located at $90^{\circ}$ intervals circumferentially around the pipe (ref. Figure 2.3). Pencil leads were broken within 1 inch to 2 inches of each sensor in turn. This plot shows that the circumferential location accuracy is very good. The axial accuracy is not as good but still within the acceptable limits of two wall thicknesses (wall thiciness at this point is 1.3 inches). The very narrow axial spacing of the AE sensors contributes to the location scatter in the axial direction; i.e., a given error in signal time-of-arrival determination has greater significance with the narrow spacing.

The helium gas jet technique similar to that used during "Preparation" (see Section 2.1) to measure AE sensor sensitivity on the calibration block was again used to evaluate sensitivity of the sensors installed on the reactor. Figure 2.12 gives the results. The output was taken directly from the sensor which omits two filter stages in the midamplifier; hence, the response curve appears rather poor relative to the similar data taken earlier on the calibration block in the laboratory (Figure 2.2) where the $40 \mathrm{~dB}$ gain midamplifier was used. In reality, the response sensitivity of the installed sensors was significantly better as indicated by the voltage values from the plots $(0.25,0.71,0.4$, and 0.56 millivolts $_{\text {peak }}$ for sensors $\# 1, \# 2, \# 3$, and \#4 respectively). This could be due to better coupling of the installed sensors and the thinner pipe wall ( 1.3 inches) compared to the calibration block ( 4 inches). The helium gas jet tends to transmit to the sensors better with thinner material.

\subsection{Problems}

The AE monitor system setup included linear preamplifiers with a linear main amplifier in the AE monitor instrument. A total of $90 \mathrm{~dB}$ electronic gain was included $(20$ and $40 \mathrm{~dB}$ in the preamplifiers and $30 \mathrm{~dB}$ in the main amplifier). Under these conditions, the system performance looked very acceptable initially; i.e., the background noise was about 2 volts $_{\text {peak }}$ and the installed sensor sensitivity checks were satisfactory. Subsequently, however, a spike transient noise signal appeared on all sensors which was in excess of 10 volts $_{\text {peak }}$ out of the monitor instrument. This condition precludes effective $A E$ detection. The detection threshold of the AE instrument cannot be raised high enough to ignore the noise signals because it would also be far too high to detect AE signals. The repetition rate of the noise signal was such that it was filling up a tape cartridge (2.1 million signals) record in a few days and in a few instances the data rate became high enough to cause the monitor instrument to saturate and stop processing data. This noise problem was unexpected because a similar AE system had been installed at Watts Bar Unit 1 reactor and operated during hot functional testing of the plant without any noise problem. In spite of the very diligent efforts on the part of PECO personnel and the PNL specialist, the specific source of the noise signal could not be identified. The magnitude of the noise transient reduced substantially during reactor startup and has remained low enough to allow effective $\mathrm{AE}$ monitoring. The $\mathrm{AE}$ monitor instrument has been modified to eliminate recording any signals that appear simultaneously on all sensors (noise transients appear on all sensors simultaneously while AE signals from cracking will show a difference in time of arrival at the various sensors depending on the location of the cracking). The fact remains, however, that the AE system is vulnerable to noise signal pickup.

The Watts Bar and Limerick installations are compared in Table 2.1. The most prominent difference in signal lead shielding is in the containment penetration arrangement where the Limerick installation has only two wires while at Watts Bar there are three wires which are twisted to provide shielding. Another difference that could be significant is the signal cabling inside 
Table 2.1. Comparison of Watts Bar and Limerick $\mathbf{A E}$ Installations

\begin{tabular}{||l|l|l||}
\hline \multicolumn{1}{|c|}{ Item } & \multicolumn{1}{|c|}{ Watts Bar } & \multicolumn{1}{c|}{ Limerick } \\
\hline Sensor & 3' long two-piece waveguide & 9' long one-piece waveguide \\
\hline Sensor tuning & $375 \mathrm{kHz}$ and $500 \mathrm{kHz}$ & $425 \mathrm{kHz}$ \\
\hline Sensor-to-cable connect & BNC & BNC \\
\hline Cable inside containment & RG141 in conduit & RG58 in cable tray \\
\hline $\begin{array}{l}\text { Cable-to-penetration inside } \\
\text { connection }\end{array}$ & BNC & Cannon plug \\
\hline Penetration & $\begin{array}{l}\text { Three-wire twisted with 2' of } \\
\text { wire at inside end and 6' of } \\
\text { wire at outside end of plug }\end{array}$ & $\begin{array}{l}\text { Two-wire straight with 3' of } \\
\text { wire at each end of plug }\end{array}$ \\
\hline $\begin{array}{l}\text { Cable-to-penetration outside } \\
\text { connection }\end{array}$ & BNC & Cannon plug \\
\hline Cable outside containment & RG58 & RG58 \\
\hline Preamplifiers & $\begin{array}{l}20 \mathrm{~dB} \text { at sensor and 40 dB } \\
\text { outside penetration }\end{array}$ & $\begin{array}{l}20 \mathrm{~dB} \text { at sensor and 40 dB } \\
\text { outside penetration }\end{array}$ \\
\hline
\end{tabular}

of containment, which is a high-temperature coaxial cable contained in metal conduit at Watts Bar compared to standard RG58 cable in a tray at Limerick. This emphasizes the need for extreme care in maintaining good shielding in such a high-gain electronic system.

Another step was taken to guard against the return of the noise transient. This consisted of including a differential amplifier between the midamplifier and the $A E$ monitor instrument. A differential amplifier (unity gain) is intended to cancel out signals which appear simultaneously on different signal lines. This is needed because if the noise transient returns, it can still lock up the monitor system buffer memory if the repetition rate is sufficiently high. Two versions of differential amplifiers were tried with very limited benefit due to grounding problems and difficulty with passing the sensor power supply which is carried on the signal lead. These problems were remedied, and the amplifier was installed in the AE system. It reduced background noise by about a factor of two.
A second problem arose in early June 1989 when it was found that Sensor \#2 was no longer responding. This was discovered in a pulser check on June 9 when Sensor \#2 did not show any responses (Figure 2.13). There are two possible causes of this -- either the collar on the end of the waveguide, which is the bearing surface for the spring holding the waveguide against the pipe surface, slipped or the integral preamplifier had failed. In the numerous applications of this type of sensor, including monitoring molten vitrified waste experiments, this is the first sensor failure we have experienced. The source location program has been modified to give source location using three sensors. In order to do this, it was necessary to split the Channel 1 output and run it into both Channel 1 and 2 of the monitor instrument because the logic is arranged to work only with a four- or two-sensor array; and if Channel 2 was left open, it would never recognize valid data from the three-channel array. Figure 2.14 shows the results of testing the three-sensor program on recorded data from the pencil lead break input during the checkout of the installed system. These results can be 
compared with Figure 2.11. The three-sensor program results are very good.

As of mid-September 1989, the AE system setup consisted of:

- Original linear preamplifiers (40 dB gain) plus a unity gain differential amplifier

- Sensor \#2 was not functional

- Sensor \#1 output was split to feed both Channel 1 and 2

- Detection threshold was set at 2.5 volts, down from the previous 3.7 volts

- An AE signal identification module was installed in the monitor instrument

\subsection{Data Analysis}

PECO personnel managed the normal operation of the AE system. The plans for data analysis called for PECO personnel to remove the data tape cartridges at least once per month and send them to PNL for analysis. Instructions have been provided on loading and removing the tape cartridges associated with the $\mathrm{AE}$ monitor instrument. PNL analyzed the data for source location of recorded signals, number of signals from a given location, and signal classification. This information was then compiled in a report to be submitted to PECO at least once per month.

Originally, the $\mathrm{AE}$ monitoring period was planned for one fuel cycle ( $\approx 18$ months); however, at the end of the first fuel cycle, the decision was made to continue for a second fuel cycle under joint funding by PECO and NRC-RES.

\subsection{Summary}

The installed $\mathrm{AE}$ system was functional and capable of detecting and locating AE signals. It was installed and checked within a very stringent time window. Coolant flow noise did not cause a problem of increased background noise level. This was a point of concern at the outset because we had not previously monitored a BWR during operation. The remaining point of concern was the fact that the $A E$ system was subject to picking up electrical/electronic noise signals due to a weak point in the shielding (felt to be primarily at the containment penetration). Day-to-day operation of the $\mathrm{AE}$ system and replacement of the data storage cartridges for transfer of data to PNL was handled by PECO personnel. 


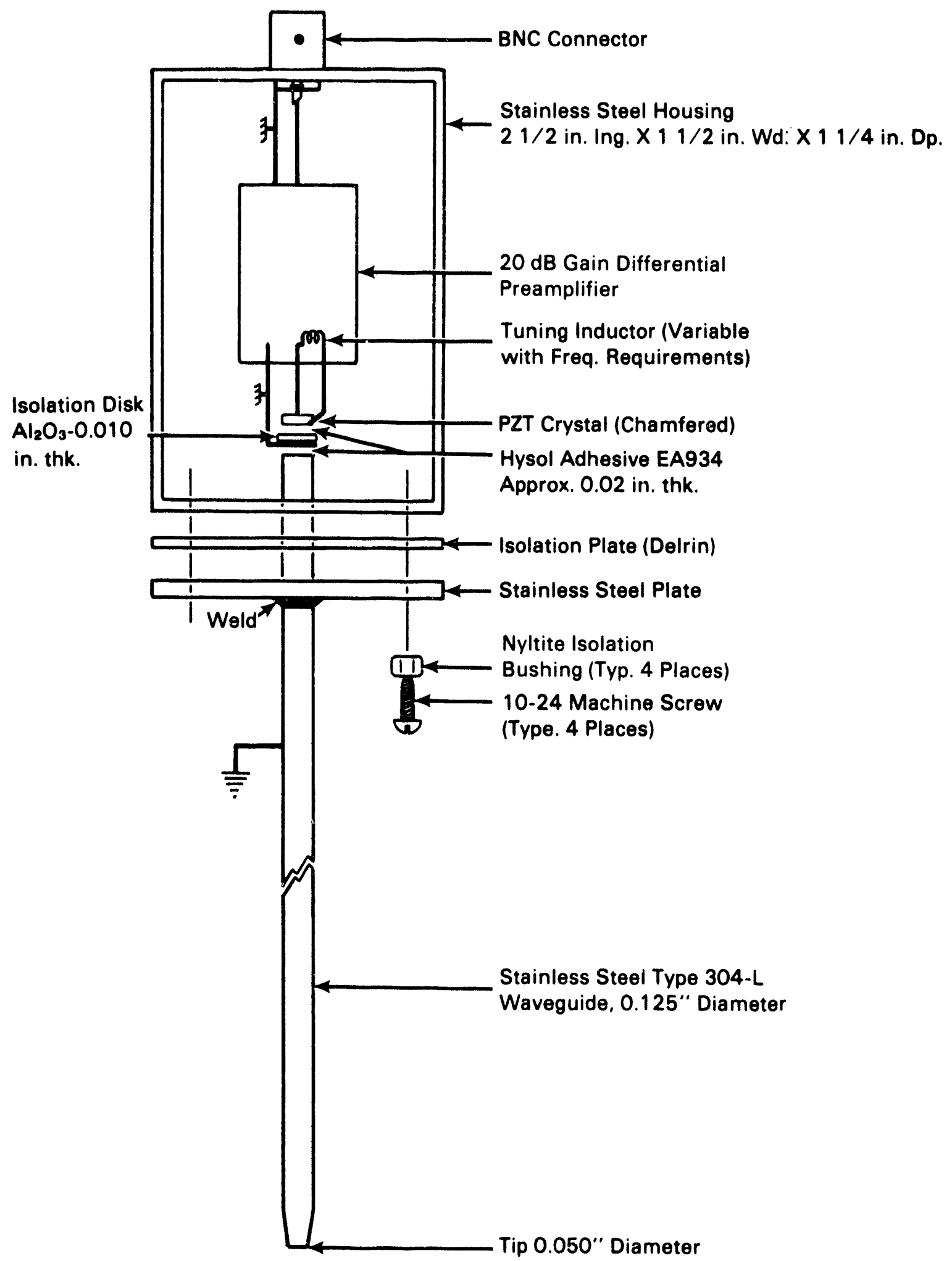

Figure 2.1. Construction of the Waveguide AE Sensors 


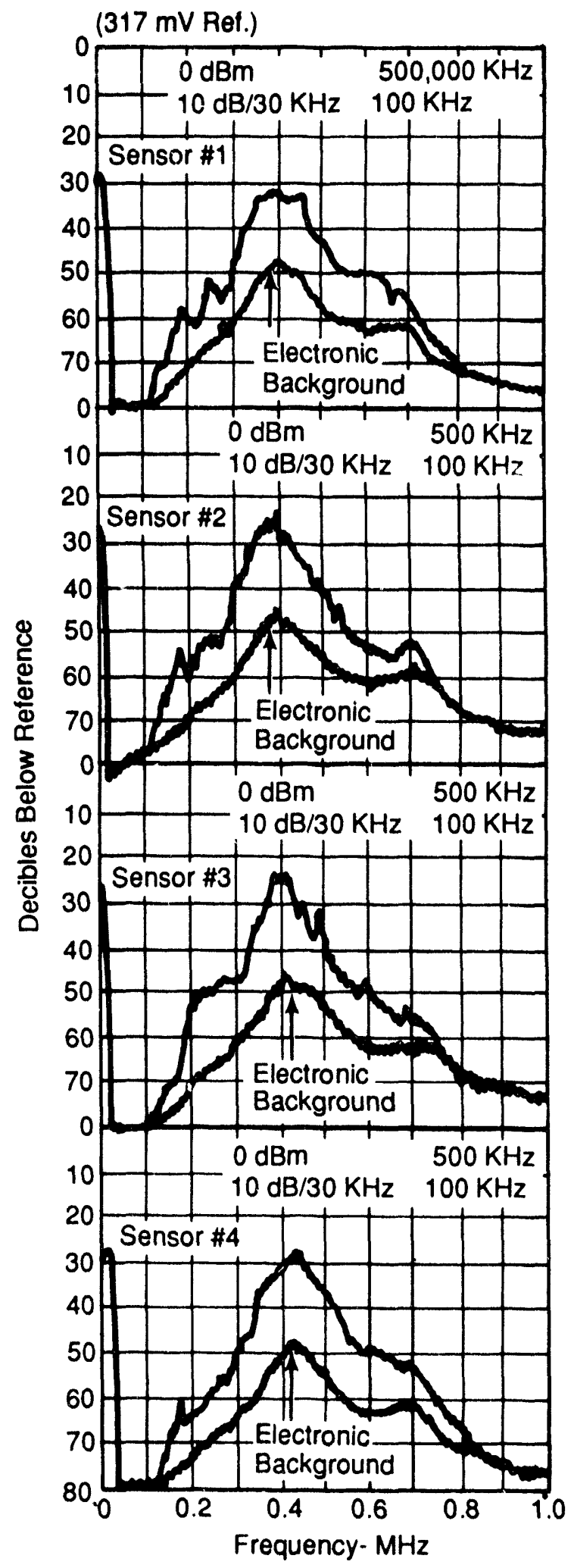

Figure 2.2. Sensitivity Test of Waveguide AE Sensors on Calibration Block 


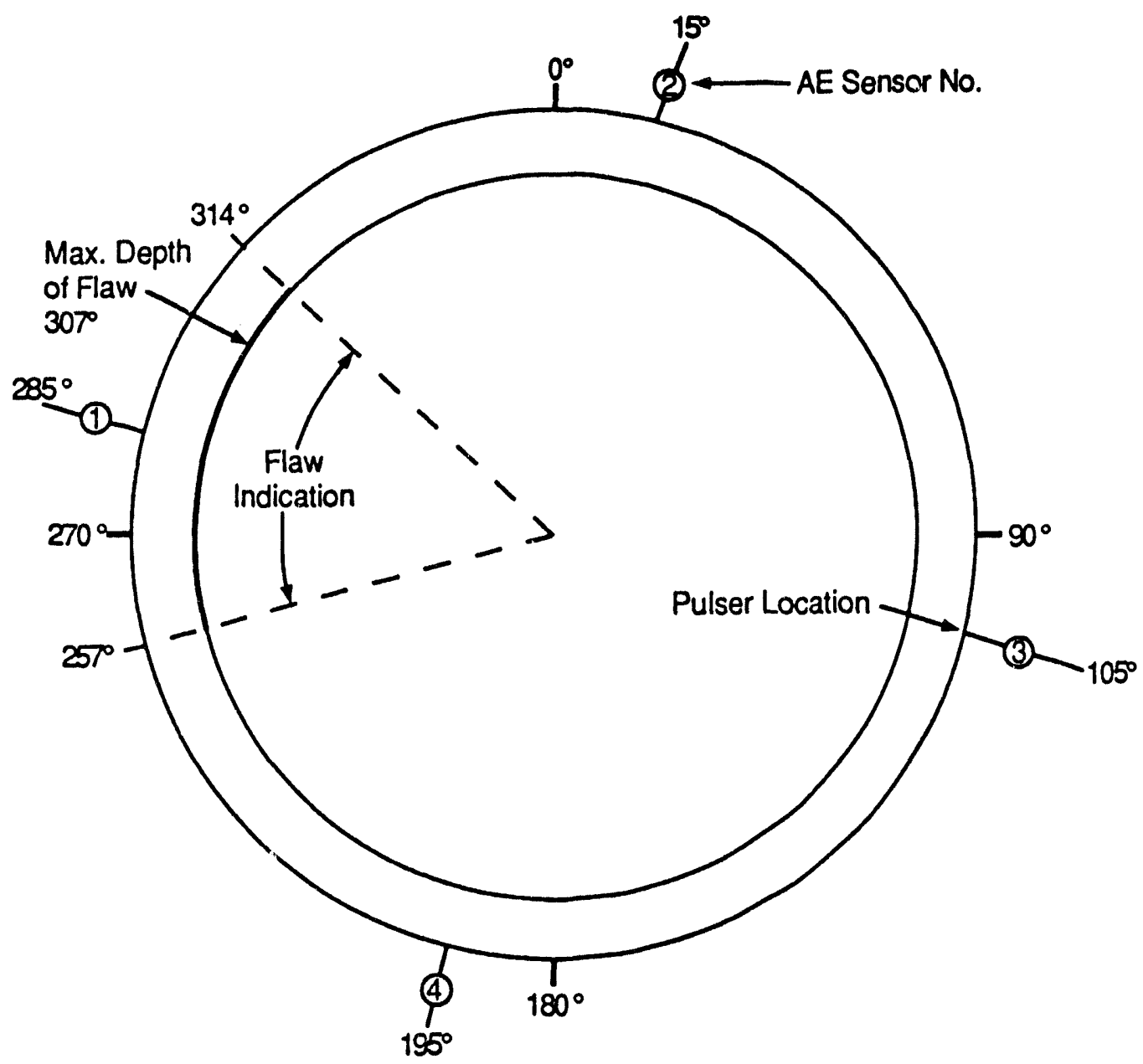

AO10051522

Figure 2.3. Location of AE Sensors on Pipe Weld NRR-1RD-1A N2H - Lmerick Unit 1 


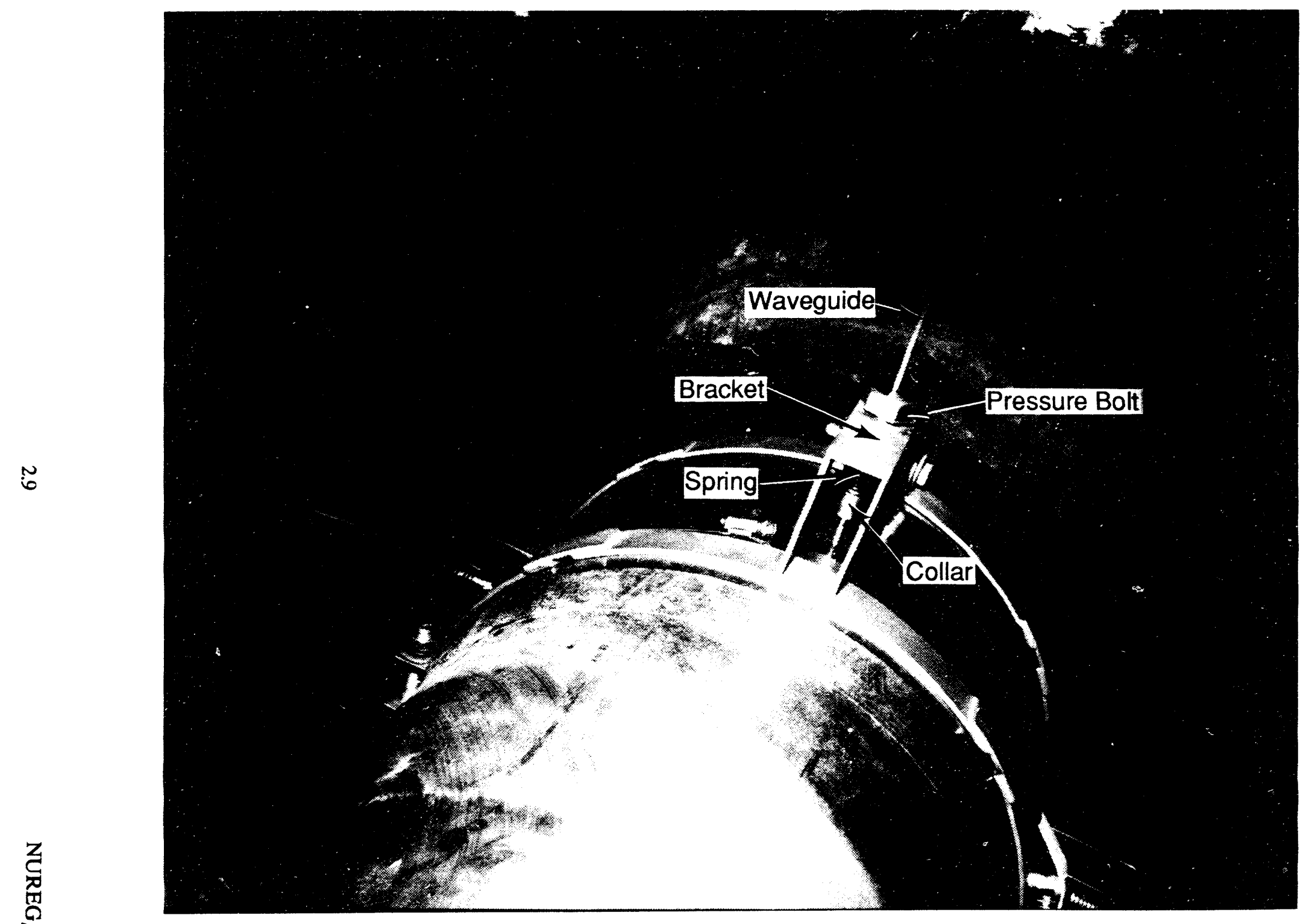

Figure 2.4. Waveguide AE Sensors Mounted Near Weld VRR-1RD-1A N2H - Limerick Unit 1 


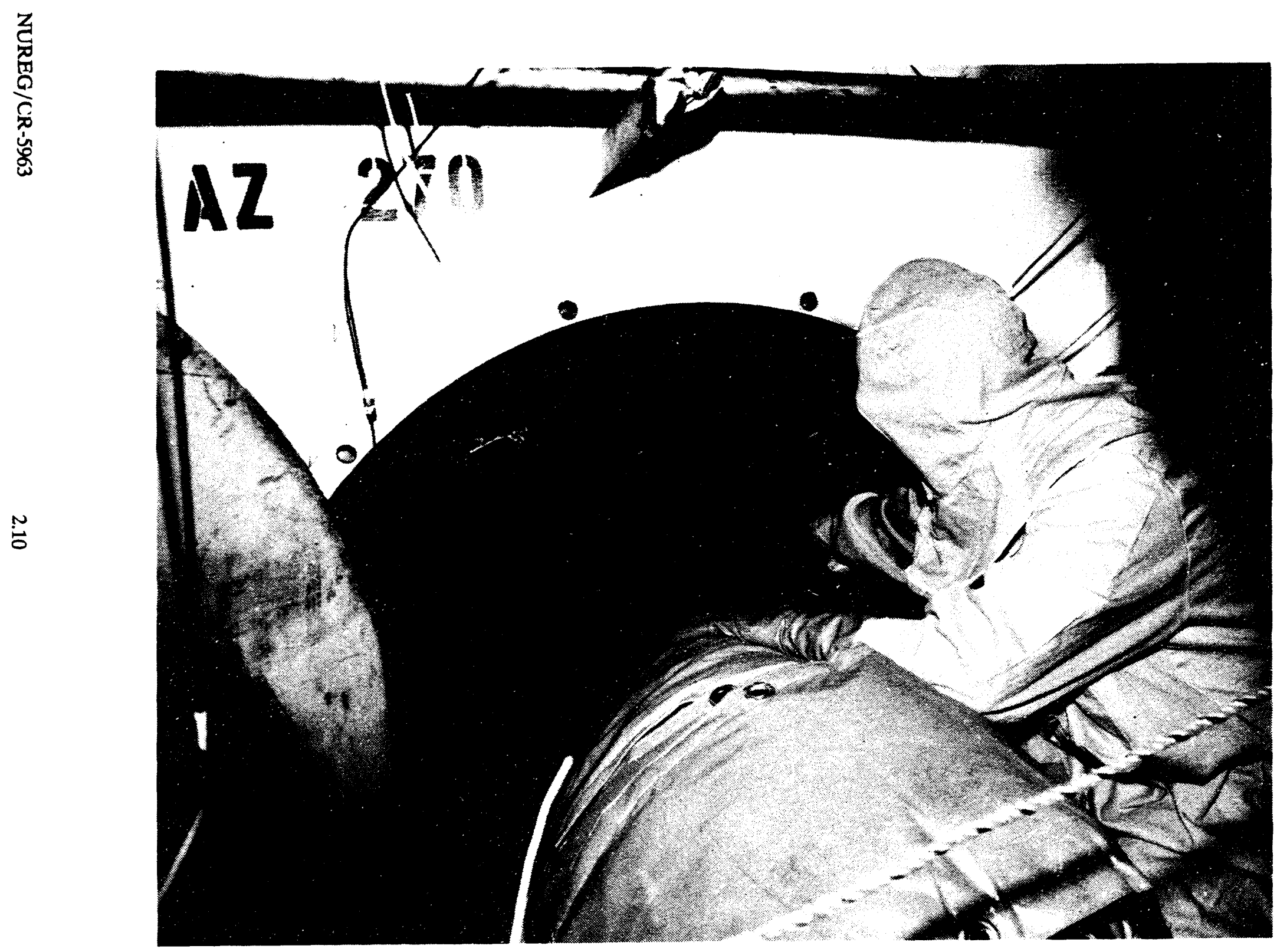

Figure 2.5. Waveguide AE Sensor Being Pressure Coupled to the Pipe Surface - Limerick Unit 1 


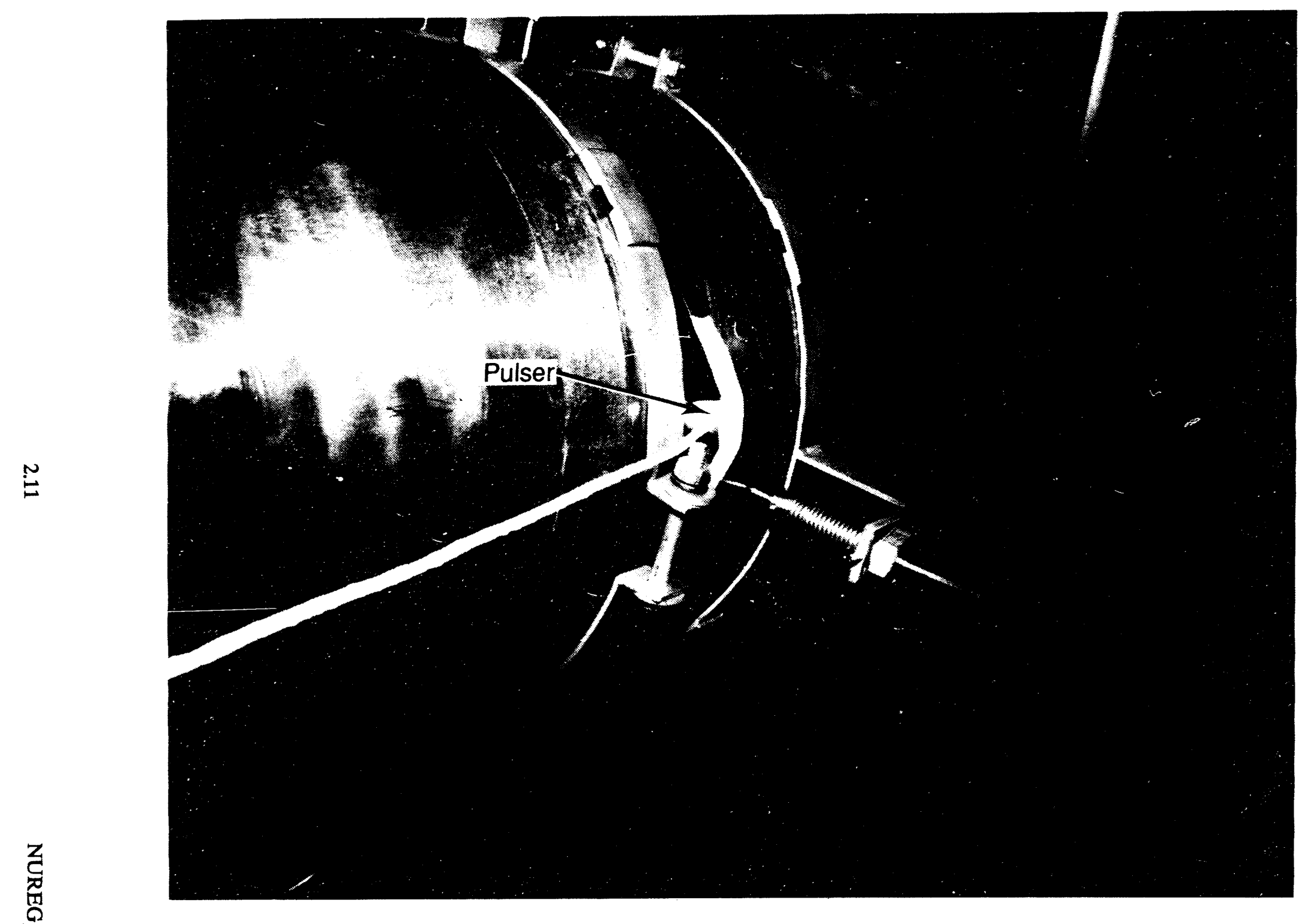

Figure 2.6. Electronic Pulser Mounted Near AE Sensor No. 3 - Limerick Unit 1 


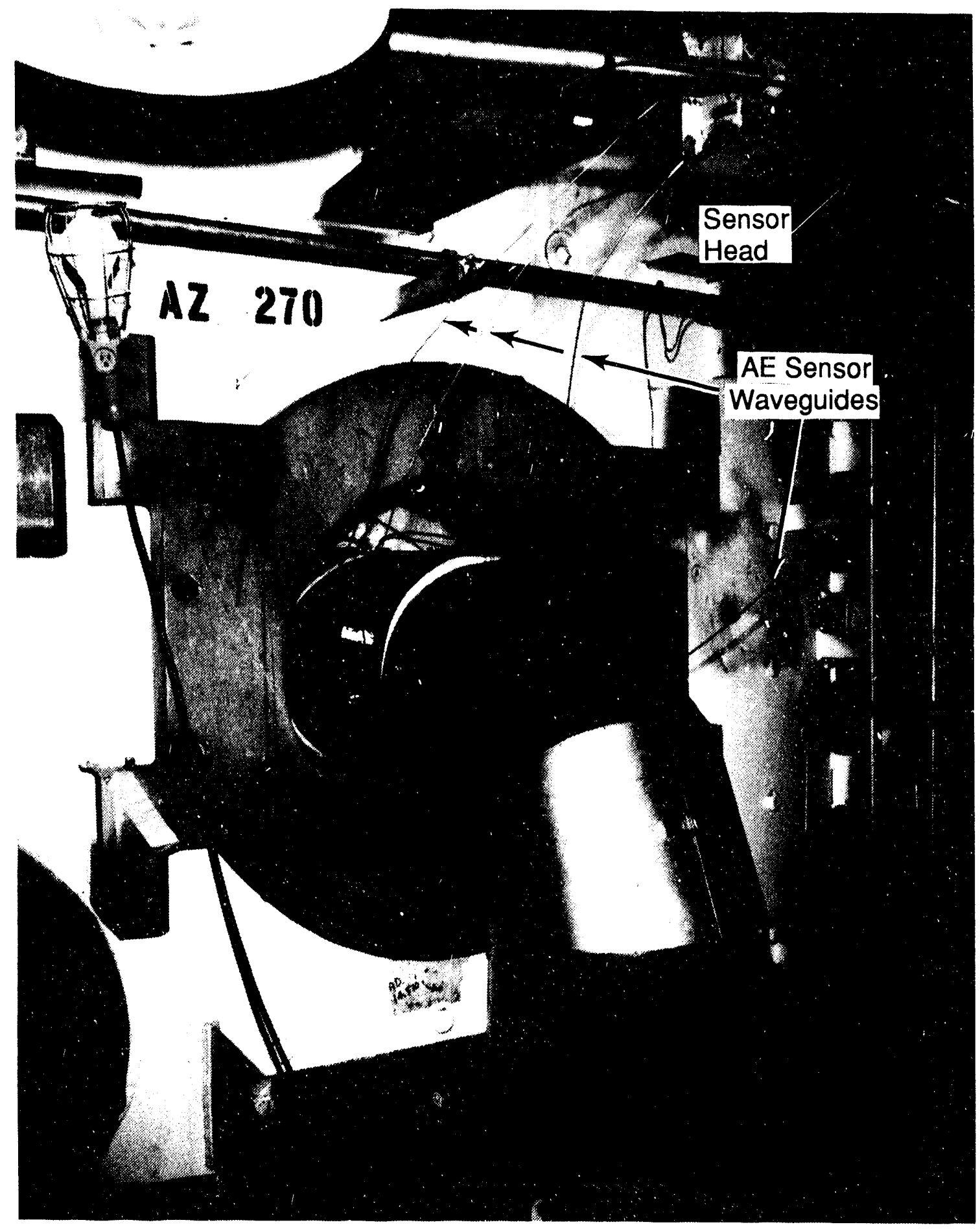

Figure 2.7. Waveguide AE Sensors Emerging from Weld Region Limerick Unit 1 


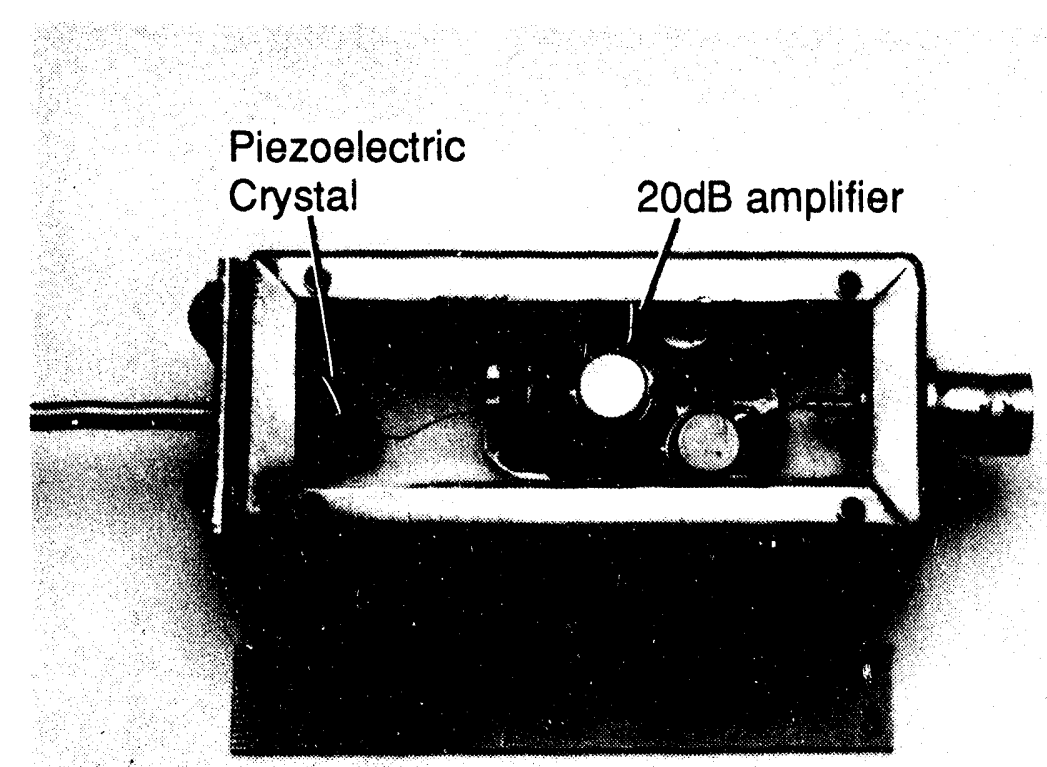

Figure 2.8. Waveguide AE Sensor Head 
2.0 AE System Installation and Calibration

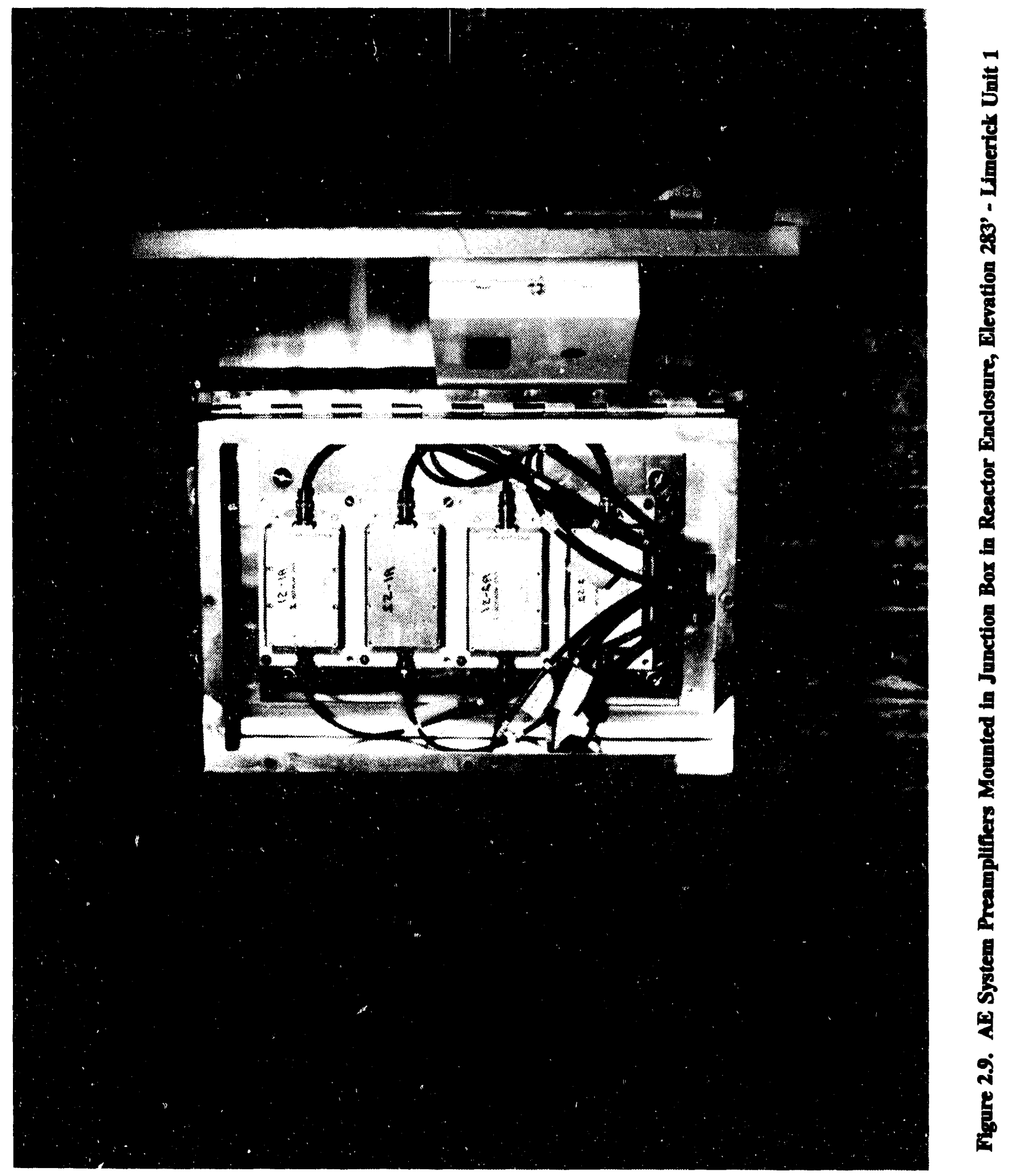




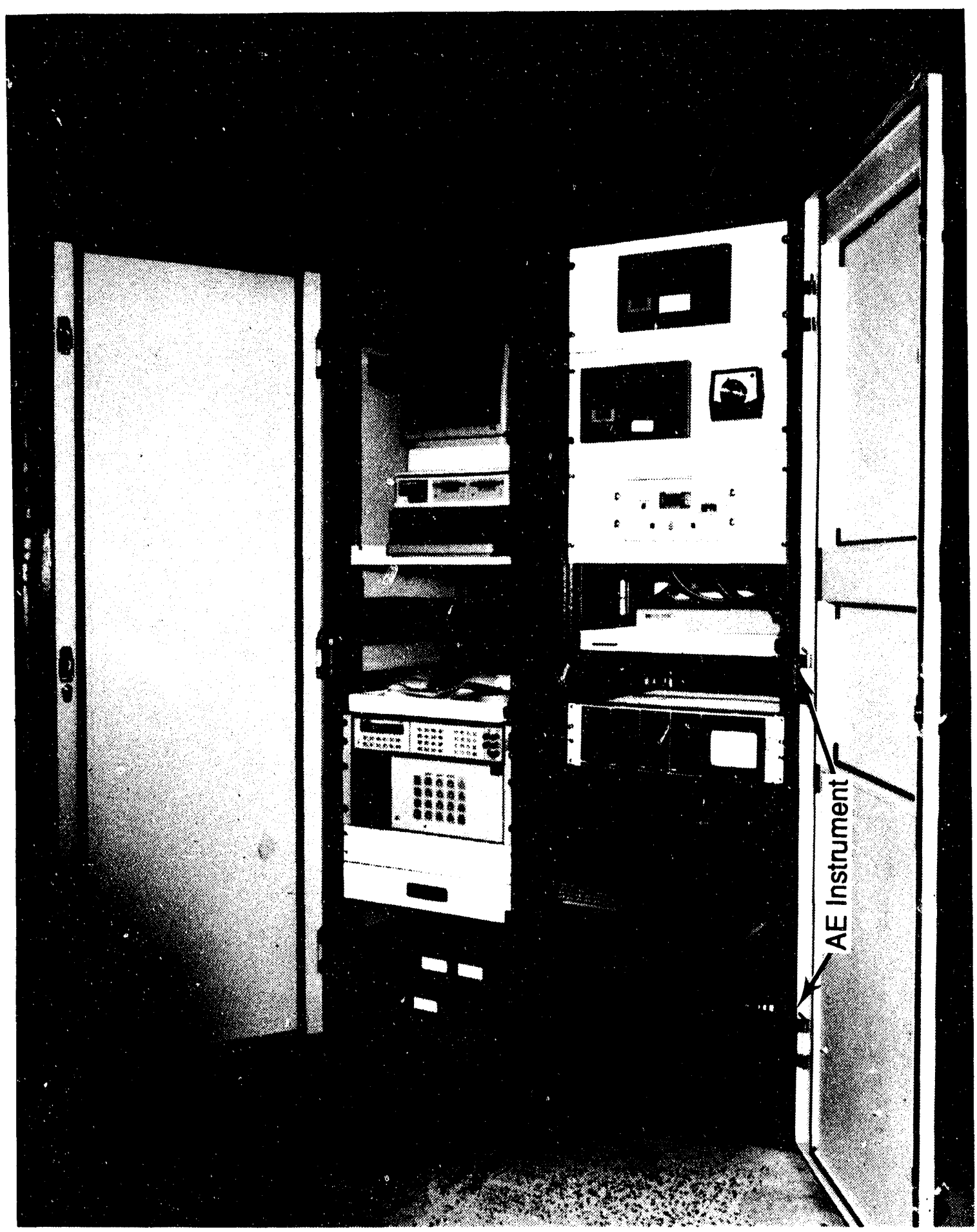

Figure 2.10. AE Monitor Instrument Mounted in a Cabinet in Reactor Enclosure, Elevation 283' - Limerick Unit 1 


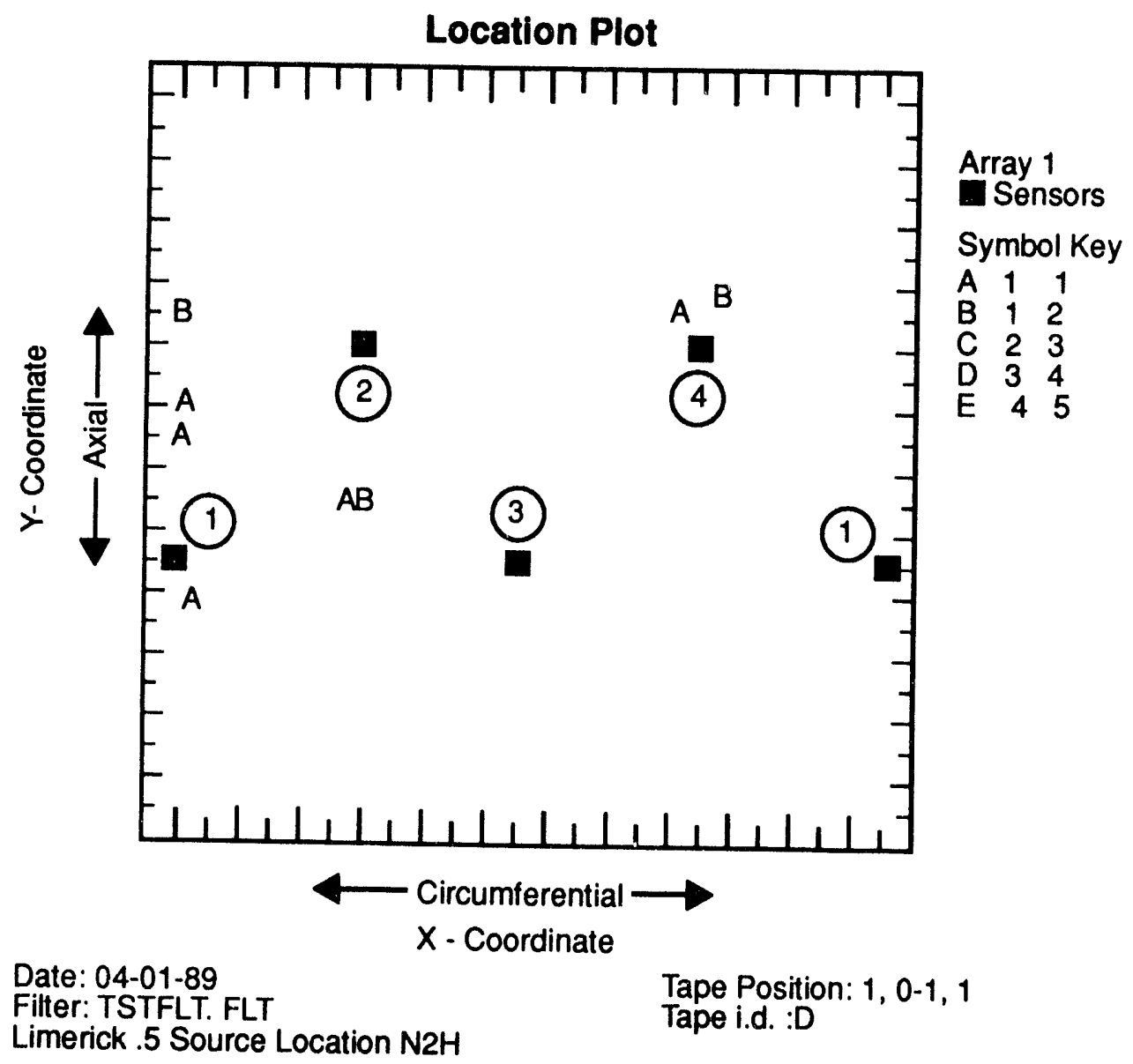

Figure 2.11. Test of Signal Source Location by AE System Using Signal Input from 0.5-mm Pencil Lead Breaks - Limerick Unit 1 
2.0 AE System Installation and Calibration

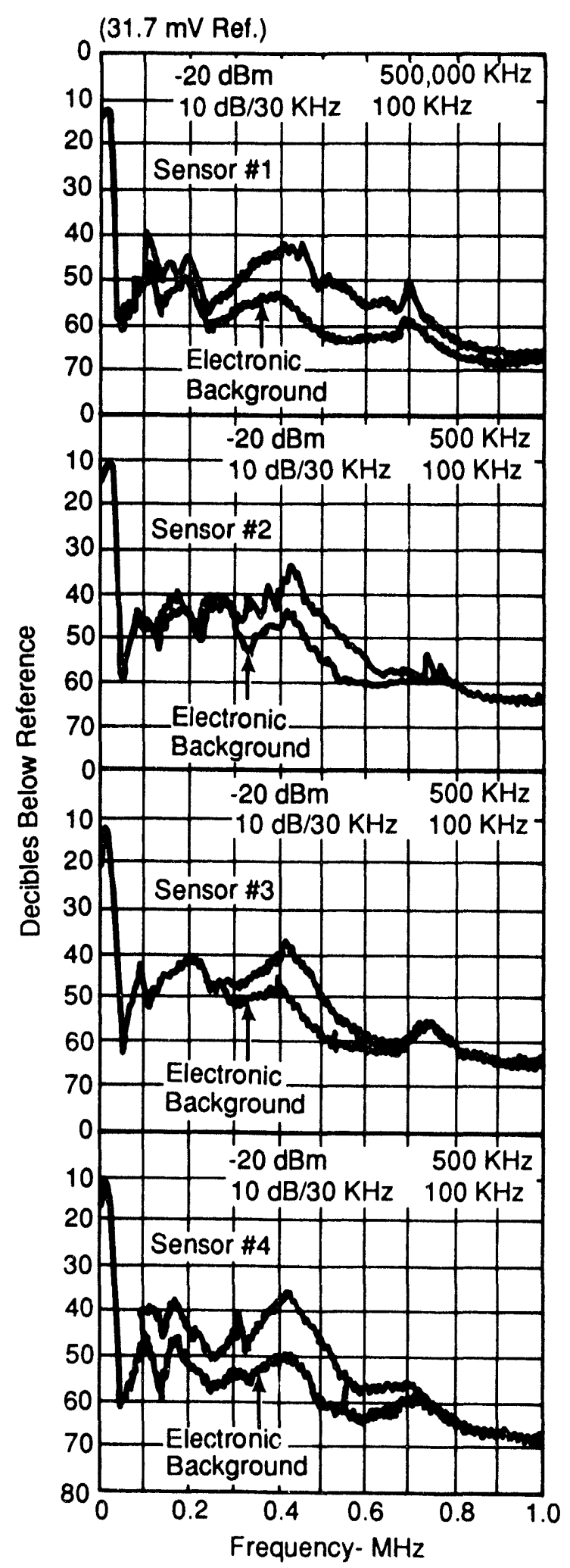

Figure 2.12. Sensitivity Test of Waveguide AE Sensors Installed on Reactor Pipe - Limerick Unit 1 


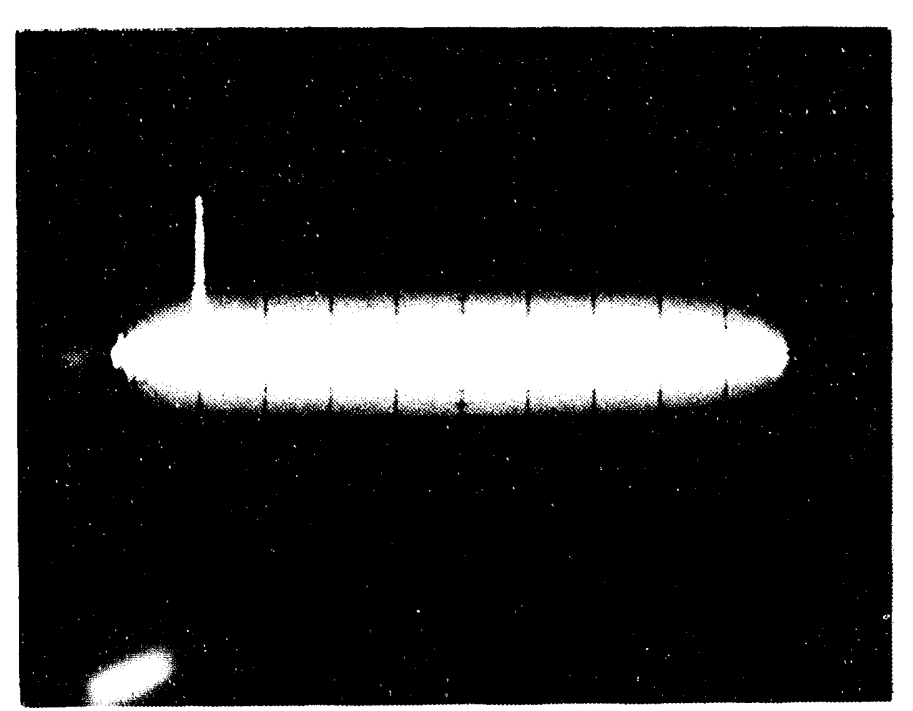

Channel 1

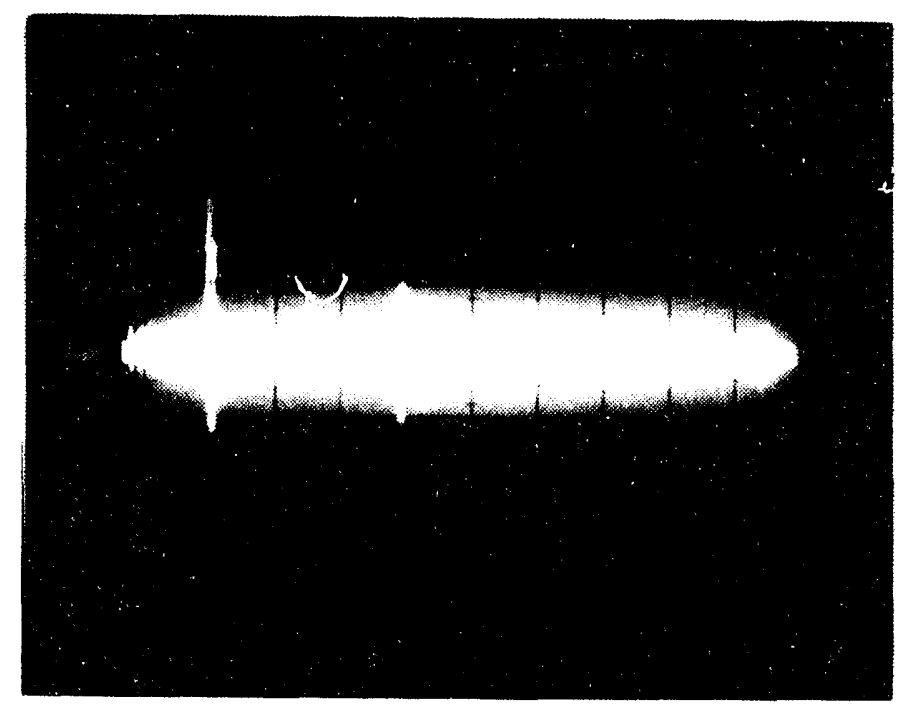

Channel 3

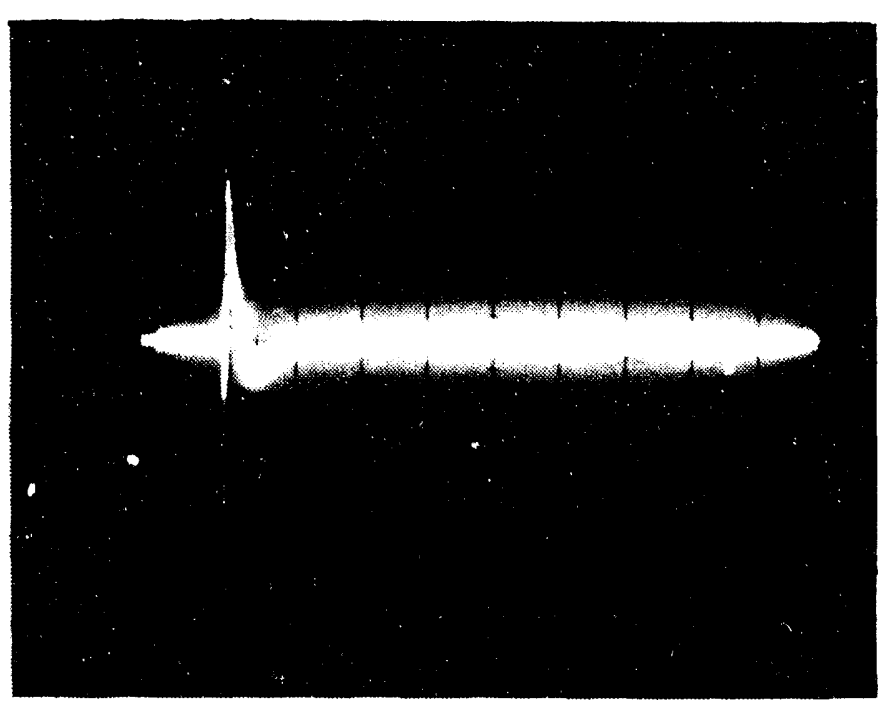

Channel 2

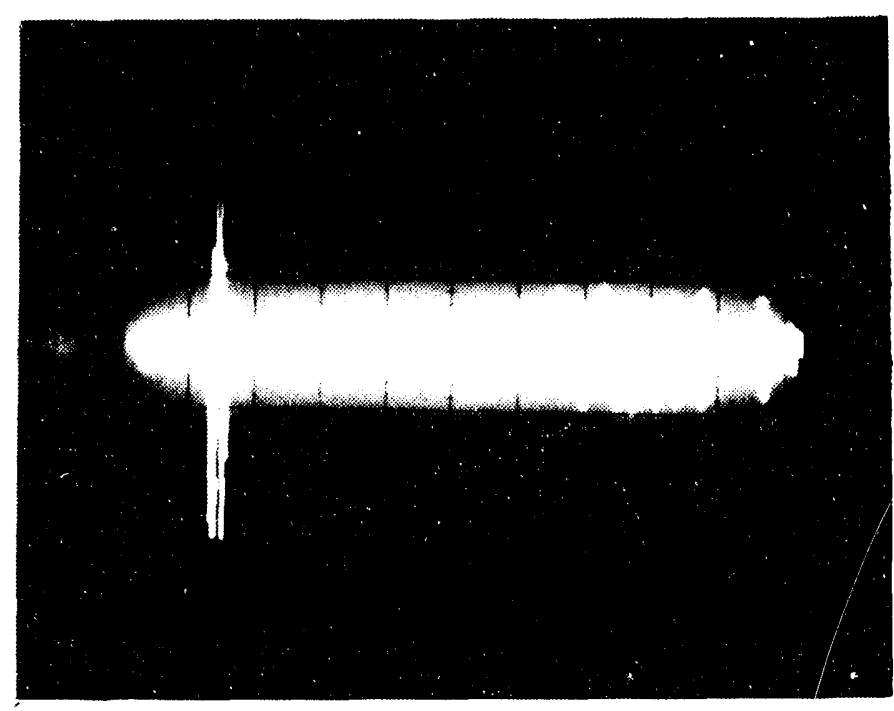

Channel 4

All Photos: 5.0 volts/division: $0.2 \mathrm{msec} /$ division

Figure 2.13. Response of AE Sensors to Pulser Signal on 6/9/89 


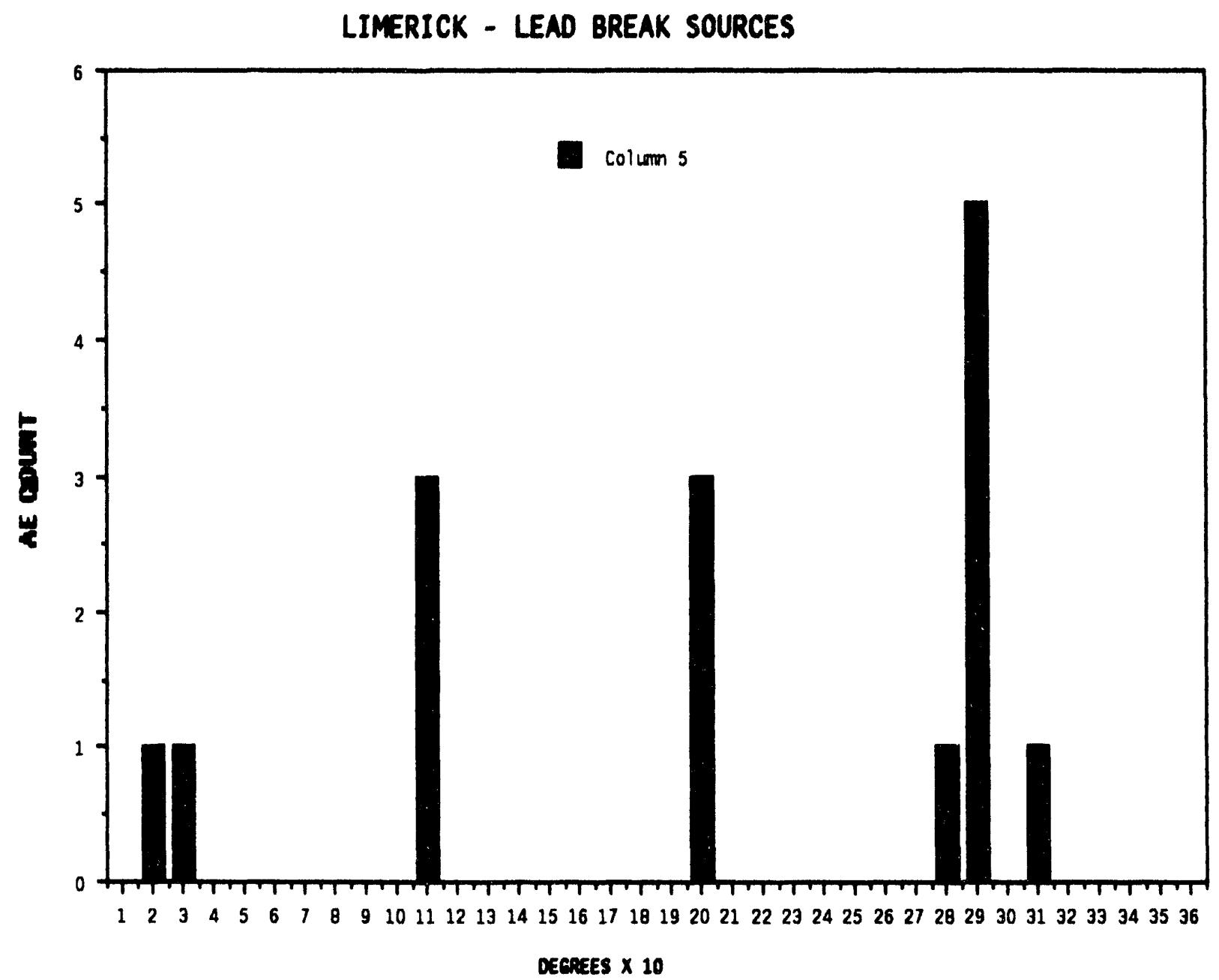

Figure 2.14. Lead Break Data Analyzed with Three-Sensor Algorithm 


\subsection{Interim Data Results}

\subsection{AE System Performance}

The AE system withstood the reactor environment well over the 16-1/2 month long first monitoring period. Two functional problems of significance developed in the course of the monitoring period. In June 1989, it was discovered that Sensor \#2 (Figure 2.3 shows the location of the AE sensors on the safe end-nozzle circumference) was not functioning properly. This did not result in any significant loss of data because the $\mathrm{AE}$ instrument was modified to operate with three instead of four sensors. Originally, the instrument was set to operate with four sensors which required that a given AE event be detected by all four sensors before the event would be recorded. The event detection requirement was modified to require only three sensors after Sensor \#2 failed. Loss of the fourth sensor has some effect on the $\mathrm{AE}$ source location by a moderate reduction in the longitudinal location resolution, but it does not adversely affect the circumferential location accuracy. This was tested by analyzing system calibration signal information recorded during the $\mathrm{AE}$ system installation using the three-sensor arrangement.

The second problem resulted in loss of AE data over the period $11 / 2 / 89$ to $1 / 5 / 90$. This was caused by what was ultimately determined to be a failure of the central processor unit board in the AE monitor instrument. Once this was replaced, the system performed satisfactorily for the remainder of the reactor fuel cycle.

\subsection{AE Data Analysis}

AE data [AE event count, difference-in-time-of-arrival of each event signal at the various $\mathrm{AE}$ sensors (deltatime), sequence of signal arrival at the sensors, time for each event signal to reach maximum amplitude, peak amplitude of each event signal, and clock time information] was recorded in digital form on magnetic tape cartridges. The cartridges were replaced on approximately monthly intervals by PECO personnel and the used cartridge was sent to PNL for analysis. The data on the tape cartridge was played back to a computerized analysis program to compile AE event count by source location. Source location format is in terms of signals originating within each of 36 equal segments (source location elements) around a cross-section of the pipe.
Tables 3.1 through 3.3 give the AE event count by source location element for each of the data tapes analyzed during the first monitoring period. This is basic data - no special filters were applied in analyzing the information. As we began to analyze the data for a correlation between the AE data and the crack growth as indicated by the ISI results, it became evident that the basic data still contained a significant number of noise-induced counts in spite of steps taken during data acquisition to alleviate the recognized noise problem with the original AE system installation. Detailed examination of the basic data showed that there were many accepted signals with two identical delta-time values such that they could not represent real AE signals from the weld area. A very restrictive filter which precludes accepting data with two simultaneous deltatime values and which limits delta-time values to those rational for the size of the pipe (weld) and the AE sensor locations was applied to the basic data recorded on the digital tapes with the results shown in Tables 3.4 through 3.6. The use of this filter could eliminate a small amount of legitimate data from crack growth because there is a small source area from which $\mathrm{AE}$ signals could reach two of the sensors at the same time. It was concluded that the possible loss of a small amount of real AE data was justified for the benefit of the filter. This is a legitimate method to use in the context of the $\mathrm{N} 2 \mathrm{H}$ weld monitoring and also in the context of the ASME Code Case N-471 for AE monitoring of reactor components because both concern $\mathrm{AE}$ monitoring of a limited and well-defined volume of the structure. This filter was not used originally in the hope of achieving a more universal result which would be applicable to a case where the volume of material to be monitored was not defined or limited. This should still be attainable with a normally quiet $\mathrm{AE}$ monitoring arrangement.

Examination of the basic $A E$ data and the revised $A E$ data showed a significant feature. The $A E$ count in source location element 29 for the period $2 / 2 / 90$ to $2 / 26 / 90$ is the same in both sets of data; i.e., the deltatime filter did not affect this particular data at all. Since location 29 coincides with a region of crack growth indicated by the ISI (see Figure 3.1), it appears that this is all valid $\mathrm{AE}$ data and suitable for determining an initial correlation between $\mathrm{AE}$ and crack growth in the $\mathrm{N} 2 \mathrm{H}$ weld. The AE/Fatigue Crack Growth relationship shown in Figure 3.2 which was developed 
from experimental fatigue crack growth data was tested using the Location 29 data and the crack growth indicated by the October 1990 ISI results. It was found that the less conservative curve of the two; i.e., $\mathrm{dN} / \mathrm{dt}$ $=1.6 \times 10^{-4}(\mathrm{da} / \mathrm{dt})^{1.9}$, fit quite well. ${ }^{2}$ Solving the equation for da/dt gives da/dt $=103(\mathrm{dN} / \mathrm{dt})^{0.53}$ where $\mathrm{da} / \mathrm{dt}$ is crack growth rate in $\mu$-inches/second and $\mathrm{dN} / \mathrm{dt}$ is $\mathrm{AE}$ count/second/degree. Count/second/ degree is used in this case instead of just count/second to normalize the count over the 10 degree location segment. This recognizes the fact that the $A E$ count accumulated is distributed in some fashion across the 10 degrees. Taking the $22 \mathrm{AE}$ counts from Location 29,22 counts +10 degrees $=2.2$ counts $/$ degree. The data accumulacion period was 24 days or 2,073,600 seconds. 2.2 counts $/$ degree $+2.073,600$ seconds $=1.06$ $x 10^{-6} \mathrm{AE}$ counts/second/degree. Solving now for $\mathrm{da} / \mathrm{dt}$,

$$
\begin{aligned}
\mathrm{da} / \mathrm{dt} & =103\left(1.06 \times 10^{-6}\right)^{0.53} \\
& =0.07 \mu-\mathrm{in} . / \mathrm{sec} . \\
& =7.0 \times 10^{-8} \mathrm{in} . / \mathrm{sec} .
\end{aligned}
$$

Considering the full time period for data accumulation, this equates to $7.0 \times 10^{-8} \mathrm{in} . / \mathrm{sec} . \times 2,073,600 \mathrm{sec}$. or 0.145 inches of growth for the 24-day period. The UT at the end of the fuel cycle indicated 0.17 inches of crack growth for the same region. Applying this equation to the revised AE data in Tables 3.4, 3.5, and 3.6 produced crack growth indications as given in Tables 3.7, 3.8, and 3.9. The results are summarized in Figure 3.3. It is worth noting that most of the crack growth indications derived from $\mathrm{AE}$ are below the nominal detection threshold for ultrasonic inspection.

\footnotetext{
${ }^{2}$ This equation is based on crack growth/AE data sets generated with non-irradiated pressure vessel and piping steels (A-533B and A106). The data sets produced a conservative relationship curve of $\mathrm{da} / \mathrm{dt}=190(\mathrm{dN} / \mathrm{dt})^{0.53}$ and a median relationship curve of $\mathrm{da} / \mathrm{dt}=$ $103(\mathrm{dN} / \mathrm{dt})^{0.53}$ which is less conservative. The median curve produced a crack growth estimate that compared quite well with UT ISI results from inspection of the weld; hence, it was used in all the data analysis for this program.
}

\subsection{Flaw Indication from ISI Results and Crack-Arrest-Verification- Specimen Indications}

Information on the profile of the flaw indication is taken from inservice inspection (ISI) results obtained during the refueling outages and made available by PECO. The profile of the flaw indication is shown in Figure 3.1. The ISI information has been translated to a pictorial form on a pipe cross section with the intention of making it more easily relatable to the $\mathrm{AE}$ information. While Figure 3.1 is approximately to scale, it is not intended to be an accurate scale presentation. The light cross-hatched area describes the flaw indication as measured using ultrasonic methods in February 1989. ${ }^{3}$ Enlargement of the flaw indication as measured by ultrasonics in October $1990^{4}$ is shown in Figure 3.1 by the dark cross-hatched area. The AE source location element pattern is overlayed on the flaw indication profile to provide a connection between the AE sources and the flaw indication. To facilitate conversion between the AE source location in degrees and the ISI location nomenclature in inches around the pipe OD, $8.09^{\circ}$ equals 1 inch on the OD surface of the pipe. One must also keep in mind that although the $\mathrm{AE}$ source location can be very accurate, the accepted accuracy range is \pm 2 wall thicknesses of the component being monitored. In this case, the location could vary by $2 x$ 1.3 inches or 2.6 inches which translates to $\pm 20^{\circ}$. The accuracy tolerance is due to variations in the $\mathrm{AE}$ signal propagation velocity to the various sensors and the difficulty of precisely defining the position in time of the AE signal wave front.

A crack-arrest-verification-specimen (CAVS) assembly previously used at Peach Bottom 2 was installed at Limerick Unit 1 to provide a basis for estimating growth of the flaw indication in Weld N2H during reactor operation. Basically, the CAVS system exposes a fracture mechanics specimen of appropriate material

\footnotetext{
${ }^{3}$ General Electric Nuclear Energy. February 1989. Limerick Generating Station Unit 1 Inservice Inspection Report No. 89-003.

${ }^{4}$ General Electric Nuclear Energy. September 21, 1990. Limerick Generating Station Unit 1 Inservice Report No. D-3001-4.
} 
to the reactor coolant water. The specimen is loaded externally with the intent of simulating the stress present around the flaw indication and a potential drop method is used to measure resulting crack growth. Results from the CAVS system surveillance indicated crack growth rate of 0.026 inches/year.

\subsection{Correlation between AE, CAVS, and UT Results}

Results from the three surveillance methods are considered on a common basis in Table 3.10.

The value for the UT method was derived from the maximum indicated crack growth of 0.47 -in. deep measured at 39-in. pipe circumference during the 1990 ISI by a simple ratio of 12 months/year +15 months total operating period $x 0.47^{\prime \prime}=0.38^{\prime \prime} /$ year. The value for the AE method was similarly derived from the maximum indicated crack growth of 0.35 -in. deep in Location Element 2 (see Table 3.9).

\footnotetext{
${ }^{5}$ Ranganath, S. and D. A. Hale. October 1990. Structural Evaluation of the Indication in the Limerick 1 Recirc. Inlet Nozzle N2H Safe End Weld, General Electric Nuclear Energy.
}

It is evident from the numbers in Table 3.10 that the UT inspection results and the AE results are in reasonably good agreement - the UT being about $30 \%$ nigher. The CAVS system prediction is an order-of-magnitude lower. The crack growth indicated by the AE monitoring is summarized in Figure 3.4. This indicates some crack growth in areas of the weld where it was not identified by UT inspection during the ISI, but this does not necessarily refute their validity when examined in light of the detection threshold for UT (nominally $20 \%$ of wall thickness) as illustrated in Figure 3.5. At the same time, it must be conceded that the AE indications of crack growth less than 0.1 inches may be questionable on the basis that the values are derived from an AE event count of three to five. A frustrating dilemma in this comparison is the fact that the only positive comparator is destructive examination of the weld when it is removed from service, which makes it very important that provision for this be considered in any future plans to replace the section of pipe. 


\subsection{Interim Data Results}

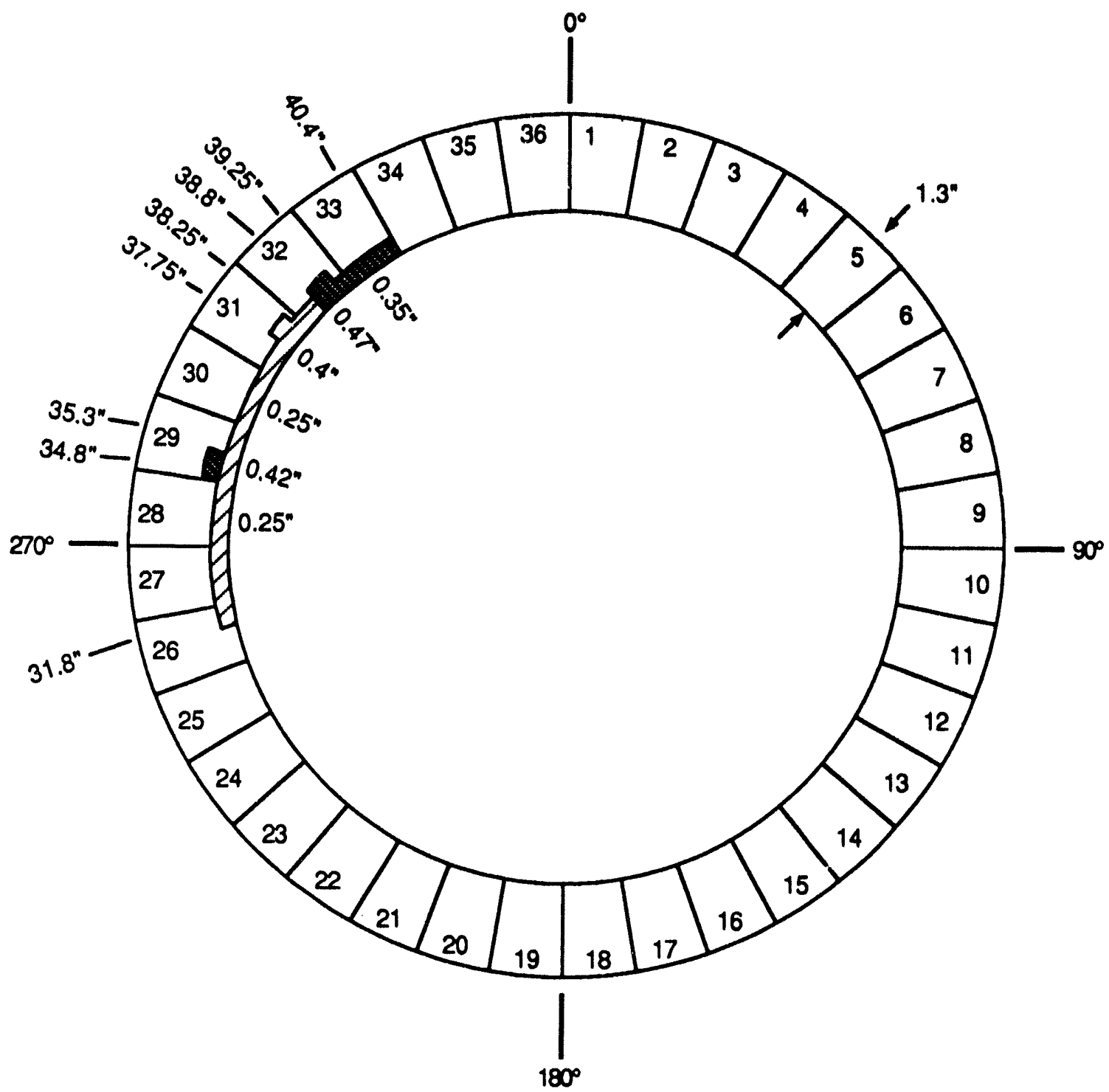

1. $\triangle \nabla$ Crack Size per ISI - 2/89

2. 2 Crack Growth per ISI - $10 / 90$

3. Numbered Sectors Identify AE Source

Location Eloments - Each $10^{\circ}$ Wide

Figure 3.1. AE Source Location Elements Superimposed on Pipe Cross Section with Flaw Profile - N2H Weld at Limerick Unit 1 Reactor 


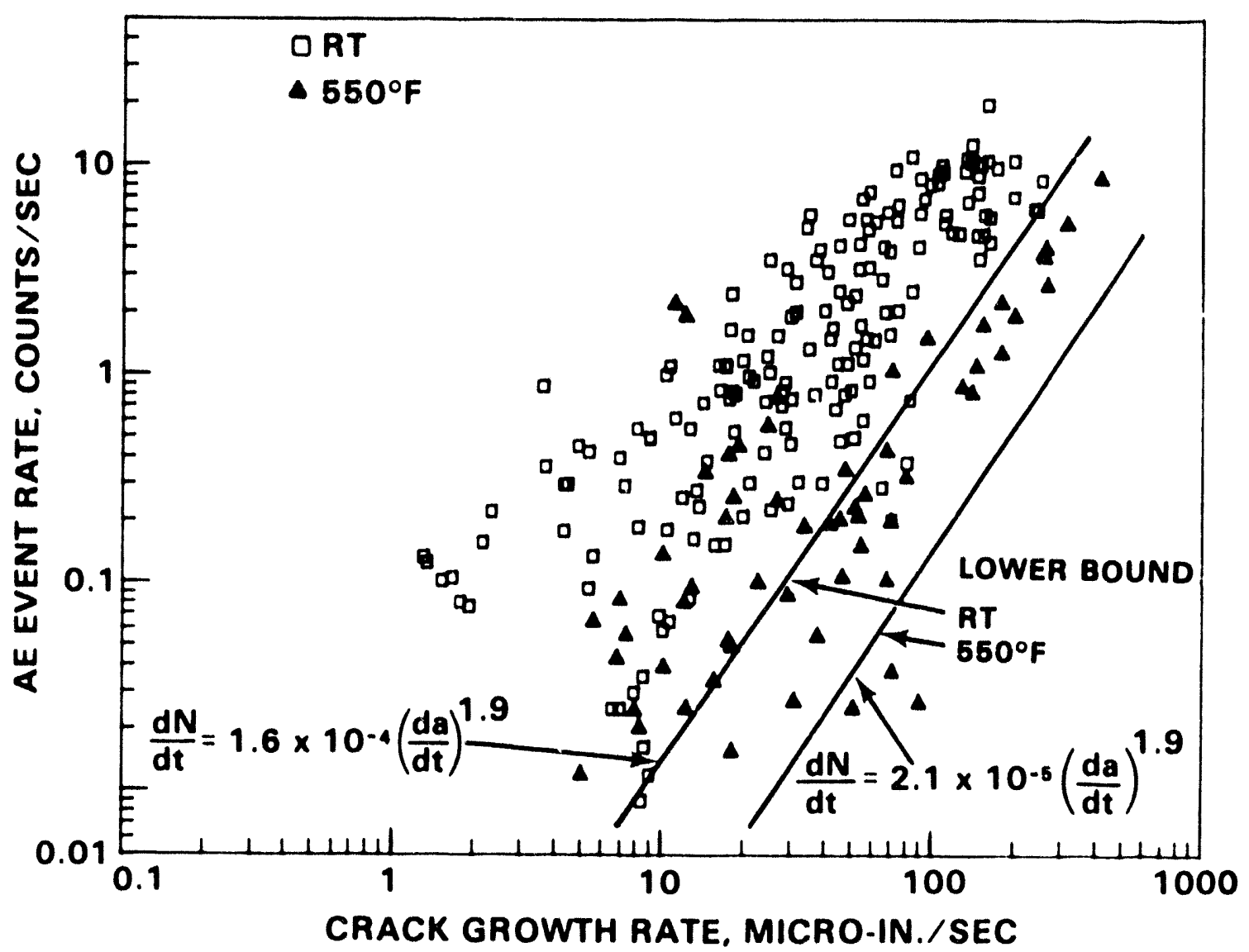

Figure 3.2. AE Rate - Crack Growth Rate Relationship for Cyclic Fatigue Crack Growth (Hutton 1985) 


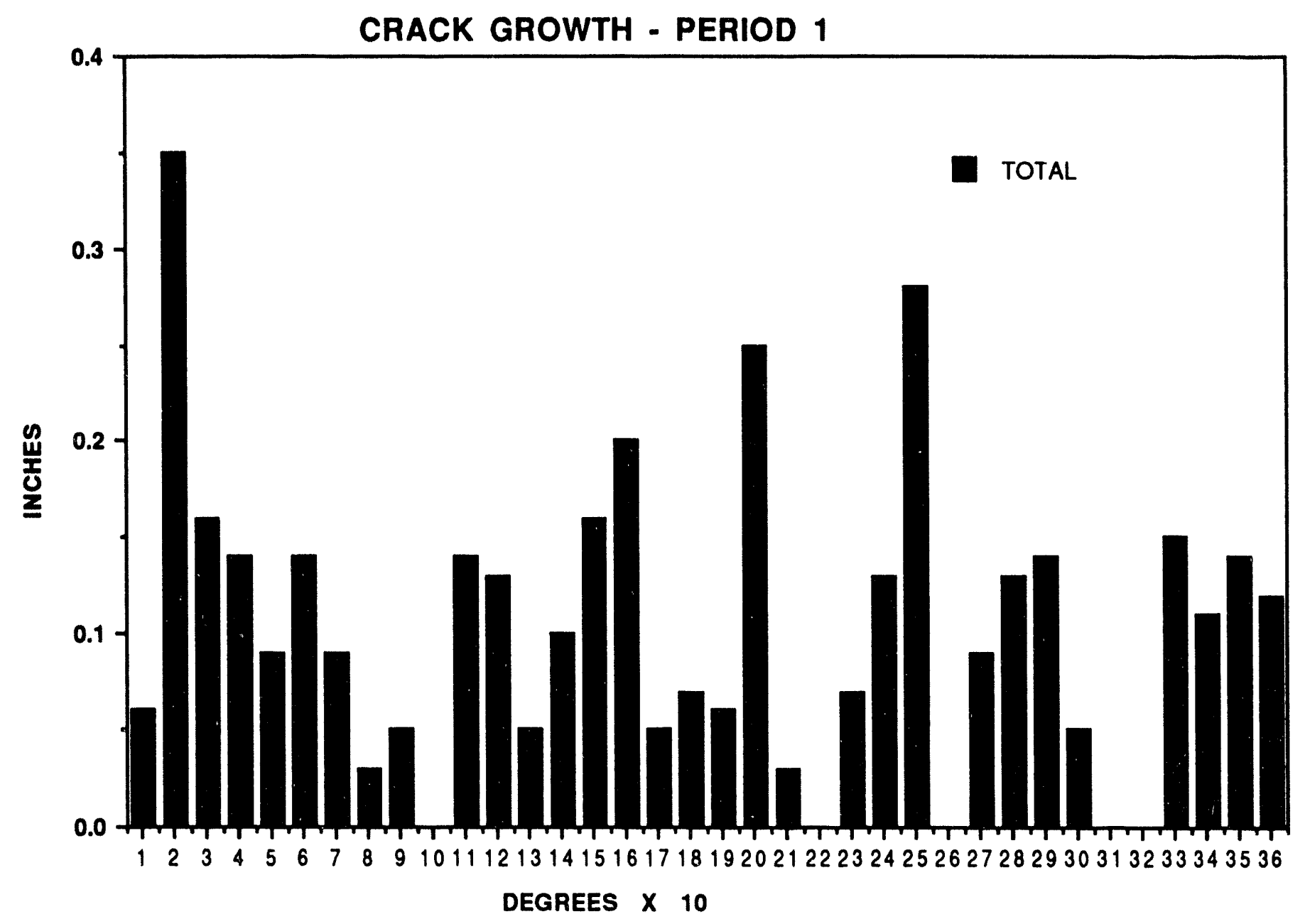

Figure 3.3. Crack Growth Over the Period 5/89 to 9/90 as Indicated by AE - N2H Weld at Limerick Unit 1 Reactor 


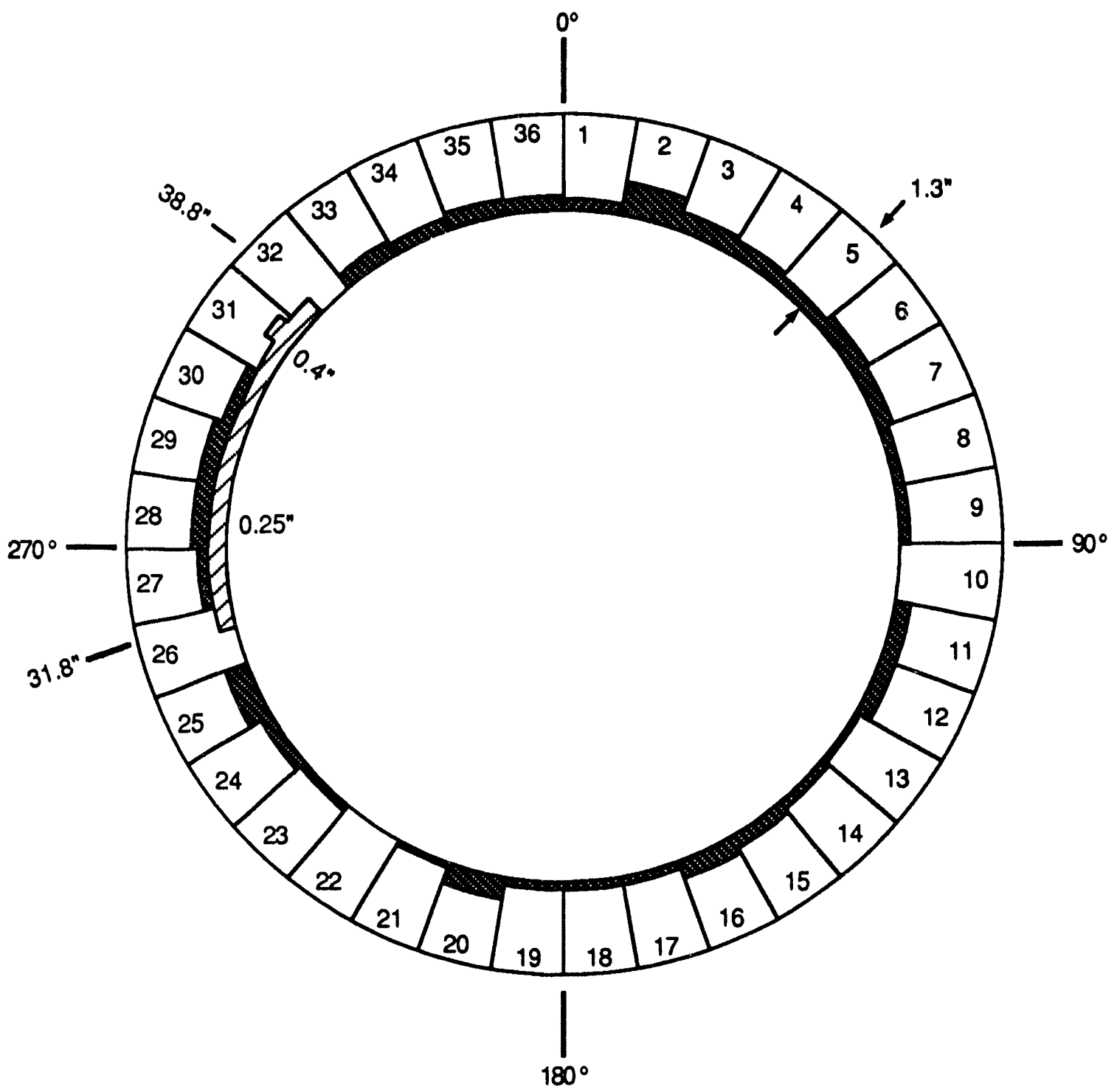

1. $\triangle \nabla$ Crack Size per ISI - 2/89

2. $\mathrm{N}$ Crack Growth during 5/12/89 - 9/11/90 period per AE

3. Numbered Sectors Identify AE Source

Location Elements - Each $10^{\circ}$ Wide

Figure 3.4. Crack Growth Values Derived from AE Data over the Period 8/89 to 9/90 Shown on Pipe Crack Section - N2H Weld at Lmerick Unit 1 Reactor 


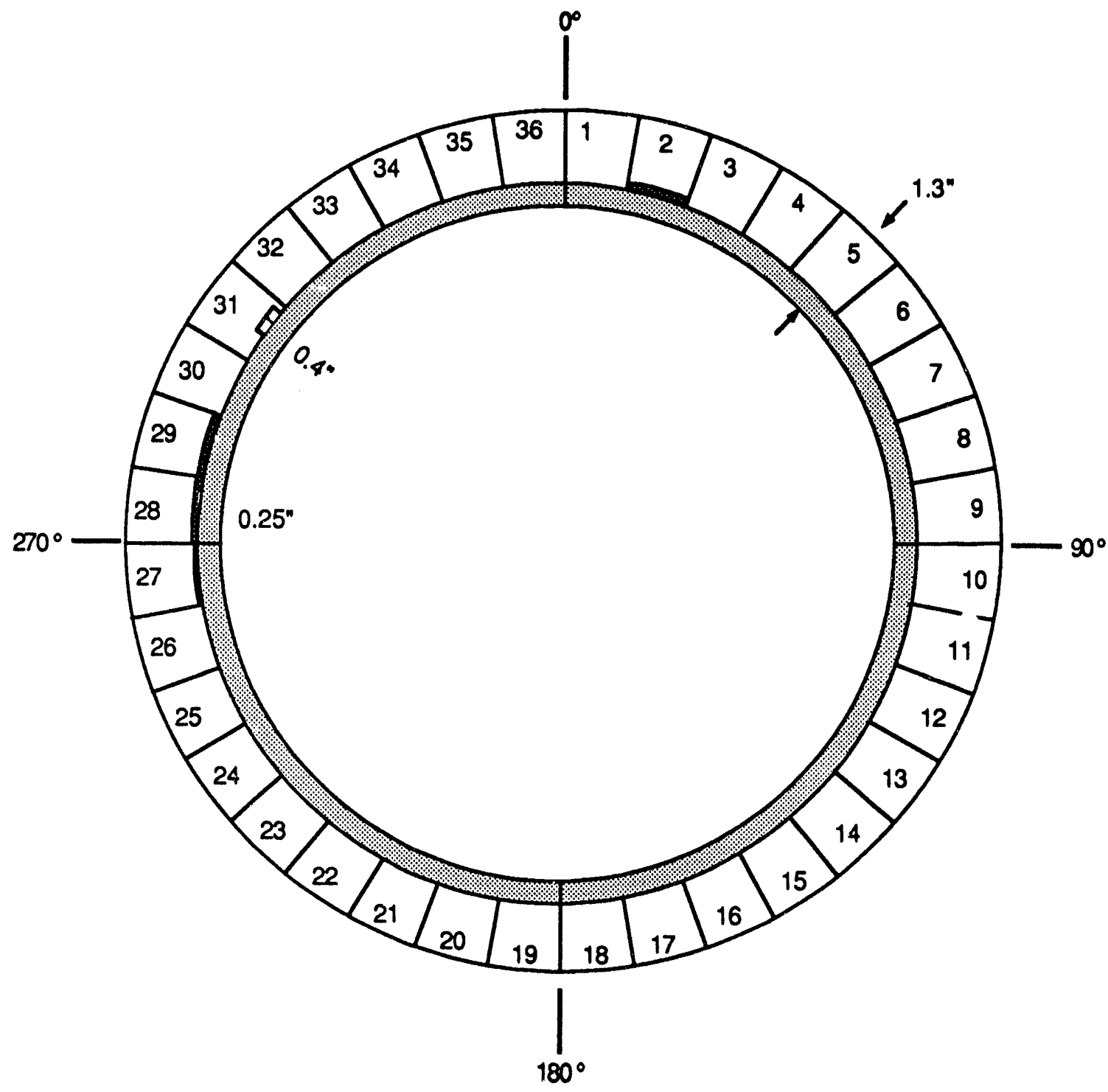

1. Crack Size per ISI - 2/89

2. Crack Growth during 5/12/89 - 9/11/90 period per AE

3. Numbered Sectors Identify AE Source

Location Elements - Each $10^{\circ}$ Wide.

4. WT Detection Threshold @ $20 \%$ of Wall = $0.26^{\prime \prime}$

A9103152.1

Figure 3.5. UT Detection Threshold (20\% of Wall) Superimposed on Crack Growth Prediction from AE Data - N2H Weld at Limerick Unit 1 Reactor 
Table 3.1. AE Event Count by Source Location Element - 5/12/89 - 10/6/89 N2H Weld at Limerick Unit 1 Reactor

\begin{tabular}{|c|c|c|c|c|c|c|c|c|}
\hline \multicolumn{9}{|c|}{ IMMRRICK AE DATA Ist MONITOR } \\
\hline & $5 / 12$, & $6 / 25$. & $6 / 200$. & $\frac{6 / 29}{7 / 10}$ & $7 / 10$ & $8 / 8$. & $\begin{array}{l}8 / 15 \\
9 / 15\end{array}$ & $9 / 15$. \\
\hline 1 & & & & & 2 & 5 & 13 & 1 \\
\hline 2 & & & 5 & & 1 & & & \\
\hline 3 & & & & & & & & \\
\hline 4 & & & & & & & & \\
\hline 5 & & & 1 & & & & & \\
\hline 6 & & & 43 & & & & & \\
\hline 7 & & & 30 & & 1 & & & \\
\hline 8 & & & 1 & & & & & \\
\hline 9 & & & 2 & & & & & \\
\hline 10 & & & & & & & & \\
\hline 11 & & & 1 & & & & & \\
\hline 12 & & & 1 & & & & & \\
\hline 13 & & & 2 & & & & & \\
\hline 14 & & & 1 & & & & & \\
\hline 15 & 2 & & 46 & 4 & 27 & & 3 & \\
\hline 16 & 4 & 51 & 88 & 159 & 201 & 10 & 23 & 12 \\
\hline 17 & 4 & 18 & 25 & 19 & 44 & & 2 & \\
\hline 18 & & 20 & 23 & 20 & 41 & 1 & 4 & \\
\hline 19 & 8 & 29 & 31 & 37 & 159 & & 3 & 1 \\
\hline 20 & 11 & 44 & 35 & 39 & 259 & & 180 & 12 \\
\hline 21 & 6 & 30 & 28 & 24 & 176 & & 2 & \\
\hline 22 & 4 & 10 & 23 & 17 & 188 & & & 1 \\
\hline 23 & 6 & 13 & 21 & 21 & 180 & 3 & & \\
\hline
\end{tabular}




\begin{tabular}{|c|c|c|c|c|c|c|c|c|}
\hline \multicolumn{9}{|c|}{ LIMERICK AE DATA - 1st MONITOR } \\
\hline & $5 / 124$ & $\begin{array}{r}5 / 25 \\
6 / 20 \\
\end{array}$ & $\begin{array}{r}6 / 20 \\
6 / 29 \\
\end{array}$ & $\begin{array}{r}6 / 29 . \\
7 / 10 \\
\end{array}$ & $7 / 10$ & $\begin{array}{l}8 / 8 \\
8 / 15\end{array}$ & $\begin{array}{l}8 / 15 \\
9 / 15\end{array}$ & $9 / 15$ \\
\hline 24 & 12 & 6 & 19 & 30 & 212 & 1 & 1 & \\
\hline 25 & 15 & 10 & 13 & 15 & 300 & & & \\
\hline 26 & & 2 & & & 15 & & & \\
\hline 27 & & & & & & & & \\
\hline 28 & & & & & & & & \\
\hline 29 & & & & & & & & \\
\hline 30 & & & & & & & & \\
\hline 31 & & & & & & & & \\
\hline 32 & & & & & & & & \\
\hline 33 & & & & & 1 & & & \\
\hline 34 & & & & & & & & \\
\hline 35 & & & & & & & & \\
\hline 36 & & & & & & & & \\
\hline
\end{tabular}


Table 3.2. AE Event Count by Source Location Element - 10/6/89 - 6/4/90 N2H Weld at Limerick Unit 1 Reactor

\begin{tabular}{|c|c|c|c|c|c|c|c|c|}
\hline \multicolumn{9}{|c|}{ LMMERICK AE DATA - 1st MONITOR } \\
\hline & $\begin{array}{l}10 / 6 \\
11 / 12\end{array}$ & $\begin{array}{l}11 / 2 \\
1 / 5\end{array}$ & $\begin{array}{l}1 / 5 . \\
1 / 19\end{array}$ & $\begin{array}{l}1 / 19 \cdot \\
2 / 2\end{array}$ & $\begin{array}{l}2 / 2 \\
2 / 26\end{array}$ & $\begin{array}{l}2 / 26- \\
3 / 29\end{array}$ & $\begin{array}{l}3 / 29 . \\
4 / 27\end{array}$ & $\begin{array}{l}4 / 27 \\
6 / 4\end{array}$ \\
\hline 1 & 1 & $\begin{array}{c}\text { NO } \\
\text { DATA }\end{array}$ & 1 & 10 & & & & \\
\hline 2 & & & 35 & 28 & 472 & 35 & 39 & 5 \\
\hline 3 & & & & 4 & & & & \\
\hline 4 & & & & 5 & & & 1 & \\
\hline 5 & & & & & & & & \\
\hline 6 & & & 5 & 6 & 39 & 2 & 7 & 2 \\
\hline 7 & 2 & & 12 & 17 & 170 & 13 & 8 & \\
\hline 8 & & & & & & & & \\
\hline 9 & & & 1 & 1 & & & & \\
\hline 10 & & & & 2 & 1 & & & 1 \\
\hline 11 & & & & 2 & 18 & 1 & & \\
\hline 12 & & & & 1 & 12 & & & \\
\hline 13 & & & 1 & 2 & 3 & & & \\
\hline 14 & & & 1 & 5 & 3 & & & \\
\hline 15 & & & 23 & 10 & 165 & 4 & 7 & 2 \\
\hline 16 & 8 & & 41 & 35 & 861 & 66 & 24 & 1 \\
\hline 17 & & & & 1 & & & & \\
\hline 18 & & & & & 1 & & & \\
\hline 19 & 1 & & 1 & & 2 & & & \\
\hline 20 & 12 & & 25 & 22 & 854 & 62 & 15 & \\
\hline 21 & 1 & & & 2 & & & & \\
\hline 22 & & & & 1 & & & & \\
\hline
\end{tabular}




\begin{tabular}{|c|c|c|c|c|c|c|c|c|}
\hline \multicolumn{9}{|c|}{ LAMERICK AE DATA · 1st MONITOR } \\
\hline & $\begin{array}{l}10 / 6 \\
11 / 12\end{array}$ & $\frac{11 / 2}{1 / 5}$ & $\begin{array}{l}1 / 5 \\
1 / 19\end{array}$ & $\begin{array}{l}1 / 19 \\
2 / 2\end{array}$ & $\begin{array}{l}2 / 2 \\
2 / 26\end{array}$ & $\begin{array}{l}2 / 26 \\
3 / 29\end{array}$ & $\begin{array}{l}3 / 29 . \\
4 / 27\end{array}$ & $\begin{array}{l}4 / 27 \\
6 / 4\end{array}$ \\
\hline 23 & & & & 1 & 2 & 1 & & \\
\hline 24 & & & 2 & 3 & 68 & 7 & 1 & 1 \\
\hline 25 & & & 22 & 15 & 329 & 15 & 10 & 3 \\
\hline 26 & & & & 1 & 1 & & & \\
\hline 27 & & & & 2 & 8 & & & \\
\hline 28 & & & 2 & 1 & 17 & 1 & & \\
\hline 29 & & & 2 & 2 & 22 & & & \\
\hline 30 & & & & 2 & 3 & & & \\
\hline 31 & & & & 2 & 1 & & & \\
\hline 32 & & & & 2 & 1 & & & \\
\hline 33 & & & 2 & 5 & 94 & & 1 & \\
\hline 34 & & & 19 & 21 & 548 & 40 & 16 & 1 \\
\hline \multicolumn{9}{|l|}{35} \\
\hline 36 & & & 1 & 2 & 1 & & 1 & \\
\hline
\end{tabular}


Table 3.3. AE Event Count by Source Location Element - 6/4/90 - 9/11/90 N2H Weld at Limerick Unit 1 Reactor

\begin{tabular}{|c|c|c|c|c|}
\hline \multicolumn{5}{|c|}{ LIMERICK AE DATA - Ist MONITOR } \\
\hline & $\frac{6 / 4}{6 / 25}$ & $\begin{array}{l}6 / 25- \\
8 / 2\end{array}$ & $\begin{array}{l}8 / 2 \\
8 / 20\end{array}$ & $\begin{array}{l}8 / 20- \\
9 / 11\end{array}$ \\
\hline 1 & 3 & & & \\
\hline 2 & 9 & 106 & 25 & 21 \\
\hline 3 & 3 & 4 & 2 & \\
\hline 4 & 1 & 6 & & \\
\hline 5 & 2 & 2 & & 1 \\
\hline 6 & 6 & 10 & 3 & 2 \\
\hline 7 & 8 & 24 & 10 & 14 \\
\hline 8 & 5 & & & \\
\hline 9 & 1 & & & 1 \\
\hline 10 & 1 & $\mathbf{1}$ & & \\
\hline 11 & 1 & & & 1 \\
\hline 12 & 3 & & & 1 \\
\hline 13 & 2 & & & \\
\hline 14 & 1 & 2 & & \\
\hline 15 & 5 & 5 & 1 & 2 \\
\hline 16 & 16 & 24 & 12 & 6 \\
\hline \multicolumn{5}{|l|}{17} \\
\hline 18 & & 1 & & 1 \\
\hline 19 & & 1 & & \\
\hline 20 & 3 & 35 & 10 & 2 \\
\hline 21 & 1 & & & \\
\hline \multicolumn{5}{|l|}{22} \\
\hline 23 & 2 & 2 & & \\
\hline
\end{tabular}




\begin{tabular}{|c|c|c|c|c|}
\hline \multicolumn{5}{|c|}{ LIMERICK AE DATA - 1st MONITOR } \\
\hline & $\begin{array}{l}6 / 4 \\
6 / 25 \\
\end{array}$ & $\begin{array}{l}6 / 25- \\
8 / 2 \\
\end{array}$ & $\begin{array}{l}8 / 2 \\
8 / 20\end{array}$ & $\begin{array}{l}8 / 20 \\
9 / 11\end{array}$ \\
\hline 24 & 2 & 2 & 1 & \\
\hline 25 & 13 & 23 & 7 & 14 \\
\hline \multicolumn{5}{|l|}{26} \\
\hline 27 & 1 & & & 1 \\
\hline 28 & 1 & & & \\
\hline 29 & 2 & 1 & & 1 \\
\hline 30 & 1 & & & \\
\hline 31 & & 1 & & \\
\hline \multicolumn{5}{|l|}{32} \\
\hline 33 & 28 & 6 & & 1 \\
\hline 34 & 134 & 74 & 20 & 6 \\
\hline 35 & 6 & 7 & & 2 \\
\hline 36 & 5 & 2 & & 1 \\
\hline
\end{tabular}


Table 3.4. Filtered AE Event Count by Source Location Element $5 / 12 / 89-10 / 6 / 89$

N2H Weld at Limerick Unit 1 Reactor

\begin{tabular}{|c|c|c|c|c|c|c|c|c|}
\hline \multicolumn{9}{|c|}{ LIMERICK - 1st Period REV. 1} \\
\hline & $\begin{array}{l}5 / 12 \\
5 / 24\end{array}$ & $\begin{array}{l}5 / 25 \\
6 / 20\end{array}$ & $\begin{array}{l}6 / 20+ \\
6 / 29 \\
\end{array}$ & $\begin{array}{l}6 / 29 \\
7 / 10 \\
\end{array}$ & $\begin{array}{l}7 / 10 \\
8 / 8 \\
\end{array}$ & $\begin{array}{l}8 / 8 \\
8 / 15\end{array}$ & $\begin{array}{l}8 / 15 \\
9 / 15\end{array}$ & $\begin{array}{l}9 / 15 \\
10 / 6\end{array}$ \\
\hline 1 & & & & & & & 3 & \\
\hline 2 & & & & & & & & \\
\hline 3 & & & & & & & & \\
\hline 4 & & & & & & & & \\
\hline 5 & & & & & & & & \\
\hline 6 & & & & & & & & \\
\hline 7 & & & & & & & & \\
\hline 8 & & & & & & & & \\
\hline 9 & & & & & & & & \\
\hline 10 & & & & & & & & \\
\hline 11 & & & & & & & & \\
\hline 12 & & & & & & & & \\
\hline 13 & & & & & & & & \\
\hline 14 & & & & & & & & \\
\hline 15 & & & & & & & & \\
\hline 16 & & & & & & & & \\
\hline 17 & & & & & & & & \\
\hline 18 & & 5 & & & & & & \\
\hline 19 & & 4 & & & & & & \\
\hline 20 & & 3 & & & & & & \\
\hline 21 & & & & & & & & \\
\hline 22 & & & & & & & & \\
\hline
\end{tabular}




\begin{tabular}{|c|c|c|c|c|c|c|c|c|}
\hline \multicolumn{9}{|c|}{ LIMERICK + 1st Period REV. 1} \\
\hline & $\begin{array}{l}5 / 12 \\
5 / 24\end{array}$ & $\begin{array}{l}5 / 25 \\
6 / 20\end{array}$ & $\begin{array}{l}6 / 20 \\
6 / 29\end{array}$ & $\begin{array}{l}6 / 29 \\
7 / 10\end{array}$ & $\begin{array}{l}7 / 10 \\
8 / 8\end{array}$ & $\begin{array}{l}8 / 8 \\
8 / 15\end{array}$ & $\begin{array}{l}8 / 15 \\
9 / 15\end{array}$ & $9 / 15$ \\
\hline 23 & & & & & & & & \\
\hline 24 & & & & & & & & \\
\hline 25 & & & & & & & & \\
\hline 26 & & & & & & & & \\
\hline 27 & & & & & & & & \\
\hline 28 & & & & & & & & \\
\hline 29 & & & & & & & & \\
\hline 30 & & & & & & & & \\
\hline 31 & & & & & & & & \\
\hline 32 & & & & & & & & \\
\hline 33 & & & & & & & & \\
\hline 34 & & & & & & & & \\
\hline 35 & & & & & & & & \\
\hline 36 & & & & & & & & \\
\hline
\end{tabular}


Table 3.5. Filtered AE Event Count by Source Location Element $10 / 6 / 89-6 / 4 / 90$

N2H Weld at Limerick Unit 1 Reactor

\begin{tabular}{|c|c|c|c|c|c|c|c|c|}
\hline \multicolumn{9}{|c|}{ LIMERICK - 1st Poriod REV. 1} \\
\hline & $10 / 6$ & $11 / 2$ & $\begin{array}{l}1 / 5 \\
1 / 19\end{array}$ & $1 / 19$ & $\begin{array}{l}2 / 2 \\
2 / 26\end{array}$ & $\begin{array}{l}2 / 26 \\
3 / 29\end{array}$ & $3 / 29$ & $4 / 27$ \\
\hline 1 & & $\begin{array}{c}\text { No } \\
\text { DATA }\end{array}$ & & & & & & \\
\hline 2 & & & & 5 & 14 & 3 & & \\
\hline 3 & & & & 5 & & & & \\
\hline 4 & & & & 5 & & & & \\
\hline 5 & & & & & & & & \\
\hline 6 & & & & 4 & & & & \\
\hline 7 & & & & & & & & \\
\hline 8 & & & & & & & & \\
\hline 9 & & & & & & & & \\
\hline 10 & & & & & & & & \\
\hline 11 & & & & & 21 & & & \\
\hline 12 & & & & & 13 & & & \\
\hline 13 & & & & & 3 & & & \\
\hline 14 & & & & 5 & 3 & & & \\
\hline 15 & & & & 3 & 18 & & & \\
\hline 16 & & & & 4 & 23 & & & \\
\hline 17 & & & & & & & & \\
\hline 18 & & & & & & & & \\
\hline 19 & & & & & & & & \\
\hline 20 & & & & & 18 & & & \\
\hline 21 & & & & 3 & & & & \\
\hline 22 & & & & & & & & \\
\hline
\end{tabular}




\begin{tabular}{|c|c|c|c|c|c|c|c|c|}
\hline \multicolumn{9}{|c|}{ LIMERICK - 1st Period REV. 1} \\
\hline & $\begin{array}{l}10 / 6- \\
11 / 2 \\
\end{array}$ & $\begin{array}{c}11 / 2- \\
1 / 5 \\
\end{array}$ & $\begin{array}{l}1 / 5 \\
1 / 19 \\
\end{array}$ & $\begin{array}{c}1 / 19- \\
2 / 2 \\
\end{array}$ & $\begin{array}{l}2 / 2- \\
2 / 26 \\
\end{array}$ & $\begin{array}{l}2 / 26- \\
3 / 29 \\
\end{array}$ & $\begin{array}{l}3 / 29- \\
4 / 27\end{array}$ & $\begin{array}{c}4 / 27- \\
6 / 4 \\
\end{array}$ \\
\hline \multicolumn{9}{|l|}{23} \\
\hline 24 & & & & & 17 & & & \\
\hline 25 & & & & 3 & 48 & & & \\
\hline \multicolumn{9}{|l|}{26} \\
\hline 27 & & & & & 9 & & & \\
\hline 28 & & & & & 19 & & & \\
\hline 29 & & & & & 22 & & & \\
\hline 30 & & & & & 3 & & & \\
\hline \multicolumn{9}{|l|}{31} \\
\hline \multicolumn{9}{|l|}{32} \\
\hline 33 & & & & & 5 & & & \\
\hline 34 & & & & & 8 & & & \\
\hline \multicolumn{9}{|l|}{35} \\
\hline 36 & & & & & & & & \\
\hline
\end{tabular}


Table 3.6. Filtered AE Event Count by Source Location Element

$6 / 4 / 90-9 / 11 / 90$

N2H Weld at Limerick Unit 1 Reactor

\section{LIMERICK - 1st Period REV. 1}

\begin{tabular}{|c|c|c|c|c|}
\hline & $\begin{array}{l}6 / 4 \\
6 / 25 \\
\end{array}$ & $\begin{array}{l}6 / 25 \\
8 / 2\end{array}$ & $\begin{array}{l}8 / 2- \\
8 / 20 \\
\end{array}$ & $\begin{array}{l}8 / 20 \\
9 / 11\end{array}$ \\
\hline \multicolumn{5}{|l|}{1} \\
\hline 2 & 4 & 14 & & \\
\hline 3 & 3 & 8 & & \\
\hline 4 & & 7 & & \\
\hline 5 & 3 & 5 & & \\
\hline 6 & 3 & 5 & & \\
\hline 7 & 3 & 5 & & \\
\hline 8 & 7 & & & \\
\hline 9 & & 3 & & \\
\hline \multicolumn{5}{|l|}{10} \\
\hline \multicolumn{5}{|l|}{11} \\
\hline 12 & 3 & & & \\
\hline \multicolumn{5}{|l|}{13} \\
\hline \multicolumn{5}{|l|}{14} \\
\hline \multicolumn{5}{|l|}{15} \\
\hline \multicolumn{5}{|l|}{16} \\
\hline 17 & & 3 & & \\
\hline \multicolumn{5}{|l|}{18} \\
\hline \multicolumn{5}{|l|}{19} \\
\hline 20 & & 5 & & \\
\hline \multicolumn{5}{|l|}{21} \\
\hline 22 & & & & \\
\hline
\end{tabular}




\begin{tabular}{|c|c|c|c|c|}
\hline & & 6 & $\mathbf{S}$ & $9 \varepsilon$ \\
\hline & & ZI & $L$ & SE \\
\hline & & & $S$ & $\forall \mathcal{E}$ \\
\hline & & $\nabla$ & $\mathcal{E}$ & $\mathcal{E} \mathcal{E}$ \\
\hline & & & & $Z E$ \\
\hline & & & & IE \\
\hline & & & & $O E$ \\
\hline & & & & 62 \\
\hline & & & & 82 \\
\hline & & & & $\angle Z$ \\
\hline & & & & 92 \\
\hline & & $\boldsymbol{\varepsilon}$ & & $\boldsymbol{\Omega}$ \\
\hline & & & & $\forall 2$ \\
\hline & & $b$ & & $\varepsilon 乙$ \\
\hline $\begin{array}{l}\mathrm{II} / 6 \\
\mathrm{Tz} / \mathrm{s}\end{array}$ & $\begin{array}{l}02 / 8 \\
2 / 8\end{array}$ & $\begin{array}{l}z / 8 \\
-\xi / 9\end{array}$ & $\begin{array}{l}5 / 9 \\
+/ 9\end{array}$ & \\
\hline \multicolumn{5}{|c|}{ 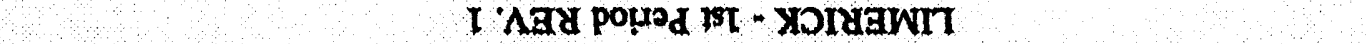 } \\
\hline
\end{tabular}


Table 3.7. Crack Growth Predicted from AE Data - 5/12/89 to 10/6/89 N2H Weld at Limerick Unit 1 Reactor

(inches)

\begin{tabular}{|c|c|c|c|c|c|c|c|c||}
\hline \multicolumn{7}{|c|}{ CRACK GROWTH - 1st Period } \\
\hline & $\begin{array}{c}5 / 12 \\
5 / 24\end{array}$ & $\begin{array}{c}5 / 24 \\
6 / 20\end{array}$ & $\begin{array}{c}6 / 20 \\
6 / 29\end{array}$ & $\begin{array}{c}6 / 29 \cdot \\
7 / 10\end{array}$ & $\begin{array}{c}7 / 10 \\
8 / 8\end{array}$ & $\begin{array}{c}8 / 8 . \\
8 / 15\end{array}$ & $\begin{array}{c}8 / 15 \\
9 / 15\end{array}$ & $\begin{array}{c}9 / 15 \\
10 / 6\end{array}$ \\
\hline 1 & & & & & & & 0.06 & \\
\hline 2 & & & & & & & & \\
\hline 3 & & & & & & & & \\
\hline 4 & & & & & & & & \\
\hline 5 & & & & & & & & \\
\hline 6 & & & & & & & & \\
\hline 7 & & & & & & & & \\
\hline 8 & & & & & & & & \\
\hline 9 & & & & & & & & \\
\hline 10 & & & & & & & & \\
\hline 11 & & & & & & & & \\
\hline 12 & & & & & & & & \\
\hline 13 & & & & & & & & \\
\hline 14 & & & & & & & & \\
\hline 15 & & & & & & & & \\
\hline 16 & & & & & & & & \\
\hline 17 & & & & & & & & \\
\hline 18 & & 0.07 & & & & & & \\
\hline 19 & & 0.06 & & & & & & \\
\hline 20 & & 0.05 & & & & & & \\
\hline 21 & & & & & & & & \\
\hline 22 & & & & & & & & \\
\hline
\end{tabular}




\begin{tabular}{|c|c|c|c|c|c|c|c|c|}
\hline \multicolumn{9}{|c|}{ CRACK GROWTH - 1st Period } \\
\hline & $\begin{array}{l}5 / 12 \\
5 / 24\end{array}$ & $\begin{array}{l}5 / 24 \\
6 / 20\end{array}$ & $\begin{array}{l}6 / 20- \\
6 / 29\end{array}$ & $\begin{array}{l}6 / 29- \\
7 / 10\end{array}$ & $\begin{array}{l}7 / 10- \\
8 / 8\end{array}$ & $\begin{array}{l}8 / 8- \\
8 / 15\end{array}$ & $\begin{array}{l}8 / 15 \\
9 / 15\end{array}$ & $\begin{array}{l}9 / 15- \\
10 / 6\end{array}$ \\
\hline 23 & & & & & & & & \\
\hline 24 & & & & & & & & \\
\hline 25 & & & & & & & & \\
\hline 26 & & & & & & & & \\
\hline 27 & & & & & & & & \\
\hline 28 & & & & & & & & \\
\hline 29 & & & & & & & & \\
\hline 30 & & & & & & & & \\
\hline 31 & & & & & & & & \\
\hline 32 & & & & & & & & \\
\hline 33 & & & & & & & & \\
\hline 34 & & & & & & & & \\
\hline 35 & & & & & & & & \\
\hline 36 & & & & & & & & \\
\hline
\end{tabular}


Table 3.8. Crack Growth Predicted from AE Data - 10/6/89 to 6/4/90 N2H Weld at Limerick Unit 1 Reactor

(inches)

\begin{tabular}{|c|c|c|c|c|c|c|c|c|}
\hline \multicolumn{9}{|c|}{ CRACK GROWTH - 1st Period } \\
\hline & $\begin{array}{l}10 / 6- \\
11 / 2\end{array}$ & $\begin{array}{c}11 / 2 \\
1 / 5\end{array}$ & $\begin{array}{l}1 / 5 \\
1 / 19\end{array}$ & $\begin{array}{r}1 / 19 . \\
2 / 2\end{array}$ & $\begin{array}{l}2 / 2 \\
2 / 26\end{array}$ & $\begin{array}{l}2 / 26 \\
3 / 29\end{array}$ & $\begin{array}{r}3 / 29 \\
4 / 27\end{array}$ & $\begin{array}{c}4 / 27 \\
6 / 4\end{array}$ \\
\hline 1 & & $\begin{array}{c}\text { No } \\
\text { DATA }\end{array}$ & & & & & & \\
\hline 2 & & & & 0.05 & 0.10 & 0.06 & & \\
\hline 3 & & & & 0.05 & & & & \\
\hline 4 & & & & 0.05 & & & & \\
\hline 5 & & & & & & & & \\
\hline 6 & & & & 0.05 & & & & \\
\hline 7 & & & & & & & & \\
\hline 8 & & & & & & & & \\
\hline 9 & & & & & & & & \\
\hline 10 & & & & & & & & \\
\hline 11 & & & & & 0.14 & & & \\
\hline 12 & & & & & 0.11 & & & \\
\hline 13 & & & & & 0.05 & & & \\
\hline 14 & & & & 0.05 & 0.05 & & & \\
\hline 15 & & & & 0.03 & 0.13 & & & \\
\hline 16 & & & & 0.05 & 0.15 & & & \\
\hline 17 & & & & & & & & \\
\hline 18 & & & & & & & & \\
\hline 19 & & & & & & & & \\
\hline 20 & & & & & 0.13 & & & \\
\hline 21 & & & & 0.03 & & & & \\
\hline 22 & & & & & & & & \\
\hline
\end{tabular}




\begin{tabular}{|c|c|c|c|c|c|c|c|c|}
\hline \multicolumn{9}{|c|}{ CRACK GROWTH 1si Period } \\
\hline & $\begin{array}{l}10 / 6 \\
11 / 2\end{array}$ & $11 / 2$ & $\begin{array}{l}1 / 5 \\
1 / 19\end{array}$ & $\frac{1 / 19}{2 / 2}$ & $\begin{array}{l}2 / 2 \\
2 / 26\end{array}$ & $\begin{array}{l}2 / 26 \\
3 / 29\end{array}$ & $3 / 27$ & $4 / 27$ \\
\hline \multicolumn{9}{|l|}{23} \\
\hline 24 & & & & & 0.13 & & & \\
\hline 25 & & & & 0.03 & 0.20 & & & \\
\hline \multicolumn{9}{|l|}{26} \\
\hline 27 & & & & & 0.09 & & & \\
\hline 28 & & & & & 0.13 & & & \\
\hline 29 & & & & & 0.14 & & & \\
\hline 30 & & & & & 0.05 & & & \\
\hline \multicolumn{9}{|l|}{31} \\
\hline \multicolumn{9}{|l|}{32} \\
\hline 33 & & & & & 0.07 & & & \\
\hline 34 & & & & & 0.09 & & & \\
\hline \multicolumn{9}{|l|}{35} \\
\hline 36 & & & & & & & & \\
\hline
\end{tabular}


Table 3.9. Crack Growth Predicted from AE Data - 6/4/90 to 9/11/90 N2H Weld at Limerick Unit 1 Reactor

(inches)

\begin{tabular}{|c|c|c|c|c|c|}
\hline \multicolumn{6}{|c|}{ 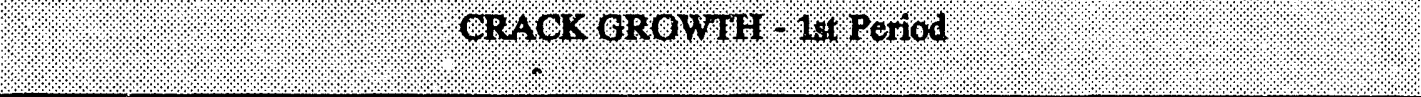 } \\
\hline & $6 / 4$. & $8 / 25$ & $8 / 2$, & $\begin{array}{r}8 / 20 \\
9 / 11\end{array}$ & Trotal \\
\hline 1 & & & & & 06 \\
\hline 2 & 02 & 0.12 & & & 0.35 \\
\hline 3 & 02 & 09 & & & 0.16 \\
\hline 4 & & 09 & & & 0.14 \\
\hline 5 & 02 & 07 & & & 09 \\
\hline 6 & 02 & 07 & & & 0.14 \\
\hline 7 & 02 & 07 & & & 09 \\
\hline 8 & 03 & & & & 03 \\
\hline 9 & & 05 & & & 05 \\
\hline \multicolumn{6}{|l|}{10} \\
\hline 11 & & & & & 0.14 \\
\hline 12 & 02 & & & & 0.13 \\
\hline 13 & & & & & 05 \\
\hline 14 & & & & & 0.10 \\
\hline 15 & & & & & 0.16 \\
\hline 16 & & & & & 0.20 \\
\hline 17 & & 05 & & & 05 \\
\hline 18 & & & & & 07 \\
\hline 19 & & & & & 06 \\
\hline 20 & & 07 & & & 0.25 \\
\hline 21 & & & & & 03 \\
\hline 22 & & & & & \\
\hline
\end{tabular}




\begin{tabular}{|c|c|c|c|c|c|}
\hline \multicolumn{6}{|c|}{ CRACK GROWTH - 1st Period } \\
\hline & $\begin{array}{l}6 / 4 \\
6 / 25 \\
\end{array}$ & $\begin{array}{l}6 / 25 \\
8 / 2\end{array}$ & $\begin{array}{l}8 / 2- \\
8 / 20 \\
\end{array}$ & $\begin{array}{r}8 / 20 \\
9 / 11 \\
\end{array}$ & Total \\
\hline 23 & & 0.07 & & & 0.07 \\
\hline 24 & & & & & 0.13 \\
\hline 25 & & 0.05 & & & 0.28 \\
\hline \multicolumn{6}{|l|}{26} \\
\hline 27 & & & & & 0.09 \\
\hline 28 & & & & & 0.13 \\
\hline 29 & & & & & 0.14 \\
\hline 30 & & & & & 0.05 \\
\hline \multicolumn{6}{|l|}{31} \\
\hline \multicolumn{6}{|l|}{32} \\
\hline 33 & 0.02 & 0.06 & & & 0.15 \\
\hline 34 & 0.02 & & & & 0.11 \\
\hline 35 & 0.03 & 0.11 & & & 0.14 \\
\hline 36 & 0.02 & 0.10 & & & 0.12 \\
\hline
\end{tabular}

Table 3.10. Indicated Crack Growth Rate at the N2H Weld Over Period 5/89 to 9/90

\begin{tabular}{|c|c|}
\hline Method & Crack Rate per Year - Max* \\
\hline UT & 0.38 in. \\
\hline CAVS & 0.026 in. \\
\hline AE & 0.28 in. \\
\hline
\end{tabular}

-Based on approximately 15 months of reactor operation. The values for UT and AE are derived from the area of maximum crack growth indication. 


\subsection{Final Monitoring Period}

\subsection{AE Data Analysis}

The analysis approach used for the final monitoring period was the same as described in Section 3.2, first paragraph for the first monitoring period.

Filtered $\mathrm{AE}$ event count by source location element for the first monitoring period $(5 / 12 / 89$ to $9 / 11 / 90)$ is recorded in Tables 3.4 through 3.6. Similar information for the second monitoring period (12/13/90 to $12 / 18 / 91$ ) is shown in Tables 4.1 through 4.3. All of the data in these six tables were filtered as described in Section 3.2 to eliminate noise-induced counts. During the first monitoring period (Tables 3.4 through 3.6), the AE monitor instrument was functional 61 weeks out of the total monitoring period of 70 weeks for an operating efficiency of $87 \%$. During the second monitoring period (Tables 4.1 through 4.3), the AE monitor instrument was functional 17 weeks out of the total monitoring period of 66 weeks for an operating efficiency of $26 \%$. The operating efficiency of the AE monitor system is discussed in detail in Section 4.4 - AE System Performance of this report.

Tables 4.4 through 4.6 summarize the estimated crack growth in the various source location elements for the second monitoring periods plus totals for each period and for both periods together. The crack growth estimates from AE data are summarized in Figures 4.1, 4.2, and 4.3.

\subsection{ISI and Crack-Arrest-Verification- Specimen Results}

Location and profile of the flaw indication as determined by ultrasonic ISI are shown in Figure 4.4 which is a translation from the ISI reports for examinations performed $2 / 89$ and $10 / 90$. The original flaw indication (light cross-hatched area) in Figure 4.4 represents the results of ultrasonic ISI of the N2H weld in February $1989 .^{6}$ Subsequent growth in the flaw indication over the ensuing fuel cycle as detected by ultrasonic ISI of the $\mathrm{N} 2 \mathrm{H}$ weld in October $1990^{7}$ is illustrated by the

\footnotetext{
${ }^{6}$ General Electric Nuclear Energy. February 1989. Limerick Generating Station Unit 1 Inservice Inspection Report No. 89-003.
}

dark cross-hatched area. The latest ISI results ${ }^{8}$ showed only slight changes in the flaw indication profile from that defined in previous inspections as shown in Figure 4.5. There were no other flaw indications identified in the latest ISI of the $\mathrm{N} 2 \mathrm{H}$ weld. Information from the latest ISI is shown in Figures 4.6 through 4.11. Information in Figures 4.6, 4.7, and 4.8 cover the region of the flaw indication (31.8" to $40.4^{\prime \prime}$ by conventional ISI location terms). Figures 4.9, 4.10, and 4.11 cover the region where $\mathrm{AE}$ indications clustered ( $0^{\prime \prime}$ to $\left.7.5^{\prime \prime}\right)$ but where the ISI did not show an identifiable flaw indication.

The crack-arrest-verification-specimen (CAVS) assembly continued in place during the second monitoring period to provide a basis for estimating possible growth of the flaw indication in Weld $\mathrm{N} 2 \mathrm{H}$ during reactor operation. During the second AE monitoring period, the CAVS system indicated a crack growth rate of 0.036 inches for the full period. ${ }^{9}$ This equates to a crack growth rate of about 0.028 inches/year. Thermal cycling of the specimen resulting from cycling of the Reactor Water Cleanup System was considered to be a significant factor contributing to the indicated crack growth.

\subsection{Comparison of AE, ISI, and CAVS Results}

The AE results and the ultrasonic ISI results compare favorably in some respects and disagree in others. During the first $\mathrm{AE}$ monitoring period, the ISI results showed some growth in the original flaw indication but no other identifiable indications. The ISI results for the second $\mathrm{AE}$ monitoring period showed effectively no growth in the flaw indication and also no other flaw indications. The $\mathrm{AE}$ results summarized in Figures 4.1, 4.2 , and 4.3 -- estimated crack growth $\geq 0.1$ inches -show partial agreement between the AE and ISI infor

\footnotetext{
${ }^{7}$ General Electric Nuclear Energy. September 1990. Limerick Generating Station Unir 1 Inservice Inspection Report No. D-3001-4.

${ }^{8}$ General Electric Nuclear Energy. March 1992. Limerick Generating Station Unit 1 Inservice Inspection Report No. D-4031.

${ }^{9}$ Collier, K. B. May 1992. Informal written communication.
} 
mation. $\mathrm{AE}$ for the first monitoring period show activity in the region of the flaw indication (source location elements 26 through 33) as did the ISI. AE for the second monitoring period showed no activity in the region of the flaw indication which agrees with the ISI.

The two surveillance methods depart from each other, however, on the region of the concentration of $\mathrm{AE}$ indications (source location element 34 through topdead-center to element 6 in Figure 4.3). ISI showed intermittent root geometry and acoustic interface indications throughout the length of the weld but nothing in the area of the $\mathrm{AE}$ concentration that was indicative of a flaw. Much of the crack growth indicated by $A E$ in the location element 34 to 6 region is borderline for detection by conventional ultrasonic (UT) methods if one accepts the nominal detection threshold of $20 \%$ of wall thickness $\left(0.26^{\prime \prime}\right.$ in this case) for inspection through the weld. The area of source location element 2, however, should have been detected by ultrasonic inspection. It is obvious there are two possible answers: 1) the $\mathrm{AE}$ indications are valid and the UT is not picking the indication up - this is not a simple weld to inspect, or, 2) the AE indications are in error. The only irrefutable way of answering the question is through destructive inspection of the weld if and when it is replaced. It does not appear that this would be justified any time in the near future. One other option that may resolve the question is to inspect the weld using an advanced ultrasonic technique which has improved sensitivity and accuracy such as the Synthetic Aperture Focusing Technique (SAFT) method of flaw imaging during the next outage. The resolution of the SAFT approach may be sufficiently better than normal UT inspection to provide an answer.

The nominal crack growth indications from the CAVS system are about the same for both monitoring periods ( 0.026 to 0.028 inches/year). It appears that CAVS does not agree with either UT or AE. This is not intended as a general commentary on the CAVS technique, but simply a statement of fact as it applies to this case.

\subsection{AE System Performance}

Coolant flow noise was never a problem. The primary operational problem encountered in the $\mathrm{AE}$ monitoring process was transient acoustic noise pickup at the shielding wall penetration which was an integral part of the signal transmission path from the $\mathrm{AE}$ sensors to the monitor instrument. The approach to overcoming this problem involved filtering of the data as it was played back from the tapes to eliminate all signals that did not fit a criteria of signal-time-of-arrival that defined the source volume as the weld. This sounds like a rather obvious restriction to place on the data but normally in a system without abnormal noise, it is preferred to not limit the data this way so that general volumetric monitoring is achieved. It was a valid solution in this case since the area of interest was focused on the weld.

The operating efficiency of the AE monitor system was quite good during the first monitoring period $(87 \%)$ but during the second monitoring period, it fell to $26 \%$. There are two significant factors which contributed to this situation. In order to stay within the program budget, it was necessary to limit the number of times that a PNL instrument specialist was sent to Limerick to address operational problems. The alternate was to utilize some of the very capable instrument specialists at Limerick and communicate by telephone. The Limerick staff were handicapped by being unfamiliar with the design of the instrument and also, they had a full work load in other areas. The bottom line is that this approach worked but it was costly in elapsed time.

The second and most serious factor was the fact that the AE monitor instrument was not adequately cooled. This did not begin to become evident until the second monitoring period. Circuit boards that were sent to PNL for testing during one of the inoperative periods showed heat tinting. Although temperature measurements in the immediate vicinity of the circuit boards were not obtained, it is estimated that the temperature had to have been in the vicinity of $200^{\circ} \mathrm{F}$ to have caused some of the component problems experienced.

One AE sensor failed in the course of each monitoring period. It was possible to adjust algorithms to permit effective monitoring to continue with three sensors. The sensors are being held at Limerick for the present 
because the radiation level from them is too high for unconditional release, but the level has been steadily dropping to where they are now barely above the limit. When the sensors are released, they will be carefully examined and tested to determine what caused the one sensor to fail and the condition of the remaining sensors.
The AE monitor system was in continuous service with limited attention for 1-1/4 years during the first monitoring period and continued on into the second monitoring period before significant problems appeared. The amount of down time could have been greatly reduced if qualified technical personnel could have been available at all times. The problems were significantly aggravated by instrument overheating. All factors considered, the AE monitor system performed well. 
4.0 Final Monitoring Period

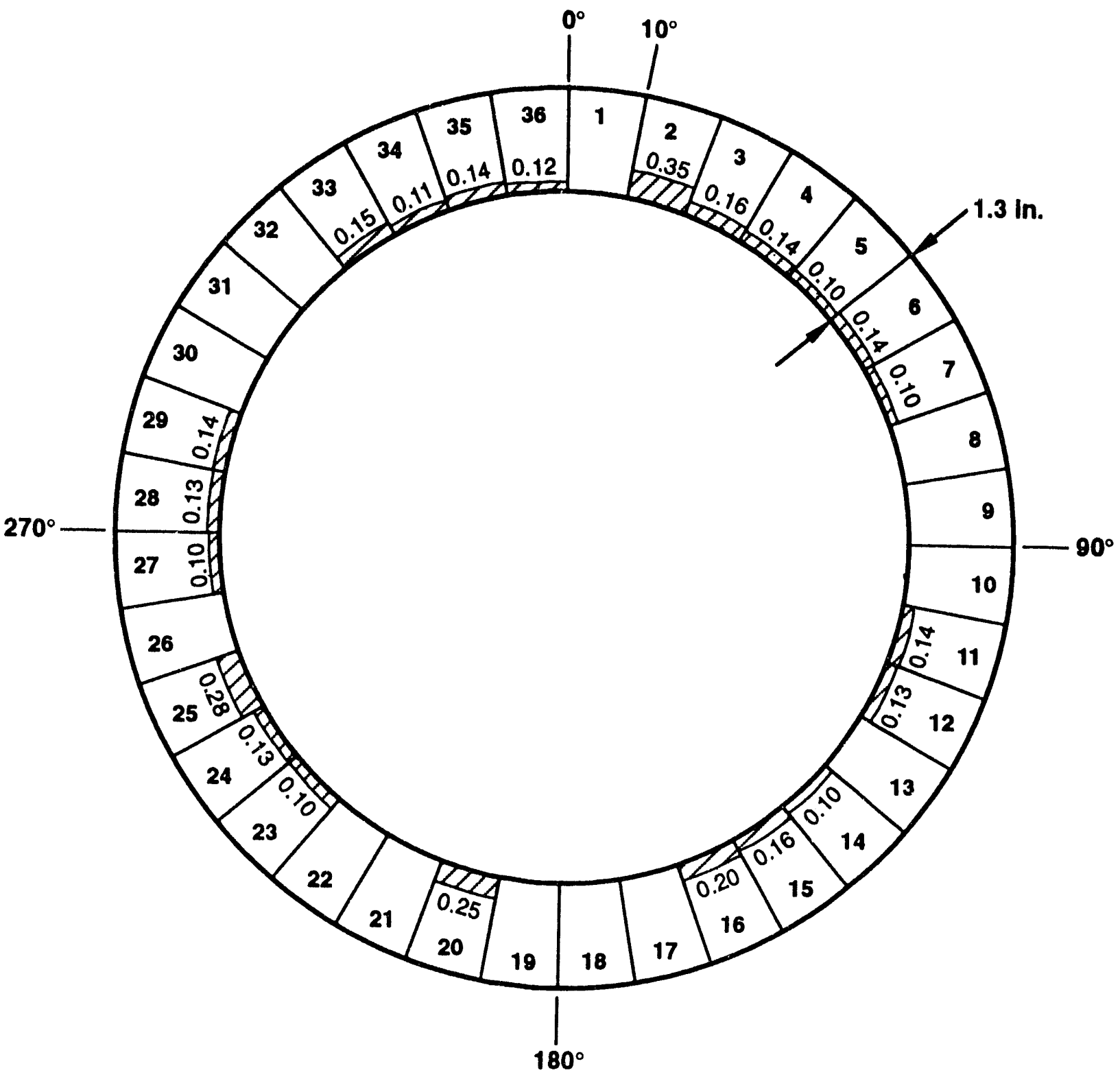

1. $Z 77$ Crack growth in inches per AE - May 12, 1989 to September 11, 1990 (Period 1).

2. Numbered sectors identify AE source location elements - each $10^{\circ}$ wide.

A9012108.2

Figure 4.1. Crack Growth Values $\geq 0$ 0.1" Estimated from AE Data over the Period 5/89 to 9/90 - N2H Weld at Limerick Unit 1 Reactor 
4.0 Final Monitoring Period

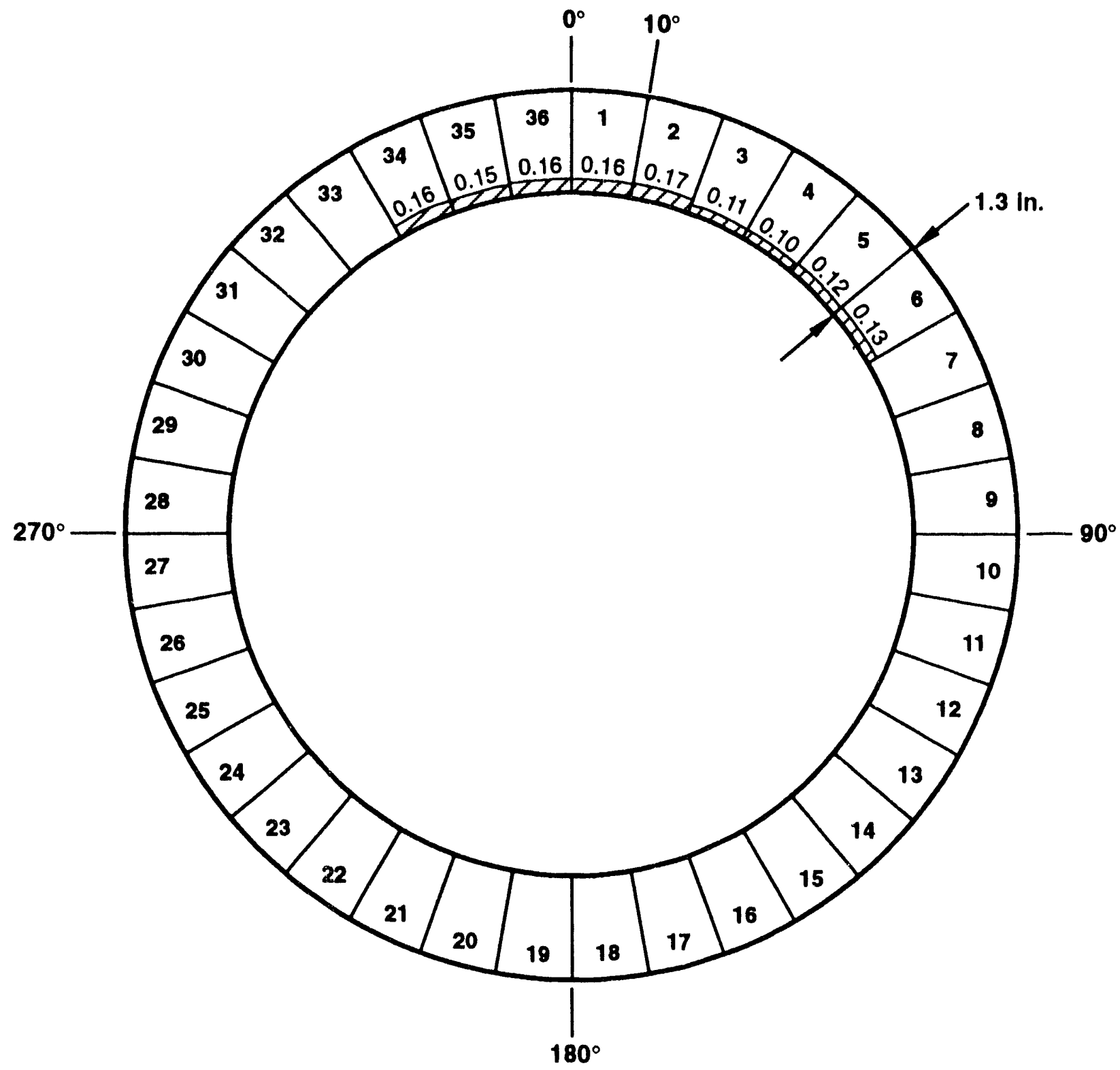

1. $Z 7 Z$ Crack growth in inches per AE - September 13, 1990

to February 18, 1992 (period 2).

2. Numbered sectors identify AE source

location elements - each $10^{\circ}$ Wide.

R9012108.3

Figure 4.2. Crack Growth Values $\geq$ 0.1" Estimated from AE Data over the Period 12/90 to 12/91 - N2H Weld at Limerick Unit 1 Reactor 


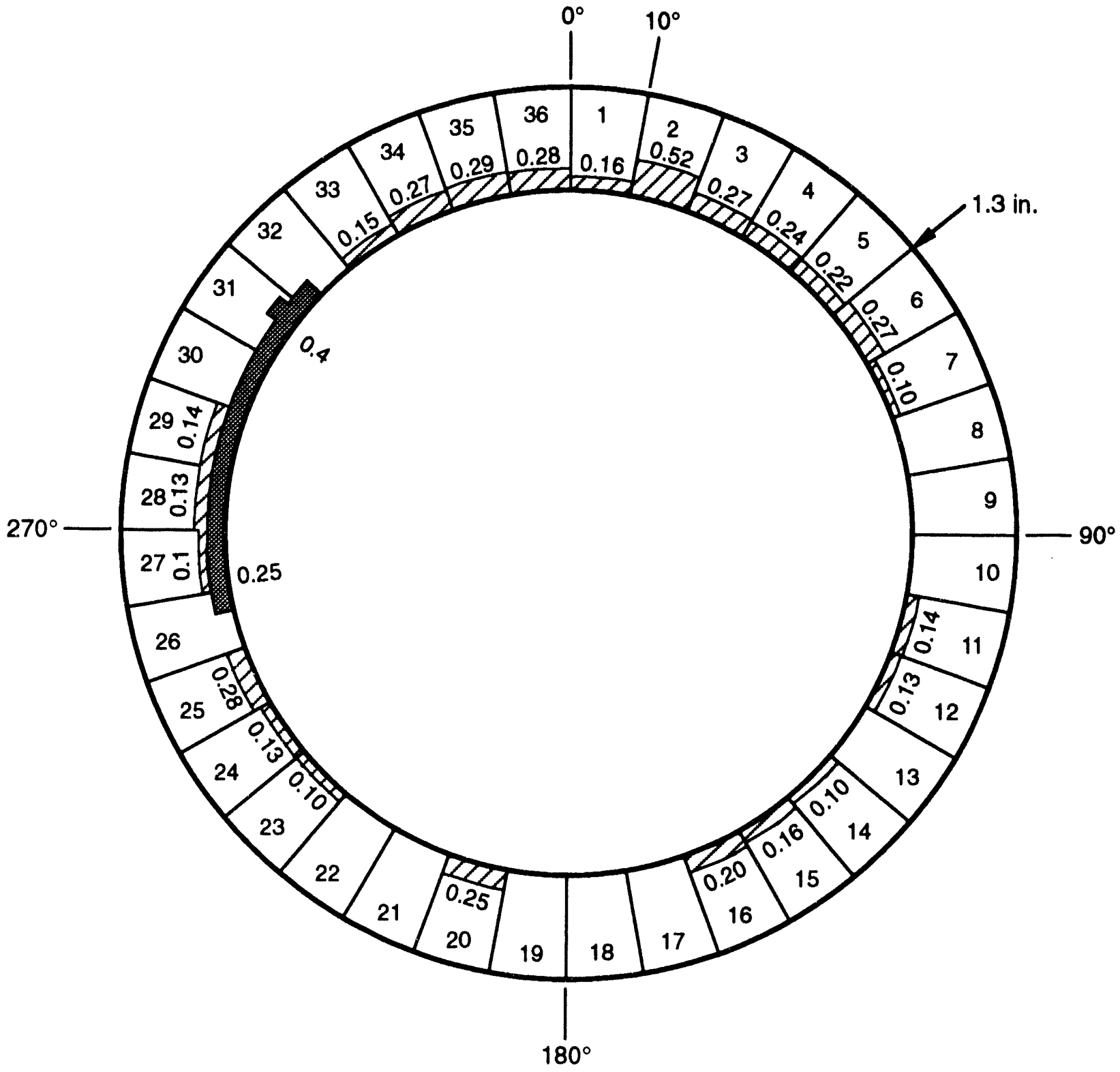

1. ZZ Crack growth in inches per AE - total both periods.

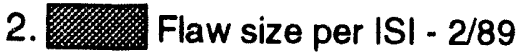
R9211002.2

3. Numbered sectors identify AE source location elements - each $10^{\circ}$ wide.

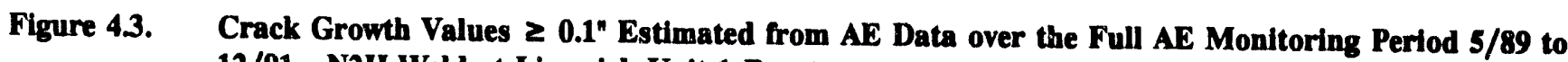
12/91 - N2H Weld at Limerick Unit 1 Reactor 


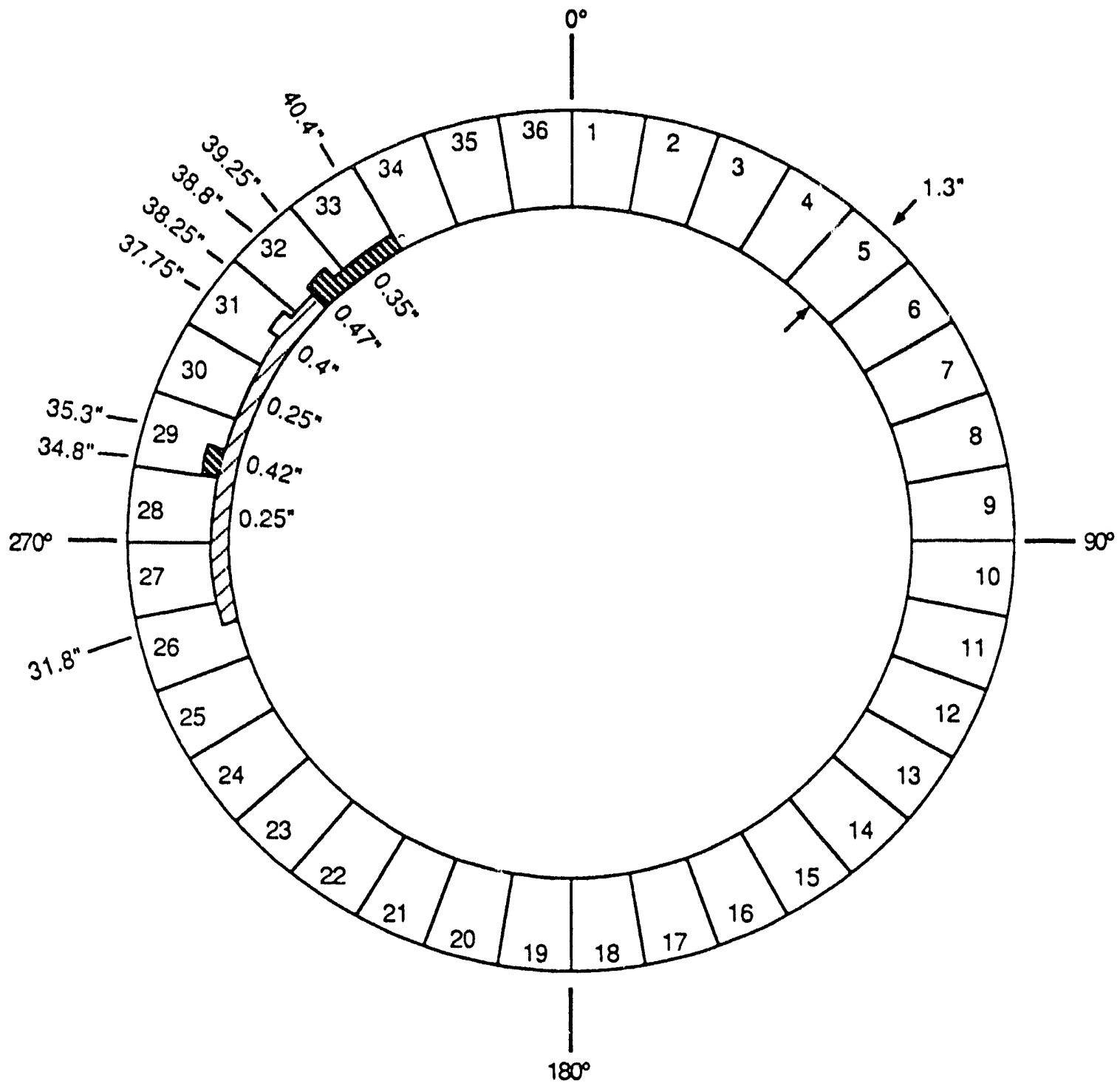

1. $\Delta \backslash$ Crack Size per ISI - 2/89

2. Crack Growth per ISI - $10 / 90$

3. Numbered Sectors Identify AE Source Location Elements - Each $10^{\circ}$ Wide

A9103152.4

Figure 4.4. AE Source Location Elements Superimposed on Pipe Cross Section with Flaw Profile - N2H Weld at Limerick Unit 1 Reactor 
4.0 Final Monitoring Period

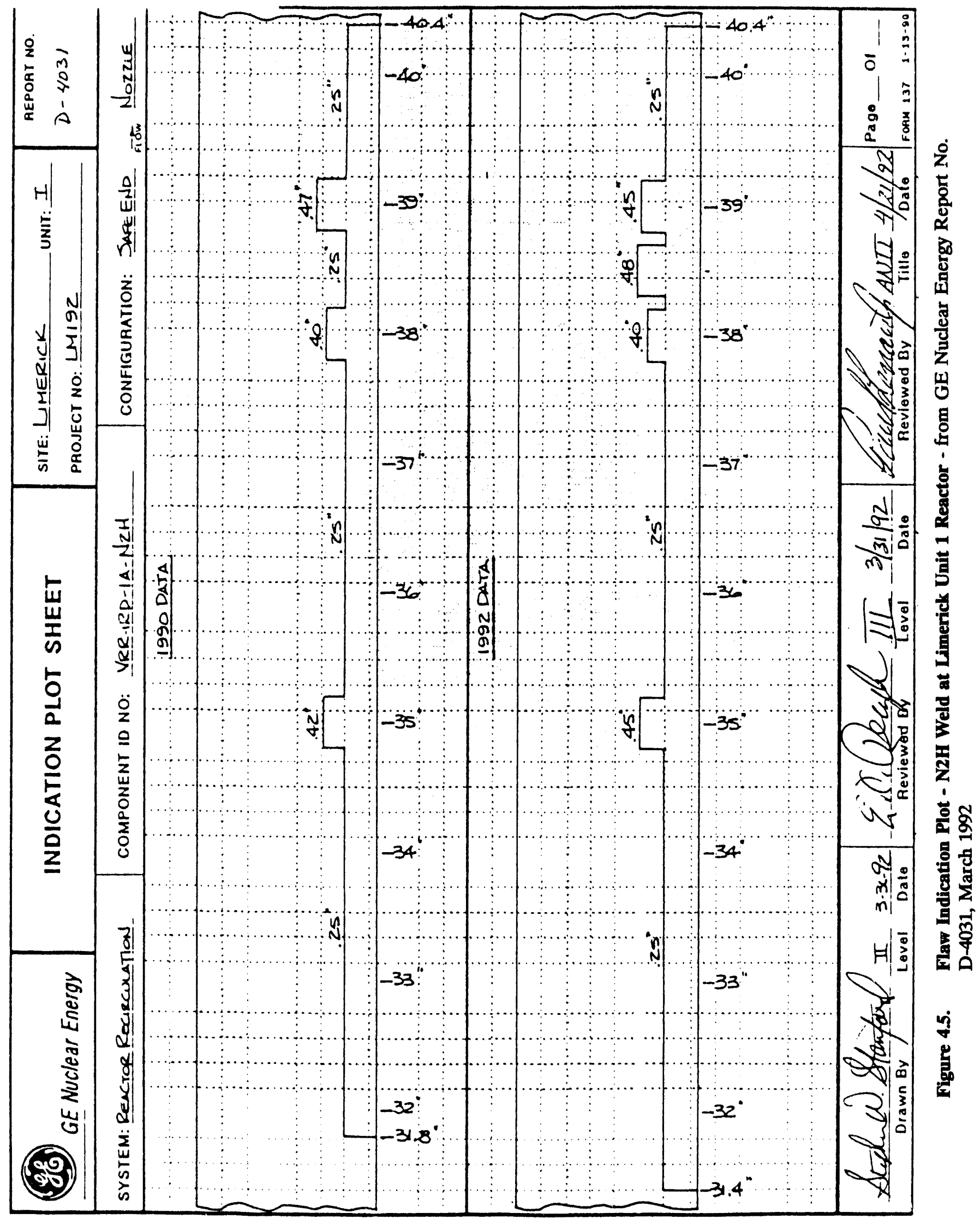




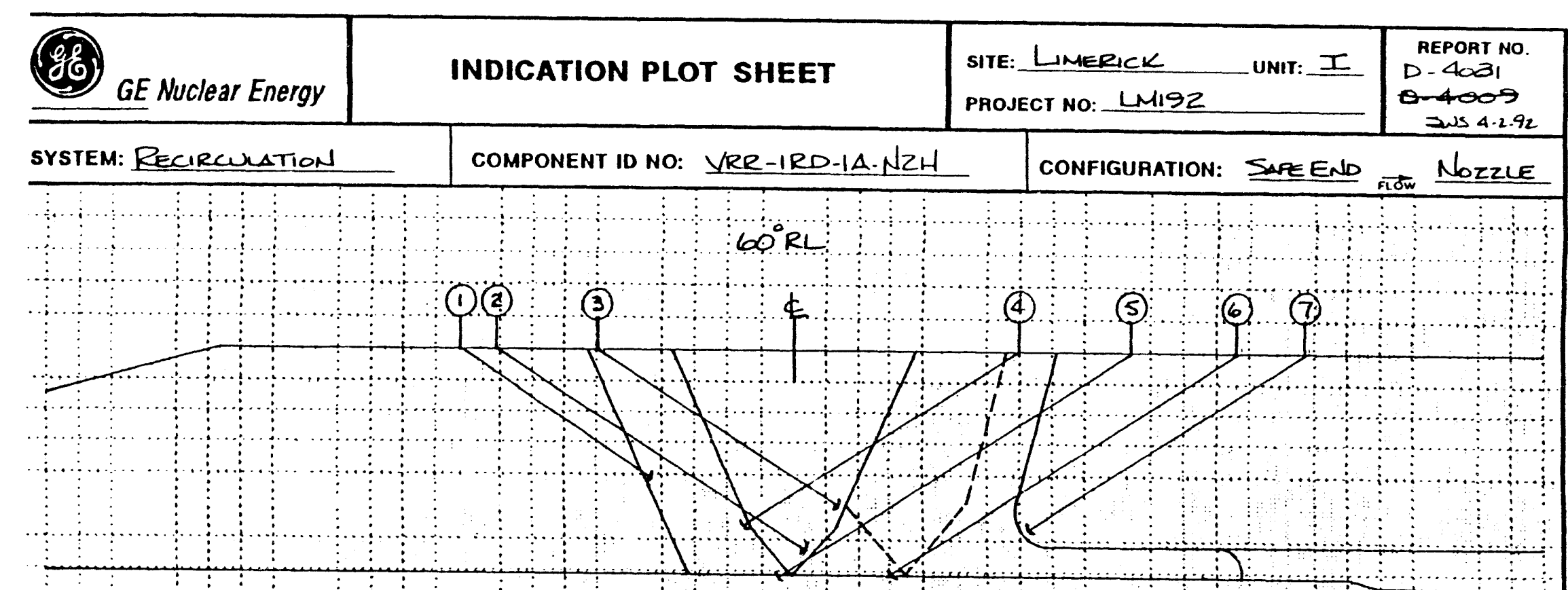

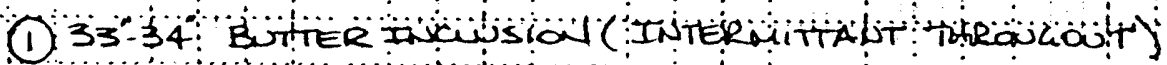

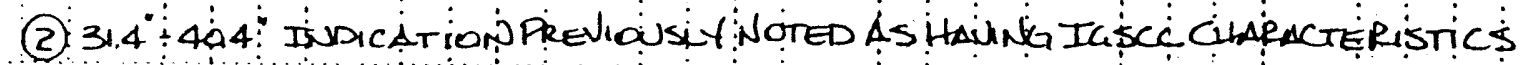

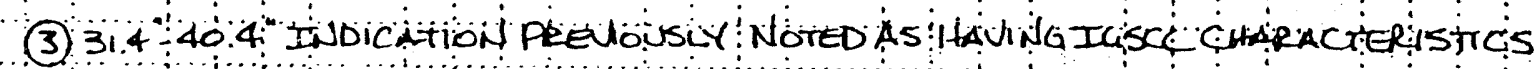

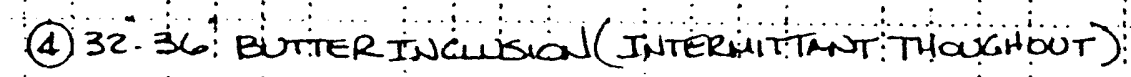

(5) INTERTITANT 3W0 ROOT GEOMETR

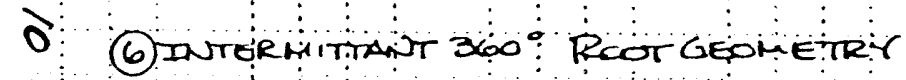

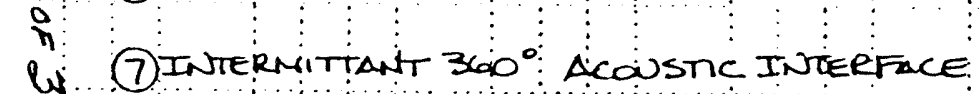

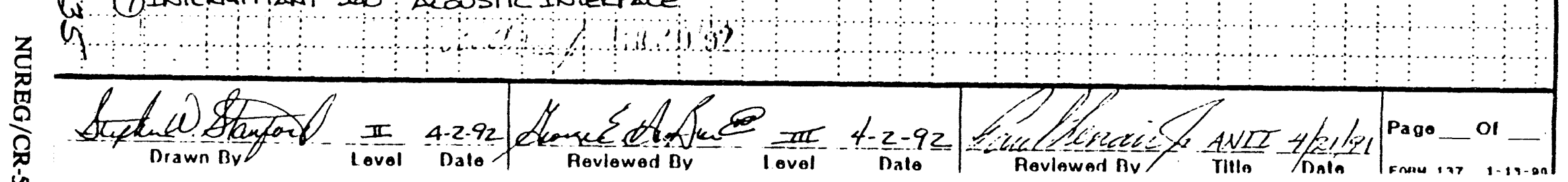




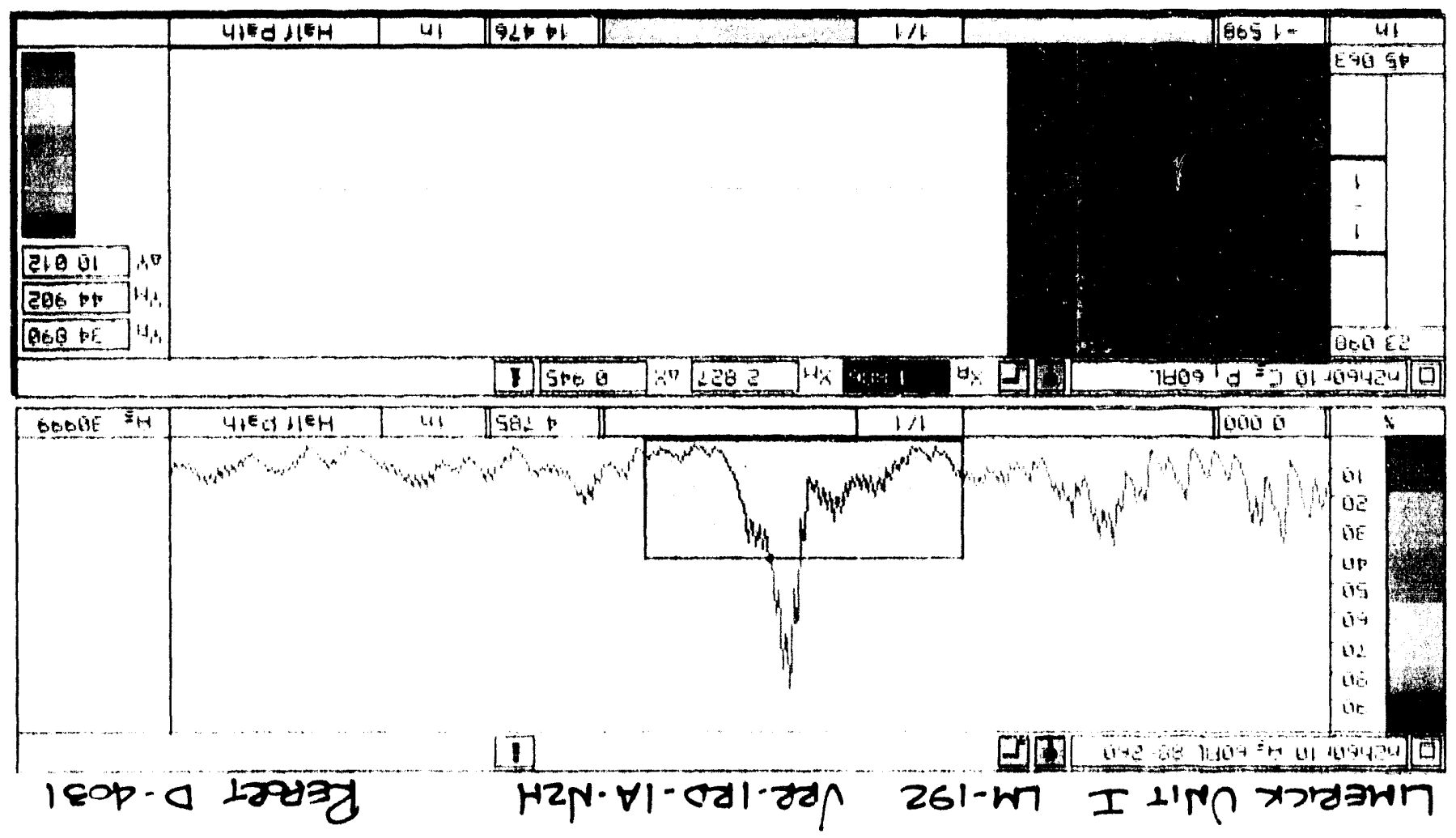




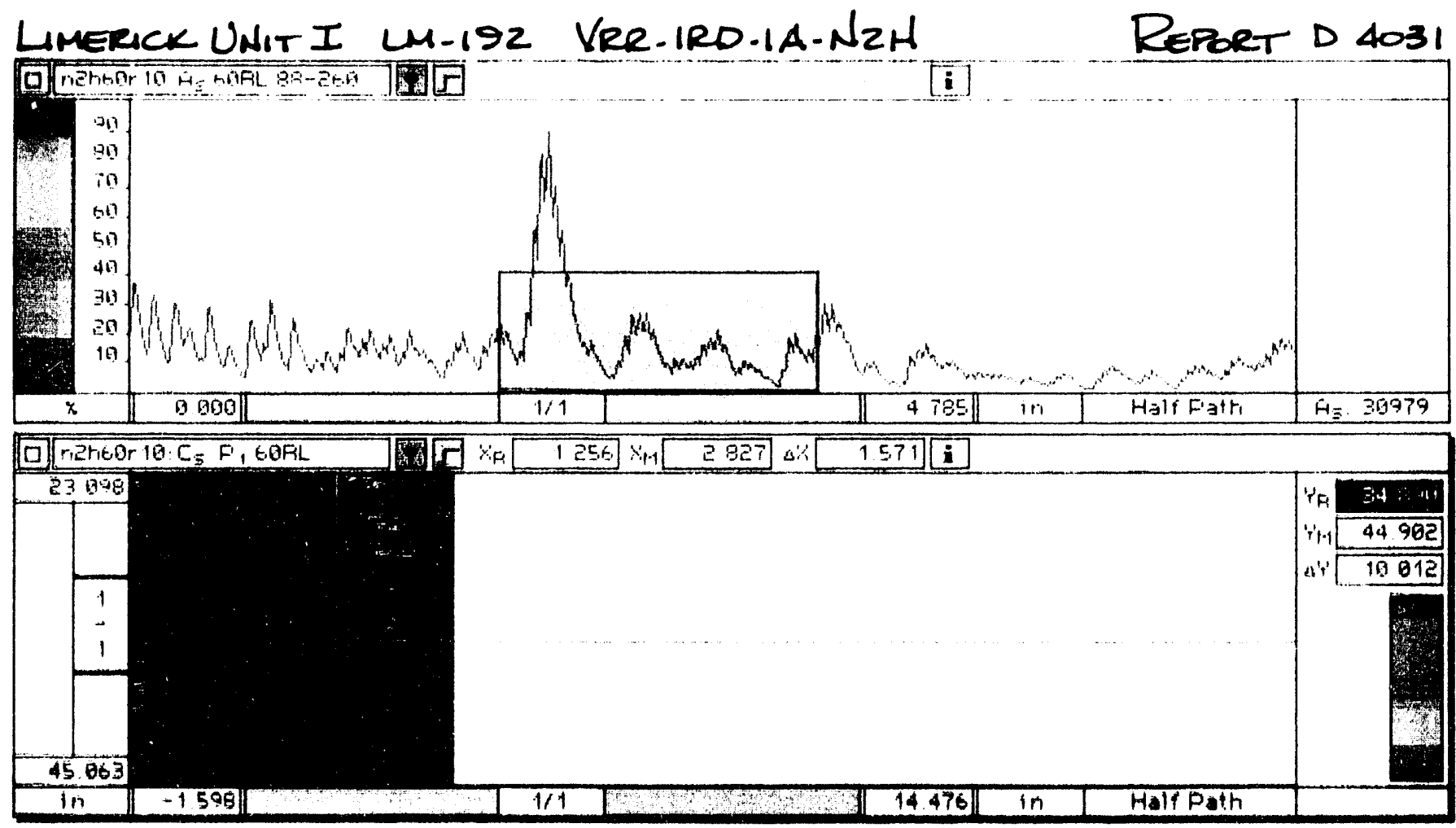

Fizure 48. $60^{\circ}$ RL Indication $3-34.89^{\prime \prime}$ to $44.9^{\prime \prime}$ 


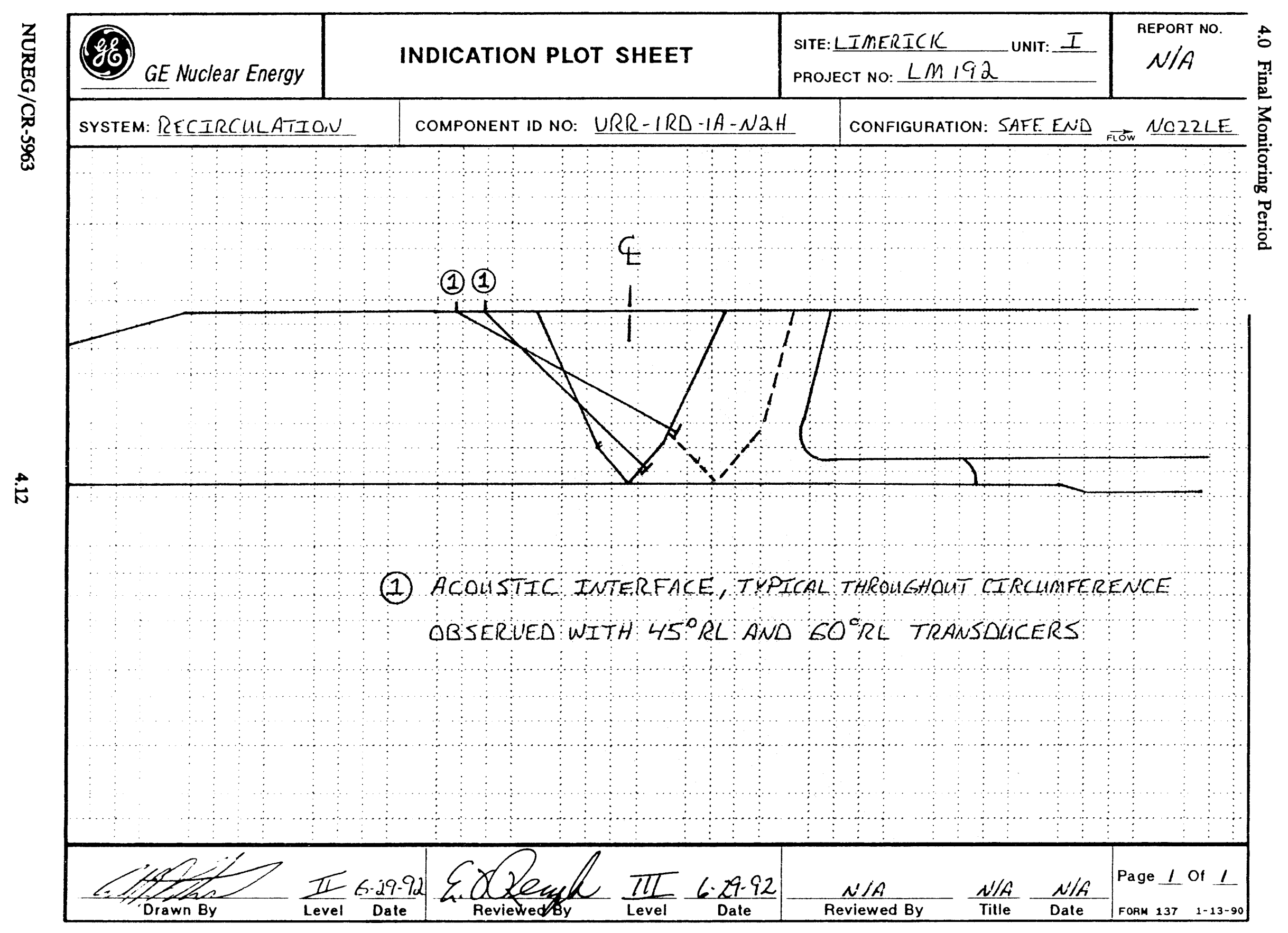

Figure 4.9. Indication Plot Sheet for $0^{n}$ to $7.5^{n}$ 

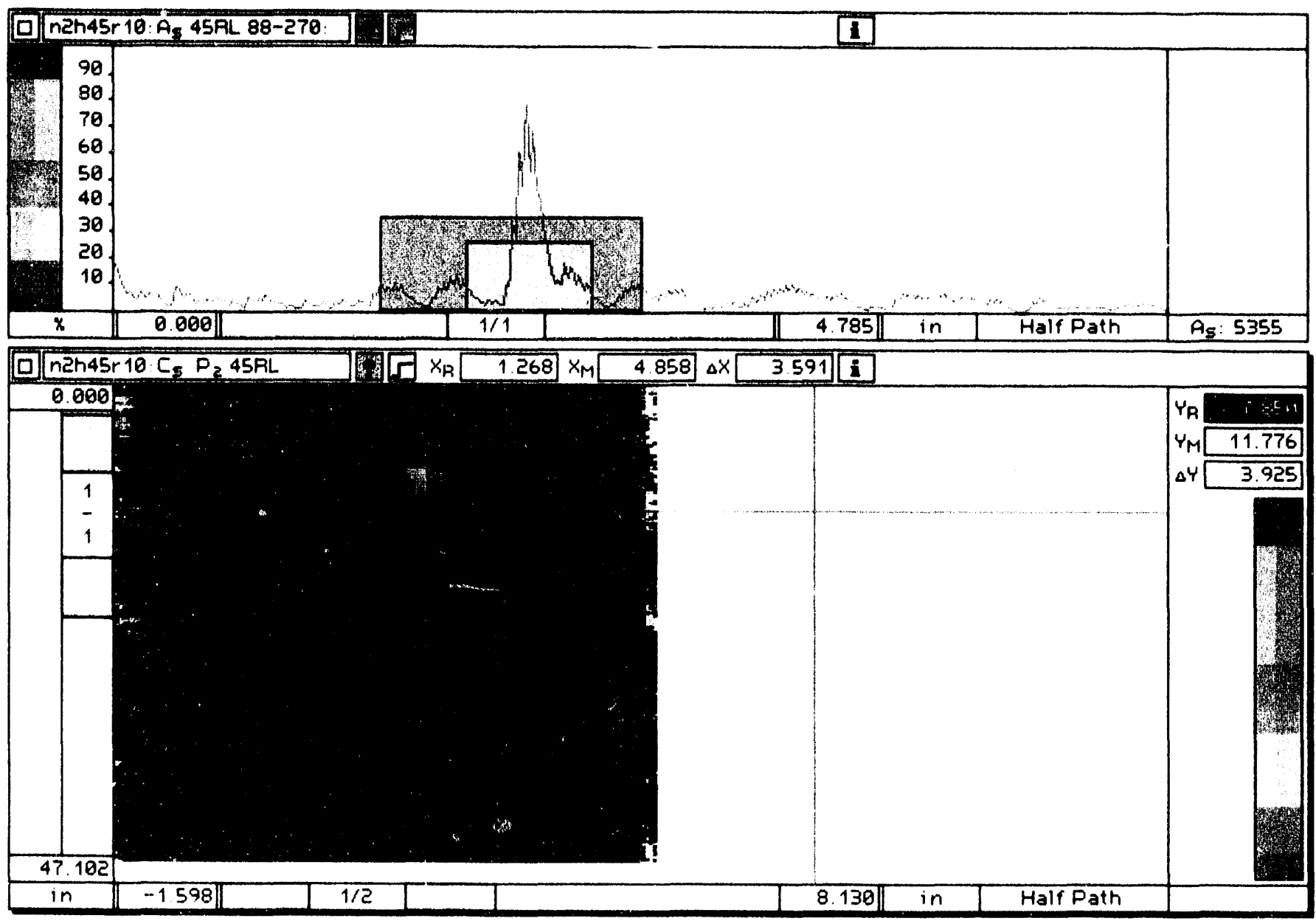

Figure 4.10. 45 RL Indication $1-7.85 "$ to $11.776^{\prime \prime}$ 


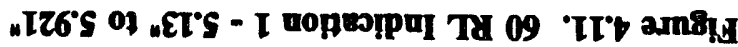

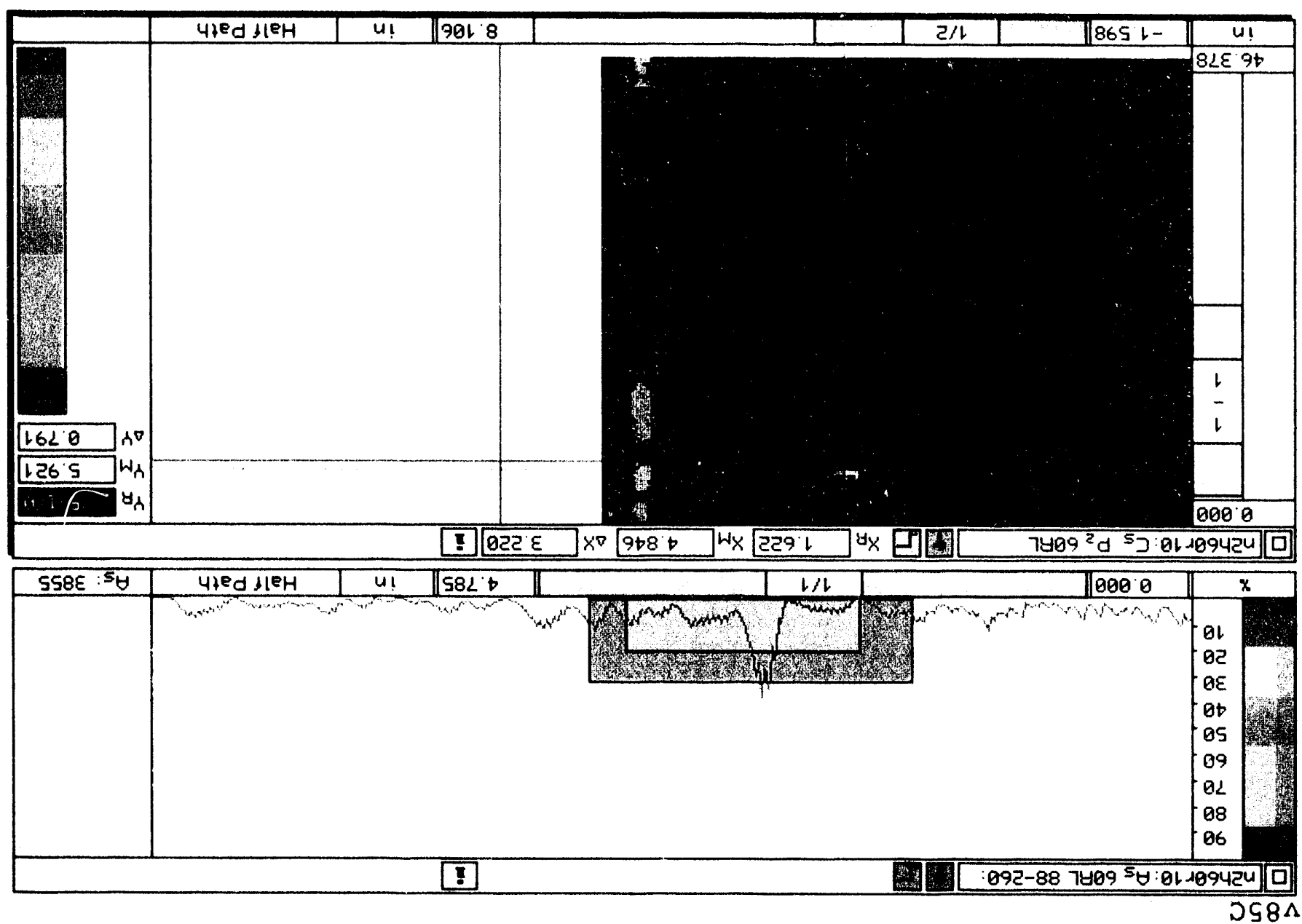


Table 4.1. Filtered AE Event Count by Source Location Element $12 / 13 / 90$ to $4 / 27 / 91$ - N2H Weld at Limerick Unit 1 Reactor

\begin{tabular}{|c|c|c|c|c|c|c|c|c|}
\hline \multicolumn{9}{|c|}{ LIMERICK - 2nd Period } \\
\hline & $\begin{array}{l}12 / 13 \\
1 / 23\end{array}$ & $\begin{array}{l}1 / 24 \\
4 / 10\end{array}$ & $\begin{array}{l}4 / 11- \\
4 / 12\end{array}$ & $\begin{array}{l}4 / 12 \\
4 / 16\end{array}$ & $\begin{array}{r}4 / 17- \\
4 / 19 \\
\end{array}$ & $\begin{array}{l}4 / 20 \\
4 / 22\end{array}$ & $\begin{array}{r}4 / 23 \\
4 / 25 \\
\end{array}$ & $\begin{array}{l}4 / 26 \\
4 / 27\end{array}$ \\
\hline 1 & 3 & \multirow{23}{*}{$\begin{array}{c}\text { No } \\
\text { Data }\end{array}$} & & 3 & 1 & 1 & 2 & 1 \\
\hline 2 & 7 & & & & 1 & 5 & 1 & 1 \\
\hline 3 & 10 & & & & & 1 & & 1 \\
\hline 4 & 6 & & & 1 & & & 1 & 1 \\
\hline 5 & 10 & & & 3 & & & 2 & 1 \\
\hline 6 & 13 & & & & & & & \\
\hline 7 & 1 & & & & 1 & & & \\
\hline 8 & & & & & & & & \\
\hline 9 & & & & & & & & \\
\hline 10 & & & & & & & & \\
\hline 11 & & & & & & & & \\
\hline 12 & & & & & & & & \\
\hline 13 & & & & & & & & \\
\hline 14 & & & 1 & & & & & \\
\hline 15 & & & & & & & & \\
\hline 16 & & & & & & & & \\
\hline 17 & & & & & & & & \\
\hline 18 & & & & & & & & \\
\hline 19 & & & & & & & & \\
\hline 20 & & & & & & & & \\
\hline 21 & & & & 1 & & & & \\
\hline 22 & & & & 3 & & & & \\
\hline 23 & & & & 3 & & & & \\
\hline
\end{tabular}




\begin{tabular}{|c|c|c|c|c|c|c|c|c|}
\hline \multicolumn{9}{|c|}{ LIMERICK - 2nd Period } \\
\hline & $\begin{array}{r}12 / 13 \\
1 / 23 \\
\end{array}$ & \multirow[t]{14}{*}{$\begin{array}{l}1 / 24 \\
4 / 10\end{array}$} & $\begin{array}{r}4 / 11 \\
4 / 12 \\
\end{array}$ & $\begin{array}{r}4 / 12 \\
4 / 16 \\
\end{array}$ & $\begin{array}{l}4 / 17 \\
4 / 19 \\
\end{array}$ & $\begin{array}{r}4 / 20 \\
4 / 22 \\
\end{array}$ & $\begin{array}{r}4 / 23 \\
4 / 25 \\
\end{array}$ & $\begin{array}{l}4 / 26 \\
4 / 27 \\
\end{array}$ \\
\hline 24 & & & & 1 & & & & \\
\hline 25 & & & 2 & & & & & \\
\hline 26 & & & 1 & & & & & \\
\hline 27 & & & & 1 & & & & \\
\hline 28 & & & 1 & & & & & \\
\hline 29 & 1 & & & & & & & \\
\hline 30 & & & & & & & & \\
\hline 31 & & & & & & & & \\
\hline 32 & & & & & & & & \\
\hline 33 & 3 & & & & & & & \\
\hline 34 & & & & & & 2 & 4 & 3 \\
\hline 35 & & & & 1 & & & 5 & 3 \\
\hline 36 & 0 & & 1 & 0 & 0 & 1 & 0 & 3 \\
\hline
\end{tabular}


Table 4.2. Filtered AE Event Count by Source Location Element $4 / 28 / 91$ to 8/9/91 - N2H Weld

at Limerick Unit 1 Reactor

\begin{tabular}{|c|c|c|c|c|c|c|c|c|}
\hline \multicolumn{9}{|c|}{ LIMERICK - 2nd Period } \\
\hline & $4 / 28,5 / 3$ & $5 / 3-5 / 7$ & $5 / 8-5 / 12$ & $5 / 13$ & $5 / 19$ & $7 / 22$ & $7 / 25-8 / 5$ & $8 / 6-8 / 9$ \\
\hline 1 & 2 & & 1 & 1 & \multirow{23}{*}{$\begin{array}{c}\text { No } \\
\text { Data }\end{array}$} & 1 & \multirow{23}{*}{$\begin{array}{l}\text { No } \\
\text { Data }\end{array}$} & \\
\hline 2 & 3 & & 3 & 4 & & & & \\
\hline 3 & 2 & & & & & & & \\
\hline 4 & & & & 1 & & & & \\
\hline 5 & 1 & & & 2 & & & & \\
\hline 6 & & & & 5 & & & & 3 \\
\hline 7 & & 1 & & & & & & \\
\hline 8 & & & & & & & & \\
\hline 9 & & & & & & & & \\
\hline 10 & & & & & & & & \\
\hline 11 & & & & & & & & \\
\hline 12 & & & & & & & & \\
\hline 13 & & & & & & & & \\
\hline 14 & & & & & & & & \\
\hline 15 & & & & & & & & \\
\hline 16 & & & & & & & & \\
\hline 17 & & & & & & & & \\
\hline 18 & & & & & & & & \\
\hline 19 & & & & & & & & \\
\hline 20 & & & & & & & & \\
\hline 21 & & & & & & & & \\
\hline 22 & & & & & & & & \\
\hline 23 & & & & & & & & \\
\hline
\end{tabular}


4.0 Final Monitoring Period

\begin{tabular}{|c|c|c|c|c|c|c|c|c|}
\hline \multicolumn{9}{|c|}{ LIMERICK - 2nd Period } \\
\hline & $4 / 28,5 / 3$ & $5 / 3.5 / 7$ & $5 / 8 \cdot 5 / 12$ & $\begin{array}{l}5 / 13 \\
5 / 18\end{array}$ & \multirow[t]{14}{*}{$\begin{array}{l}5 / 19 \\
7 / 21\end{array}$} & $\begin{array}{l}7 / 22 \\
7 / 24\end{array}$ & \multirow[t]{14}{*}{$7 / 25-8 / 5$} & $8 / 6.8 / 9$ \\
\hline \multicolumn{7}{|l|}{24} & & \\
\hline 25 & 2 & & & & & & & \\
\hline \multicolumn{7}{|l|}{26} & & \\
\hline \multicolumn{7}{|l|}{27} & & \\
\hline \multicolumn{7}{|l|}{28} & & \\
\hline \multicolumn{7}{|l|}{29} & & \\
\hline 30 & 1 & & & & & & & \\
\hline \multicolumn{7}{|l|}{31} & & \\
\hline 32 & & & 1 & & & & & \\
\hline 33 & 3 & & & & & & & \\
\hline 34 & 3 & 4 & 3 & 4 & & & & \\
\hline 35 & 3 & 4 & & 2 & & & & \\
\hline 36 & 4 & 2 & 2 & 3 & & 1 & & \\
\hline
\end{tabular}


Table 4.3. Filtered AE Event Count by Source Location Element $8 / 9 / 91$ to $12 / 18 / 91$ - N2H Weld at Limerick Unit 1 Reactor

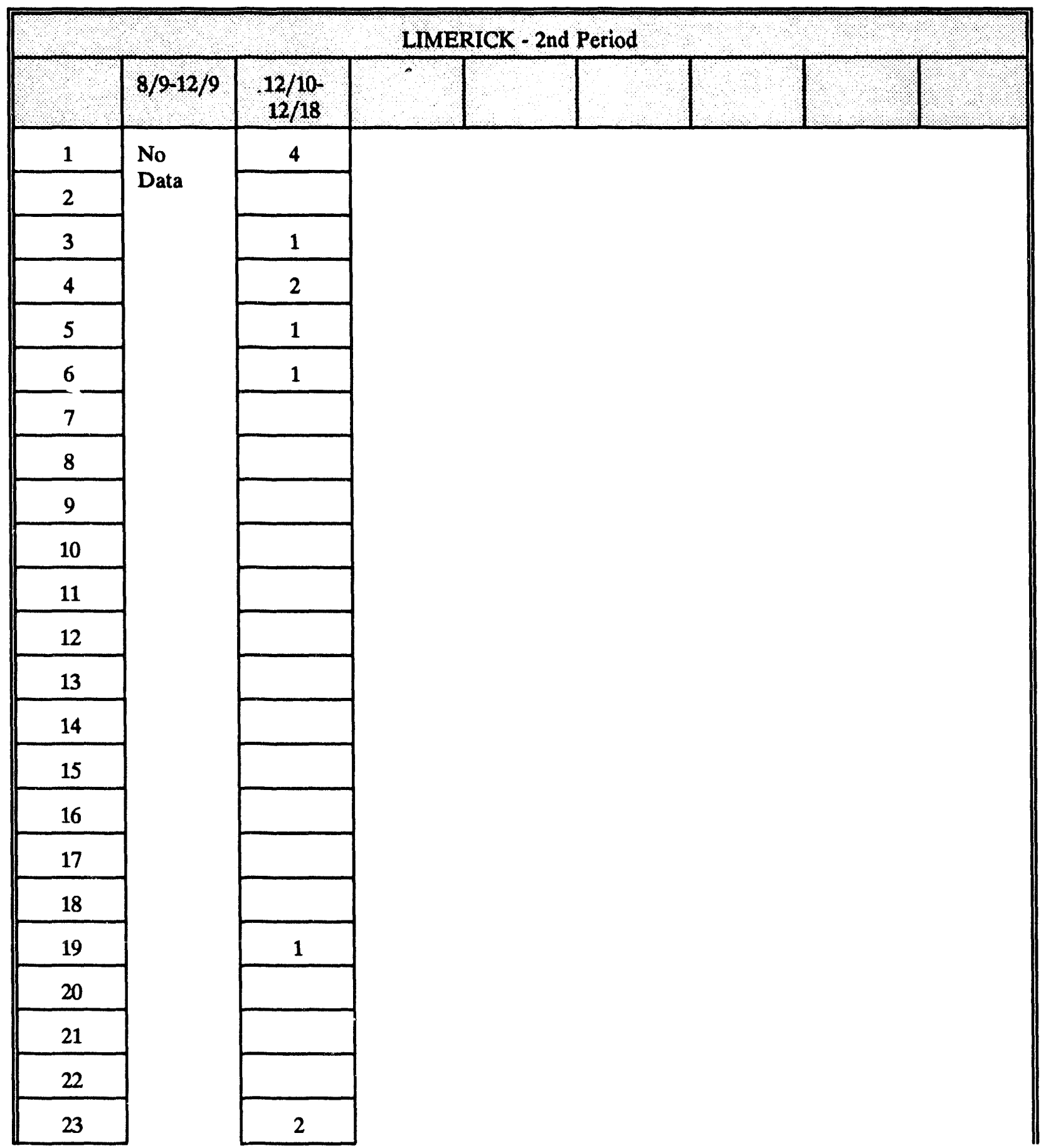




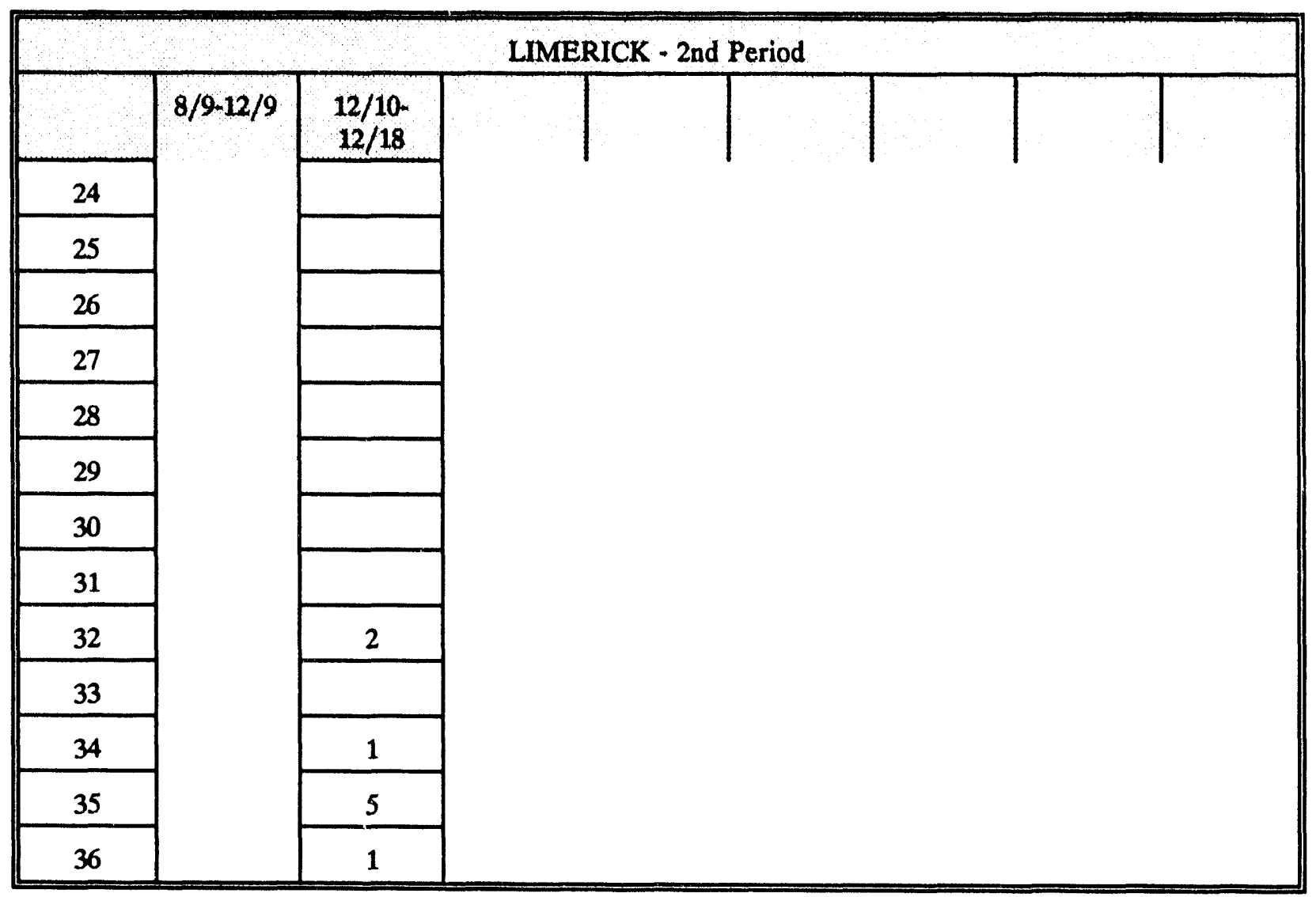


Table 4.4. Crack Growth Predicted from AE Data - 12/13/90 to 4/27/91 -

N2H Weld at Limerick Unit 1 Reactor

(inches)

\begin{tabular}{|c|c|c|c|c|c|c|c|c|}
\hline \multicolumn{9}{|c|}{ CRACK GROWTH - 2nd Period } \\
\hline & $\begin{array}{l}12 / 13 \\
1 / 23 \\
\end{array}$ & $\begin{array}{l}1 / 24 \\
4 / 10 \\
\end{array}$ & $\begin{array}{l}4 / 11- \\
4 / 12 \\
\end{array}$ & $\begin{array}{l}4 / 12- \\
4 / 16 \\
\end{array}$ & $\begin{array}{l}4 / 17 \\
4 / 19 \\
\end{array}$ & $\begin{array}{l}4 / 20 \\
4 / 22\end{array}$ & $\begin{array}{l}4 / 23- \\
4 / 25 \\
\end{array}$ & $\begin{array}{l}4 / 26- \\
4 / 27\end{array}$ \\
\hline 1 & 0.03 & \multirow{23}{*}{$\begin{array}{l}\text { No } \\
\text { Data }\end{array}$} & & 0.01 & 0.01 & 0.01 & 0.01 & 0.01 \\
\hline 2 & 0.04 & & & & 0.01 & 0.02 & 0.01 & 0.01 \\
\hline 3 & 0.05 & & & & & 0.01 & & 0.01 \\
\hline 4 & 0.04 & & & & & & 0.01 & \\
\hline 5 & 0.05 & & & & & & 0.01 & 0.01 \\
\hline 6 & 0.06 & & & & & & & \\
\hline 7 & 0.01 & & & & 0.01 & & & \\
\hline 8 & & & & & & & & \\
\hline 9 & & & & & & & & \\
\hline 10 & & & & & & & & \\
\hline 11 & & & & & & & & \\
\hline 12 & & & & & & & & \\
\hline 13 & & & & & & & & \\
\hline 14 & & & 0.01 & & & & & \\
\hline 15 & & & & & & & & \\
\hline 16 & & & & & & & & \\
\hline 17 & & & & & & & & \\
\hline 18 & & & & & & & & \\
\hline 19 & & & & & & & & \\
\hline 20 & & & & & & & & \\
\hline 21 & & & & 0.01 & & & & \\
\hline 22 & & & & 0.01 & & & & \\
\hline 23 & & & & 0.01 & & & & \\
\hline
\end{tabular}


4.0 Final Monitoring Period

\begin{tabular}{|c|c|c|c|c|c|c|c|c|}
\hline \multicolumn{9}{|c|}{ CRACK GROWTH - 2nd Period } \\
\hline & $\begin{array}{c}12 / 13 \\
1 / 23\end{array}$ & \multirow[t]{14}{*}{$\begin{array}{l}1 / 24 \\
4 / 10\end{array}$} & $\begin{array}{l}4 / 11 \\
4 / 12\end{array}$ & $\begin{array}{l}4 / 12 \\
4 / 16\end{array}$ & $\begin{array}{c}4 / 17 \\
4 / 19\end{array}$ & $\begin{array}{l}4 / 20 \\
4 / 22\end{array}$ & $\begin{array}{l}4 / 23 \\
4 / 25\end{array}$ & $\begin{array}{l}4 / 26 \\
4 / 27\end{array}$ \\
\hline 24 & & & & 0.01 & & & & \\
\hline 25 & & & 0.01 & & & & & \\
\hline 26 & & & 0.01 & & & & & \\
\hline 27 & & & & 0.01 & & & & \\
\hline 28 & & & 0.01 & & & & & \\
\hline 29 & 0.01 & & & & & & & \\
\hline 30 & & & & & & & & \\
\hline 31 & & & & & & & & \\
\hline 32 & & & & & & & & \\
\hline 33 & 0.03 & & & & & & & \\
\hline 34 & & & & & & 0.01 & 0.02 & 0.01 \\
\hline 35 & & & & 0.01 & & & 0.02 & 0.01 \\
\hline 36 & 0.00 & & 0.01 & 0.00 & 0.01 & 0.01 & 0.00 & 0.01 \\
\hline
\end{tabular}


Table 4.5. Crack Growth Predicted from AE Data - 4/28/91 to 8/8/91 N2H Weld at Limerick Unit 1 Reactor (inches)

\begin{tabular}{|c|c|c|c|c|c|c|c|c|}
\hline & & & CRACK & OWTH & A Perio & & & \\
\hline & $4 / 28-5 / 3$ & $5 / 3-5 / 7$ & $5 / 8-5 / 12$ & $\begin{array}{l}5 / 13- \\
5 / 18 \\
\end{array}$ & $\begin{array}{l}5 / 19 \\
7 / 21 \\
\end{array}$ & $\begin{array}{l}7 / 22- \\
7 / 24\end{array}$ & $7 / 25-8 / 5$ & $8 / 6-8 / 8$ \\
\hline 1 & 0.02 & & 0.01 & 0.01 & \multirow{23}{*}{$\begin{array}{l}\text { No } \\
\text { Data }\end{array}$} & & \multirow{23}{*}{$\begin{array}{l}\text { No } \\
\text { Data }\end{array}$} & \\
\hline 2 & 0.02 & & 0.02 & 0.03 & & 0.01 & & \\
\hline 3 & 0.02 & & & & & & & \\
\hline 4 & & & & 0.01 & & & & \\
\hline 5 & 0.01 & & & 0.02 & & & & \\
\hline 6 & & & & 0.03 & & & & 0.02 \\
\hline 7 & & 0.01 & & & & & & \\
\hline 8 & & & & & & & & \\
\hline 9 & & & & & & & & \\
\hline 10 & & & & & & & & \\
\hline 11 & & & & & & & & \\
\hline 12 & & & & & & & & \\
\hline 13 & & & & & & & & \\
\hline 14 & & & & & & & & \\
\hline 15 & & & & & & & & \\
\hline 16 & & & & & & & & \\
\hline 17 & & & & & & & & \\
\hline 18 & & & & & & & & \\
\hline 19 & & & & & & & & \\
\hline 20 & & & & & & & & \\
\hline 21 & & & & & & & & \\
\hline 22 & & & & & & & & \\
\hline 23 & & & & & & & & \\
\hline
\end{tabular}


4.0 Final Monitoring Period

\begin{tabular}{|c|c|c|c|c|c|c|c|c|}
\hline \multicolumn{9}{|c|}{ CRACK GROWTH - 2nd Period } \\
\hline & $4 / 28-5 / 3$ & $5 / 3 \cdot 5 / 7$ & $5 / 8-5 / 12$ & $\begin{array}{l}5 / 13 \\
5 / 18 \\
\end{array}$ & \multirow[t]{14}{*}{$\begin{array}{l}5 / 19 \\
7 / 21\end{array}$} & $\begin{array}{l}7 / 22 \\
7 / 24 \\
\end{array}$ & \multirow[t]{14}{*}{$7 / 25-8 / 5$} & $8 / 6-8 / 8$ \\
\hline \multicolumn{7}{|l|}{24} & & \\
\hline 25 & 0.02 & & & & & & & \\
\hline \multicolumn{7}{|l|}{26} & & \\
\hline \multicolumn{7}{|l|}{27} & & \\
\hline \multicolumn{7}{|l|}{28} & & \\
\hline \multicolumn{7}{|l|}{29} & & \\
\hline 30 & 0.01 & & & & & & & \\
\hline \multicolumn{7}{|l|}{31} & & \\
\hline 32 & & & 0.01 & & & & & \\
\hline 33 & 0.02 & & & & & & & \\
\hline 34 & 0.02 & 0.03 & 0.02 & 0.03 & & & & \\
\hline 35 & 0.02 & 0.03 & 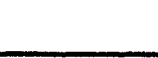 & 0.02 & & & & \\
\hline 36 & 0.02 & 0.02 & 0.02 & 0.03 & & 0.01 & & 0.00 \\
\hline
\end{tabular}


Table 4.6. Crack Growth Predicted from AE Data - 8/9/91 to 12/18/91 Plus

Totals for 5/12/89 to $12 / 18 / 91$.

N2H Weld at Limerick Unit 1 Reactor

(inches)

\begin{tabular}{|c|c|c|c|c|c|}
\hline \multicolumn{6}{|c|}{ CRACK GROWTH - 2nd Period AND SUMMARY } \\
\hline & $8 / 912,9$ & $12 / 10-12 / 18$ & $\begin{array}{l}\text { Total } \# 2 \\
\text { Period }\end{array}$ & $\begin{array}{c}\text { Total } \#_{1^{1}}{ }^{\text {Period }}\end{array}$ & $\begin{array}{l}\text { Total Both } \\
\text { Periods }\end{array}$ \\
\hline 1 & \multirow{22}{*}{$\begin{array}{l}\text { No } \\
\text { Data }\end{array}$} & 0.04 & 0.16 & 0.06 & 0.22 \\
\hline 2 & & & 0.17 & 0.35 & 0.52 \\
\hline 3 & & 0.02 & 0.11 & 0.16 & 0.27 \\
\hline 4 & & 0.03 & 0.09 & 0.14 & 0.23 \\
\hline 5 & & 0.02 & 0.12 & 0.09 & 0.21 \\
\hline 6 & & 0.02 & 0.13 & 0.14 & 0.27 \\
\hline 7 & & & 0.03 & 0.09 & 0.12 \\
\hline 8 & & & & 0.03 & 0.03 \\
\hline 9 & & & & 0.05 & 0.05 \\
\hline 10 & & & & & \\
\hline 11 & & & & 0.14 & 0.14 \\
\hline 12 & & & & 0.13 & 0.13 \\
\hline 13 & & & & 0.05 & 0.05 \\
\hline 14 & & & 0.01 & 0.10 & 0.11 \\
\hline 15 & & & & 0.16 & 0.16 \\
\hline 16 & & & & 0.20 & 0.20 \\
\hline 17 & & & & 0.05 & 0.05 \\
\hline 18 & & & & 0.07 & 0.07 \\
\hline 19 & & 0.02 & 0.02 & 0.06 & 0.08 \\
\hline 20 & & & & 0.25 & 0.25 \\
\hline 21 & & & 0.01 & 0.03 & 0.04 \\
\hline 22 & & & 0.01 & & 0.01 \\
\hline
\end{tabular}


4.0 Final Monitoring Period

\begin{tabular}{|c|c|c|c|c|c|}
\hline \multicolumn{6}{|c|}{ CRACK GROWTH - 2nd Period AND SUMMARY } \\
\hline & \multirow[t]{15}{*}{$8 / 9-12 / 9$} & $12 / 10-12 / 18$ & $\begin{array}{c}\text { Total \#2 } \\
\text { Period }\end{array}$ & $\begin{array}{c}\text { Total } \# 1^{1} \\
\text { Period }\end{array}$ & $\begin{array}{l}\text { Total Both } \\
\text { Periods }\end{array}$ \\
\hline 23 & & 0.03 & 0.04 & 0.07 & 0.11 \\
\hline 24 & & & 0.01 & 0.13 & 0.14 \\
\hline 25 & & & 0.03 & 0.28 & 0.31 \\
\hline 26 & & & 0.01 & & 0.01 \\
\hline 27 & & & 0.01 & 0.09 & 0.10 \\
\hline 28 & & & 0.01 & 0.13 & 0.14 \\
\hline 29 & & & 0.01 & 0.14 & 0.15 \\
\hline 30 & & & 0.01 & 0.05 & 0.06 \\
\hline 31 & & & & & \\
\hline 32 & & 0.03 & 0.04 & & 0.04 \\
\hline 33 & & & 0.05 & 0.15 & 0.20 \\
\hline 34 & & 0.02 & 0.16 & 0.11 & 0.27 \\
\hline 35 & & 0.04 & 0.15 & 0.14 & 0.29 \\
\hline 36 & & 0.02 & 0.16 & 0.12 & 0.28 \\
\hline
\end{tabular}

${ }^{1}$ Taken from Table 3.9. 


\subsection{Observations for Future Monitoring}

There are several lessons to be learned from this monitoring effort to enhance the effectiveness of future AE monitoring of nuclear reactor components.

\subsection{Reference Monitor Point}

Plans for the first one or two AE monitoring efforts in a given plant should include a base reference monitor point which would be a location on the reactor system in the vicinity of components of concern where cracking or other physical deterioration is highly unlikely. In the case of the N2H weld, a location on the $12^{n}$ pipe upstream of the elbow would have been a good reference location. The purpose of this reference point is to provide data from a location that is subject to all the conditions (noise, electrical transients, etc.) that the location of concern sees except flaw growth. At a stage when AE monitoring for crack growth is still being viewed with some skepticism, this would permit a more positive separation of crack growth $A E$ from other innocuous signals or noise. Such a reference point was originally planned at Limerick but other critical work in the immediate area precluded installation of the added sensors.

\subsection{Containment Penetration}

Shielding of conductors on both sides of the containment penetration plug needs to receive specific consideration. The ideal penetration would be one with coaxial lead wires but it is recognized that in most reactors, these are all used for critical reactor control instrumentation. Baring coaxial conductors, twisted-shielded-pairs with good shielding on both sides of the plug have been shown to be a suitably noise free arrangement for AE monitoring.

\subsection{Monitor Instrument Location}

The AE monitor instrument must be housed in a location where the temperature of the instrument boards can be maintained below a maximum temperature of about $100-125^{\circ} \mathrm{F}$. This should avoid any problems resulting from heating of the components.

\subsection{Calibration of the AE Source Loca- tion}

At a minimum, pulse signals such as those produced by a pencil lead break should be input at known points within the area of interest and the source location determination by the instrument recorded at the beginning and end of a fuel cycle. Additional calibrations during the fuel cycle would be beneficial if a suitable outage occurs.

\subsection{AE Signal Identification}

An improved method of implementing AE signal identification is needed. The signal identification module usea in monitoring the $\mathrm{N} 2 \mathrm{H}$ weld did not perform as expected. The basic concept of the three pulse signal produced by an $\mathrm{AE}$ event when waveguide sensors are being used is valid but the method for putting this concept into practice was not satisfactory without further testing and refinement. It was a new design with no opportunity for prior testing under field conditions, and it was not practical to have AE specialists spend time working with the module at Limerick to see if its performance could be improved. An AE signal identifier is important to $\mathrm{AE}$ monitoring because it provides another defense against being mislead by noise signals.

\subsection{Digitized AE Information}

A modification to current $\mathrm{AE}$ monitoring methodology which would overcome a large part of the noise interference and AE signal identification problem would be to digitize the information at the sensor and transmit digital information out to the monitor instrument. This approach or some variation thereof (such as digitizing the data at a point inside of the containment penetration) has been discussed by PNL staff and others for some time. The primary problem is seen as the cost to develop the necessary circuits that could withstand the environment and perform reliably inside of reactor containment. The approach to testing and calibration of the system would also need to be revised. 


\subsection{Summary and Conclusions}

The project to apply AE monitoring to the $\mathrm{N} 2 \mathrm{H}$ weld at Limerick Unit 1 to detect growth of an identified flaw indication and/or any other flaw growth in the weld is considered a success. It demonstrated that an AE monitor system can be installed and calibrated on an operating reactor system within a short time period as dictated by the outage schedule. It further demonstrated that coolant flow noise on a BWR is not a problem Iprevious tests at Watts Bar Unit 1 reactor demonstrated that flow noise on a PWR is not a problem (Hutton et al. 1984)] and that an abnormal amount of RF noise pickup can be overcome to produce useful data. The monitoring proceeded over two fuel cycles. Although the operating efficiency of the AE system was not good during the second monitoring period, evidence indicates that a significant contributor was the temperature environment which is a problem that is relatively easy to solve.

$\mathrm{AE}$ and ISI results generally agreed with regard to the growth of the flaw indication. There was modest growth shown during the first monitoring period and essentially no growth during the second monitoring period. The relationship arrived at for relating AE to crack growth gives rational results which are similar in magnitude to ultrasonic estimates. AE indicated limited flaw growth in an area near the ISI flaw indication which was not corroborated by ISI results. An absolute resolution of the validity of this indication can only be achieved by destructive examination of the weld which will not occur in the near future. Inspection of the weld using an advanced technique with improved performance such as the Synthetic Aperture Focusing Technique for ultrasonic testing may shed further light on the question. The AE system worked well, produced reasonable results, and did not pose any unwarranted problems to continuity of reactor operation.

Several observations were noted in the course of the effort which will contribute to enhanced effectiveness of future AE monitoring of reactor components. Future applications of $\mathrm{AE}$ monitoring will benefit from transfer of this technology to a commercial company(ies) that is proceeding outside this program. It is important to the effective use of the technology that it be available on a commercial basis. 


\subsection{References}

Electric Power Research Institute. May 1980. Development of an Acoustic Emission Zone Monitor and Recorder for BWR Pipe-Cracking Detection. Report No. EPRI NP-1408.

Hutton, P. H., et al. June 1984. Acoustic Emission Monitoring of Hot Functional Testing. NUREG/CR3693. Nuclear Regulatory Commission, Washington, D.C.
Hutton, P. H., et al. September 1985. Acoustic Emission Results Obtained from the ZB-1 Intermediate Scale Pressure Vessel. NUREG/CR-3915. Nuclear Regulatory Commission, Washington, D.C. 


\section{Distribution}

No. of

Copies

A. L. Hiser, Jr.

NRC/RES

Mail Stop NS 217C

J. Muscara

NRC/RES

Mail Stop NS 217C

D. W. Craig

NRC/RES

Mail Stop NS 217C

3 D. B. Fetters, 62A4-1

Nuclear Engineering Dept.

Philadelphia Electric Co.

965 Chesterbrook Blvd.

Wayne, PA 19087-5961

2 J. McElroy

Philadelphia Electric Co.

PO Box 650

Valley Forge, PA 19482

5 D. D. Nunn

Vice President, Nuclear

Projects

TVA

LP6N20E

Chattanooga, TN 37402-2801

\section{J. A. Scalice}

Plant Manager

Watts Bar Nuclear Plant

PO Box 2000

Spring City, TN 37381
No. of

Copies

B. E. Rodgers

TVA Nuclear Maintenance

BR5N49A

Chattanooga, TN 37402-2801

R. C. Emory

Maintenance Engineering and

Technical Section

MOB1L

Watts Bar Nuclear Plant

PO Box 2000

Spring City, TIJ 37381

31 Pacific Northwest Laboratory

DM Boyd

JF Dawson

SR Doctor (10)

MA Friesel

RV Harris

PH Hutton (3)

RJ Kurtz (3)

DK Lemon

RL Moffitt

JR Skorpik

JC Spanner

Technical Information (5)

Publication Coordination 


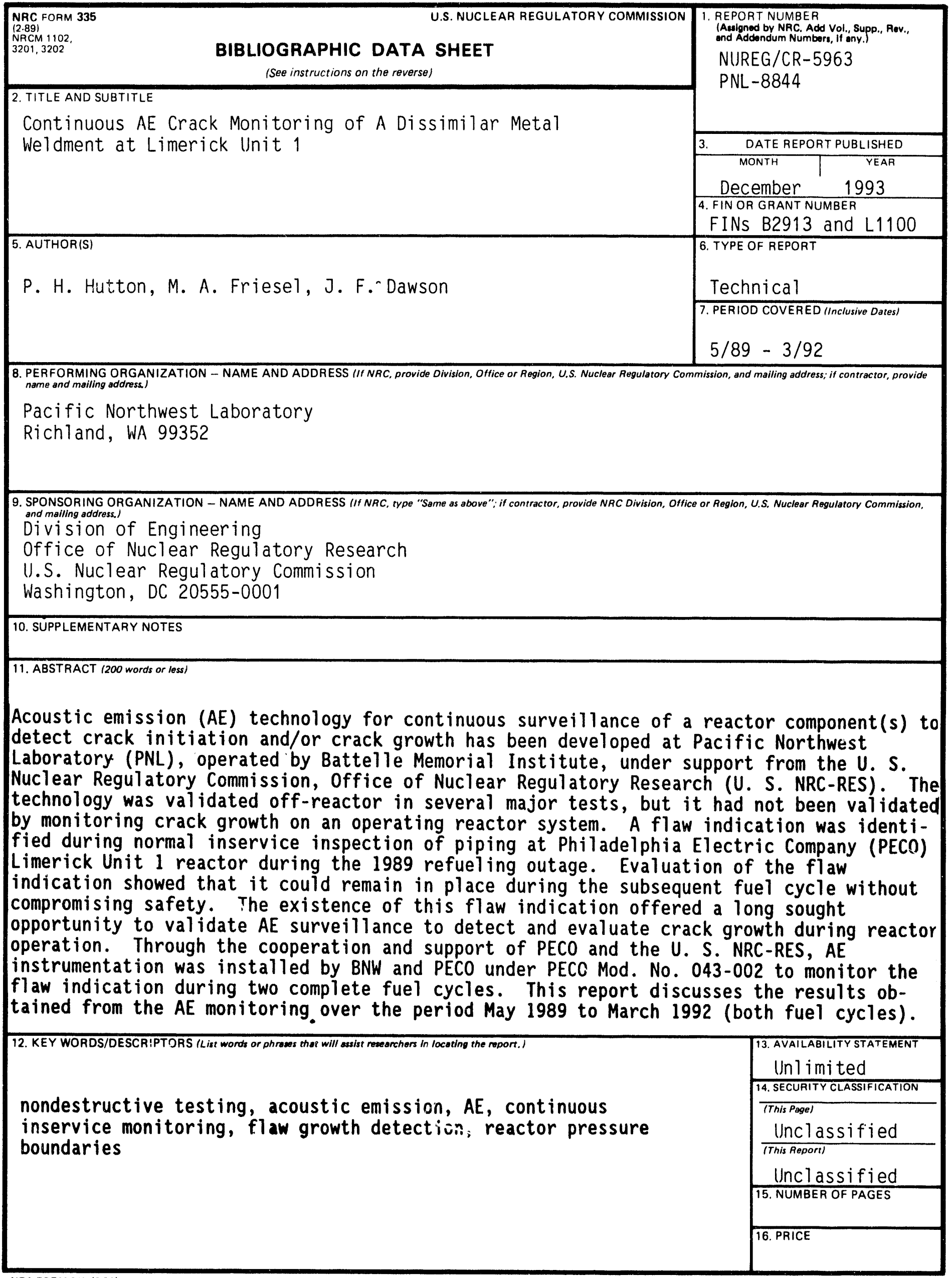



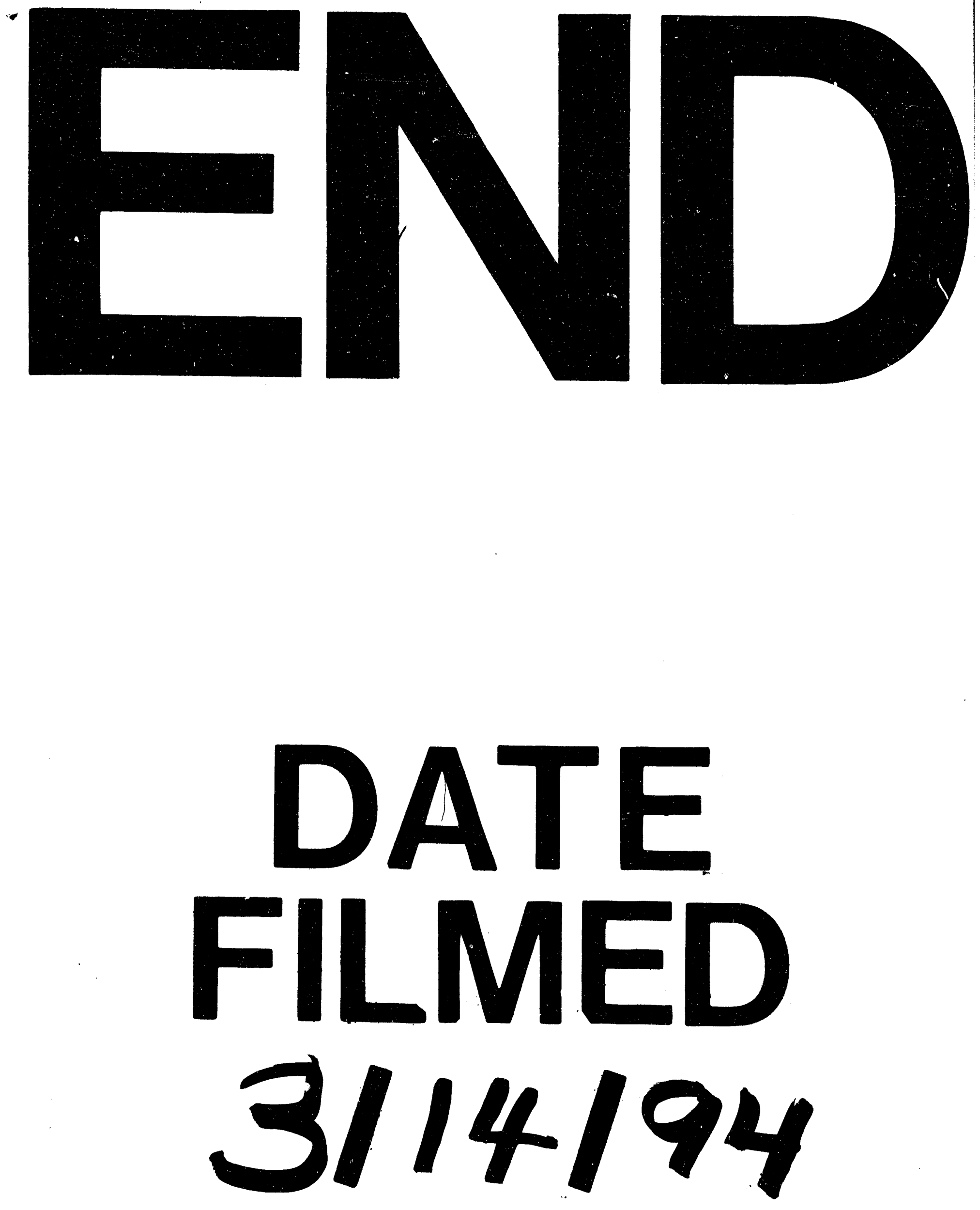
